\title{
Exploring Anti-Prion Glyco-Based and Aromatic Scaffolds: A Chemical Strategy for the Quality of Life
}

\author{
María Teresa Blázquez-Sánchez ${ }^{\dagger}$, Ana M. de Matos ${ }^{\dagger}$ and Amélia P. Rauter * \\ Centro de Química e Bioquímica, Faculdade de Ciências, Universidade de Lisboa, Ed C8, Piso 5, Campo Grande, \\ 1749-016 Lisboa, Portugal; mblazquez@fc.ul.pt (M.T.B.-S.); amamatos@fc.ul.pt (A.M.d.M.) \\ * Correspondence: aprauter@fc.ul.pt; Tel.: +351-217-500-952 or +351-964-408-824 \\ + Both authors contributed equally to this review.
}

Academic Editor: Margaret A. Brimble

Received: 24 April 2017; Accepted: 17 May 2017; Published: 24 May 2017

\begin{abstract}
Prion diseases are fatal neurodegenerative disorders caused by protein misfolding and aggregation, affecting the brain progressively and consequently the quality of life. Alzheimer's is also a protein misfolding disease, causing dementia in over 40 million people worldwide. There are no therapeutics able to cure these diseases. Cellular prion protein is a high-affinity binding partner of amyloid $\beta(A \beta)$ oligomers, the most toxic species in Alzheimer's pathology. These findings motivate the development of new chemicals for a better understanding of the events involved. Disease control is far from being reached by the presently known therapeutics. In this review we describe the synthesis and mode of action of molecular entities with intervention in prion diseases' biological processes and, if known, their role in Alzheimer's. A diversity of structures is covered, based on glycans, steroids and terpenes, heterocycles, polyphenols, most of them embodying aromatics and a structural complexity. These molecules may be regarded as chemical tools to foster the understanding of the complex mechanisms involved, and to encourage the scientific community towards further developments for the cure of these devastating diseases.
\end{abstract}

Keywords: prion; protein aggregation; amyloid; anti-prion compounds; structure optimization

\section{Introduction}

Prion diseases, also called transmissible spongiform encephalopathies (TSEs), are infectious and fatal neurodegenerative diseases. They affect the brain and the nervous system, causing deterioration of mental and physical abilities, amyloid plaque formation, neuronal death, and production of holes in the cortex that appears, when examined under a microscope, as a sponge. The clinical signs in humans may include memory problems and personality changes, depression, lack of coordination, involuntary movements or insomnia. In the later stages of the disease, dementia and loss of ability to move or speak are common. Prion diseases are the single conformational diseases transmissible, either experimentally or by natural routes, mainly by ingestion. Prions have an extraordinary resistance to conventional sterilization procedures and are capable to bind to metal and plastic surfaces without losing infectivity. They are caused by an abnormal conformational isoform $\left(\mathrm{PrP}^{\mathrm{Sc}}\right)$ of the host-encoded cellular prion protein $\left(\operatorname{PrP}^{\mathrm{C}}\right)$ [1]. Full-length $\operatorname{PrP}^{\mathrm{C}}$ is a 253 amino acid-long glycoprotein ubiquitously expressed in all mammals and anchored to the external cell membrane by a glycosylphosphatidylinositol (GPI) moiety [2]. Although there is evidence on its relevant physiological role as a cellular signalling molecule [3-5], once in the presence of infectious $\mathrm{PrP}^{\mathrm{Sc}}$ seeds, $\mathrm{PrPC}^{\mathrm{C}}$ units are remodelled to reproduce the conformation of the misfolded isoform. Newly formed $\mathrm{PrP}^{\mathrm{Sc}}$ molecules are then incorporated into prion amyloid aggregates that tend to accumulate in neurons, astroglia and microglia, eventually leading to synaptic damage and vacuolar neuropathology characteristic of TSEs [6]. The exact mechanism by which $\mathrm{PrP}^{\mathrm{Sc}}$ aggregates lead to neurotoxicity is, nevertheless, poorly understood. 
Human TSEs are rare and include familial Creutzfeld-Jacob disease (CJD) caused by polymorphisms in the $P R N P$ gene giving rise to $\mathrm{PrPS}^{\mathrm{Sc}}$, sporadic $\mathrm{CJD}$, as well as the variant $\mathrm{CJD}$ triggered by the consumption of bovine $\mathrm{PrPS}^{\mathrm{Sc}}$-contaminated food [1,7]. Attempts to develop small organic compounds targeting either $\operatorname{PrP}^{\mathrm{C}}, \mathrm{PrP}^{\mathrm{Sc}}$, or the conversion from one conformer to another have been carried out in the past two decades, but even though a few orally available compounds have been shown to significantly enhance the survival of mice infected with mouse $\operatorname{PrP}^{\mathrm{Sc}}$, the transposition of such effects to human $\operatorname{PrP}^{\mathrm{Sc}}$ has been challenging and led to rather disappointing results so far. The reasons for this include undesired toxicity and metabolic profile or, in some cases, reduced compound blood brain barrier permeability [8]. Yet, the existence of various phenotypic TSE variants caused by several different $\mathrm{PrP}^{\mathrm{PC}}$ strains is possibly the major factor contributing to these consecutive failures in the search for effective therapeutic approaches. Each $\mathrm{PrPS}^{\mathrm{Sc}}$ strain leads to a distinct disease incubation period, and each one is associated with a particular pattern of prion distribution in the brain $[1,9,10]$ and, indeed, it has been shown that one particular molecule may exert distinct effects against different prion strains [11].

Despite so many difficulties, the urgent need for efficacious treatments against prion diseases keeps the scientific community motivated to pursuing the discovery of new anti-prion molecules up until today. In this perspective, we herein provide an overview of the latest reports focusing on the development of molecules with anti-prion activity and potential against TSEs. From sugar-based compounds to aromatic and heteroaromatic compounds, this review presents also the synthesis and mode of action of the most promising molecular entities described in the literature, ultimately aiming to stimulate the development of innovative therapies against prion-mediated diseases.

\section{Synthesis and Mode of Action of Glyco-Based and Aromatic Scaffolds with anti-Prion Effects}

\subsection{Glyco-Based Molecular Entities}

Sulfated polysaccharides, as the family of heparan mimetics (HMs) and pentose polysulfate (PPS) are among the most active drugs tested in experimental models of prion disease (Figure 1, structures A-C). Heparan sulfate (HS) was found on the amyloid plaques in TSEs [12] and reported as an essential part of the cellular receptor used for prion uptake and as a crucial factor for cell infection [13]. It is known that sulfation degree and patterns of these polysaccharide structures govern the HS-protein interactions [14] and are related to their anti-prion acitivity. Other endogenous polysaccharides including heparin, chondroitin sulfate (CS) and dermatan sulfate (DS), have also shown to bind prions $[15,16]$, and to inhibit the neurotoxicity of amyloid fibrils [17].
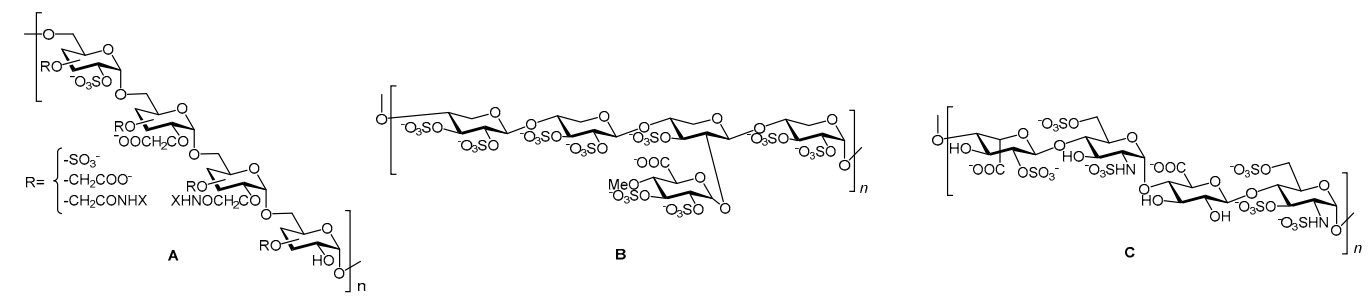

Figure 1. (A): Heparan mimetic representative fragment, abbreviated as HMCSX where n: molecular length, S: degree of sulfate substitution, C: carboxylate substitution and X: hydrophobic group substituent; (B): Pentosan polysulfate representative fragment; (C): Heparan sulfate/heparin representative fragment.

Based on these findings, Ouidja and co-workers [18] reported a library of HMs of different molecular sizes, containing various sulfation and carboxylation levels, and substituted, or not, by different hydrophobic cores with a general formula HMCSX. (Figure 1, structure A). Studies on their capacity to inhibit the accumulation of the abnormal protease-resistant prion conformation ( $\mathrm{PrP}^{\mathrm{res}}$ ) in chronically infected cells (ScGT1-7) and on their PrPrec binding ability showed that an optimal 
size and sulfation degree were needed for optimum activity. The incorporation of hydrophobic moieties increased compound efficacy while the presence of carboxymethyl moieties decreased it. It is important to add that $\mathrm{PrP}^{\mathrm{res}}$ is a disease-promoting $\mathrm{PrP}^{\mathrm{Sc}}$-like prion protein generated in vivo, following $\mathrm{PrP}^{\mathrm{SC}}$-induced misfolding of recombinant $\operatorname{PrP}^{\mathrm{C}}$ [19].

Ouidja et al. [18] also observed that increasing polyanions size increases product efficacy. When considering the same degree of sulfate substitution, a maximum effect was found at $250 \mathrm{gly} / \mathrm{chain}$ in cell assays, with the partially sulfated $\mathrm{HM}_{250} \mathrm{~S}_{1.0}\left(\mathrm{EC}_{50}=0.01 \mu \mathrm{M}\right.$ in ScGT1-7 cells). The product substituted with a phenylalanine methyl ester $(X=P h M)$ with formula $H_{250} C_{0.5} S_{0.5} X_{0.3}$ increased the ability to inhibit PrPres accumulation in ScGT1-7 cells compared with its non-hydrophobized analog $\left(\mathrm{EC}_{50}=0.6\right.$ vs. $\left.>10 \mu \mathrm{M}\right)$. The more voluminous and aromatic PhMe derivative was the one presenting the best effect, suggesting that it offers a hydrophobic binding point to the $\mathrm{C}$-terminal fragment of the $\mathrm{PrP}^{\mathrm{C}}$, rich in hydrophobic residues.

On the other hand heparin analogs may be structurally based on saccharide units whose disaccharide precursor GlcNS6S-IdoA2S 1 is presented in Scheme 1. In an attempt to know whether this disaccharide unit has sufficient anti-prion activity in prion-infected cells, recently, Teruya et al. [20] have characterized the binding profile of the representative structure of unprotected GlcNS6S-IdoA2S 1 to PrP. The synthesis of disaccharide 1 has been described by Saito and co-workers [21] using glucurono-6,3-lactone and glucosamine hydrochloride as starting materials to obtain the disaccharide building block by reaction of the sugar acceptor 2 with the conveniently protected 2-azido glycosyl donor 3 catalysed by tert-butyldimethylsilyl trifluoromethanosulfonate (TBDMSOTf). Acceptor 2 and donor 3 were synthesized over 15 steps from D-glucurono-6,3-lactone, and over 9 steps from glucosamine hydrochloride, respectively (Scheme 1).

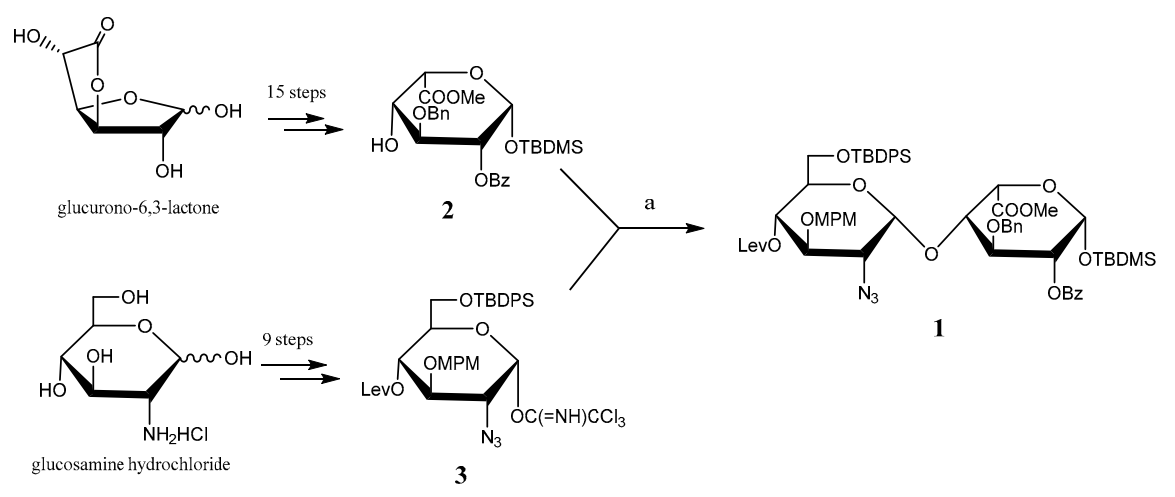

Scheme 1. Synthesis of disaccharide 1. Reagents and conditions: (a) TBDMSOTf, DCM, MS $4 \AA$, $-20{ }^{\circ} \mathrm{C}$ $\rightarrow$ r.t., 18 h, $77 \%$.

Teruya et al. described a significant binding of unprotected disaccharide GlcNS6S-IdoA2S 1 with recombinant prion protein $(\operatorname{PrP})\left(\mathrm{K}_{\mathrm{D}}=9.7 \mu \mathrm{M}\right)$, that was confirmed by competitive inhibition using heparin or pentosane polysulfate by surface plasmon resonance. However, the disaccharide structure did not exhibit anti-prion activity in prion-infected cells.

Glycosaminoglycans (GAGs) are biomolecules of interest for prion-related diseases playing important roles in prion formation and infection [22]. GAG involvement in prion disease pathogenesis and $\mathrm{PrP}^{\mathrm{C}}$ conversion into $\mathrm{PrP}^{\mathrm{Sc}}$ has been widely reported [15,23-25]. Yagamuchi et al. [26] described, for the first time, polymers of acrylamide decorated, via an amide bond, with regioselectively sulfated 2-acetamido-2-deoxyglycopyranosyloxyphenyl moieties (Figure 2), and tested them, as well as the $p$-nitrophenyl sulfated glycoside precursors mimicking GAGs monomers, to screen for their ability to inhibit $\mathrm{PrP}^{\mathrm{Sc}}$ formation in prion-infected cells.

Among the sulfated glycopyranosides and the polymeric compounds examined, the 4-sulfated derivative 6, and two glycopolymers, 10 and $\mathbf{1 1}$ (Figure 2), inhibited $\mathrm{PrP}^{\mathrm{Sc}}$ formation with $50 \%$ effective doses below $20 \mu \mathrm{g} / \mathrm{mL}\left(\mathrm{ED}_{50}=10,4\right.$ and $9 \mu \mathrm{g} / \mathrm{mL}$, respectively). A combination of an $N$-acetyl group 
at C-2 and a sulfate group at either C-4 or C- 6 on glucopyranoside might be involved in the inhibition of $\mathrm{PrP}^{\mathrm{Sc}}$ formation. Furthermore, $\mathrm{PrP}^{\mathrm{Sc}}$ formation was inhibited by polymeric compound 11 but not by the glucoside 7 , suggesting the importance of a polyvalent structure.
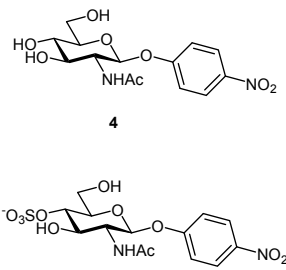

6
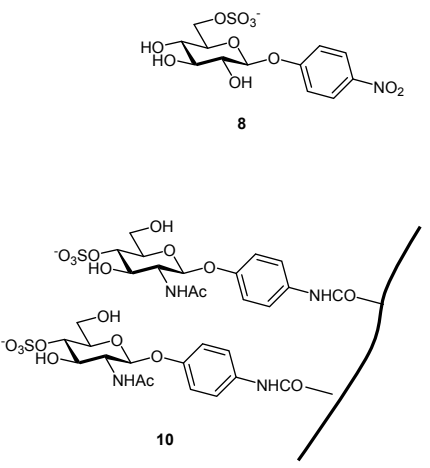
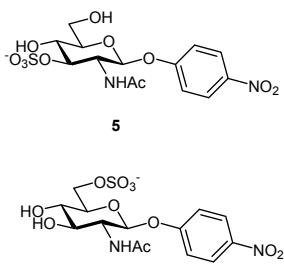

7
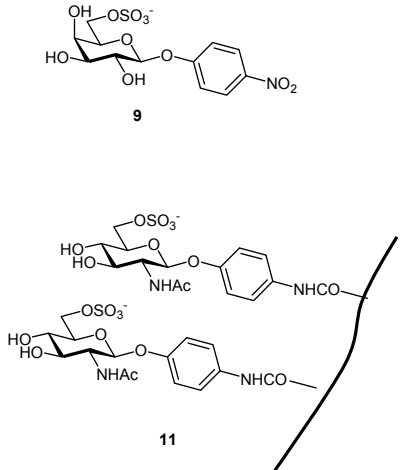

Figure 2. Compounds tested for the inhibition of $\operatorname{PrP}^{\mathrm{PC}}$ formation in prion-infected cells: sulfated $p$-nitrophenyl glycopyranosides, and glycopolymers composed by a polyacrylamide chain decorated with sulfated 2-acetamido-2-deoxy- $\beta$-D-glucopyranosyloxyphenyl moieties via amide bond (adapted from [26]).

The synthesis of the $p$-nitrophenyl glycosides sulfated at 3,4 or 6 position is depicted in Scheme 2 [27]. Position 6 of $p$ NP- $\beta$-D-GlcNAc was selectively sulfated with a sulfur trioxide complex $\left(\mathrm{Me}_{3} \mathrm{~N} \cdot \mathrm{SO}_{3}\right)$ affording compound 7 in $52 \%$ yield. In order to generate sulfated glucosides at position 3 and 4, tert-butyldiphenylsilyl chloride (TBDPSCl) was chosen to firstly protect position 6 . After sulfation with sulfur trioxide complex both 5 and $\mathbf{6}$ regioisomers were obtained in $63 \%$ overall yield and then separated by column chromatography.
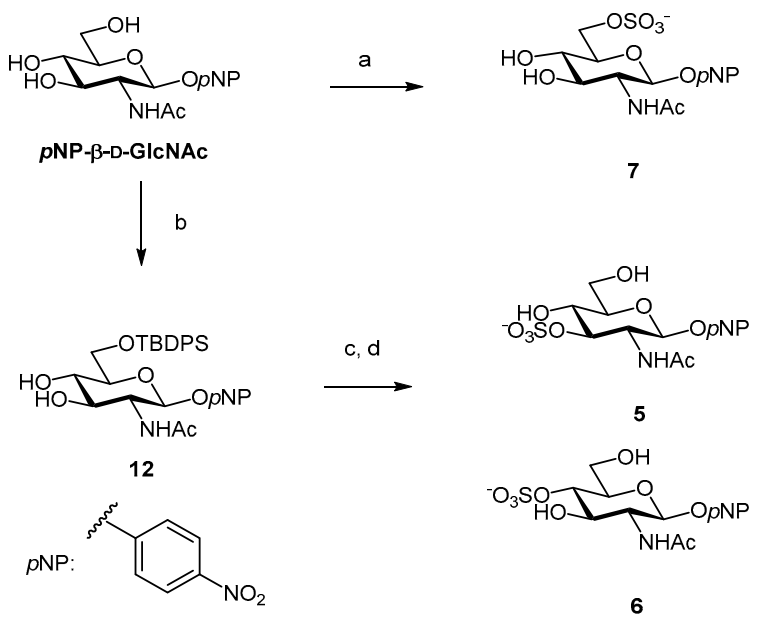

Scheme 2. Synthesis of compounds 5-7. Reagents and Conditions: (a) $\mathrm{Me}_{3} \mathrm{~N} \cdot \mathrm{SO}_{3}, \mathrm{DMF}, 40{ }^{\circ} \mathrm{C}, 3 \mathrm{~h}$, Dowex $\left(\mathrm{Na}^{+}\right), 52 \%$; (b) TBDPSCl, py, DMAP, r.t., 24 h, 95\%; (c) $\mathrm{Me}_{3} \mathrm{~N} \cdot \mathrm{SO}_{3}, \mathrm{DMF}, 40{ }^{\circ} \mathrm{C}, 10 \mathrm{~h}$, Dowex $\left(\mathrm{Na}^{+}\right), 63 \%(5 / 6=1.4 / 1)$; (d) TBAF, THF, r.t., 24 h, $98 \%$. 
More recently Nishizawa et al. introduced the $p$-methoxyphenyl aminoglucoside 13 (Figure 3) as a new type of anti-prion compound, commercially available, and able to inhibit abnormal prion protein formation in prion-infected neuroblastoma cells in a prion strain-independent manner, when the cells were treated for more than 1 day. The $50 \%$ inhibition dose for $\operatorname{PrP}^{\mathrm{res}}$ formation is 5.36 and $3.33(\mu \mathrm{g} / \mathrm{mL})$ in prion-infected ScN2a cells and N167 cells, respectively [28].

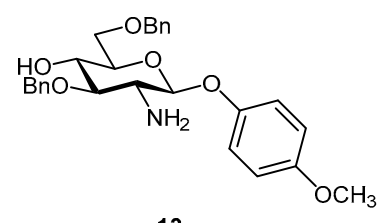

13

Figure 3. Molecular structure of the aminoglucoside 13.

In 2009, Charvériat and co-workers presented two different families of prion replication inhibitors [29]. One of them is based on 3-aminosteroid structures and the other on erythromycin A derivatives bearing saccharide residues and an oxime functionality (Figure 4). The eight compounds inhibited PrPres accumulation in two cell cultures (SN56 and GT1 cell lines) infected by the Chandler scrapie strain, and by mouse-adapted scrapie strain $22 \mathrm{~L}$, respectively.
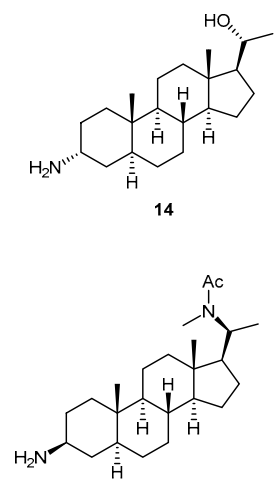

18

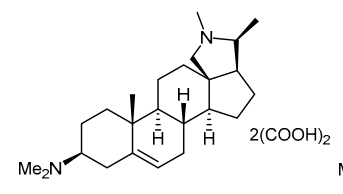

15

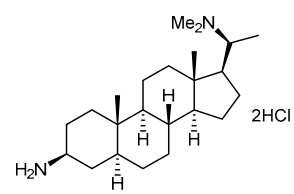

19
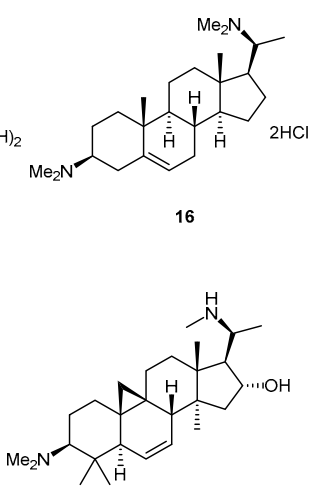

20

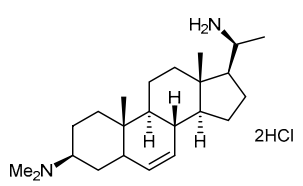

17

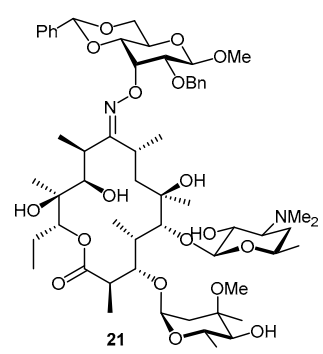

Figure 4. Chemical structure of inhibitors belonging to distinct chemical families: 3-aminosteroids 14-20 and erythromycin A derivative 21 [29].

Dose-response curves, with the identification of $\mathrm{IC}_{50}$ by densitometry, confirmed the concentration-dependent PrPres inhibitory activity of compounds 14-21 on Chandler-infected SN56 cells [29]. Compound 17 and erythromycin derivative 21 showed the lowest $\mathrm{IC}_{50}(0.4$ and $0.3 \mu \mathrm{M})$, respectively. Interestingly, they found that compound 21 interacted directly with PrPres stability observing a change in the shape of the $\mathrm{T}_{\mathrm{m}}$ curve in the fluorescence-based thermal shift assay. These results indicated that the interaction between $\mathrm{PrP}^{\mathrm{C}}$ and compound 21 leads to a peculiar conformation of $\operatorname{PrP}^{\mathrm{C}}$ that could induce alteration of its amyloidogenic properties, and consequently lead to the inhibition of conversion to $\operatorname{PrP}^{\mathrm{res}}$ [29].

More recently other natural glycosides with anti-prion activity have been described in literature, namely bacoside-A (22, Figure 5). This natural triterpene glycoside bearing a trisaccharide moiety has been recently found to exhibit anti-amyloid properties [30]. It is an active principle of the medicinal plant Bacopa monniera, whose components include amphiphilic compounds structurally based on sterol glycosides, and is used in traditional Indian medicine to treat various nervous disorders, and to promote memory enhancement $[31,32]$. 


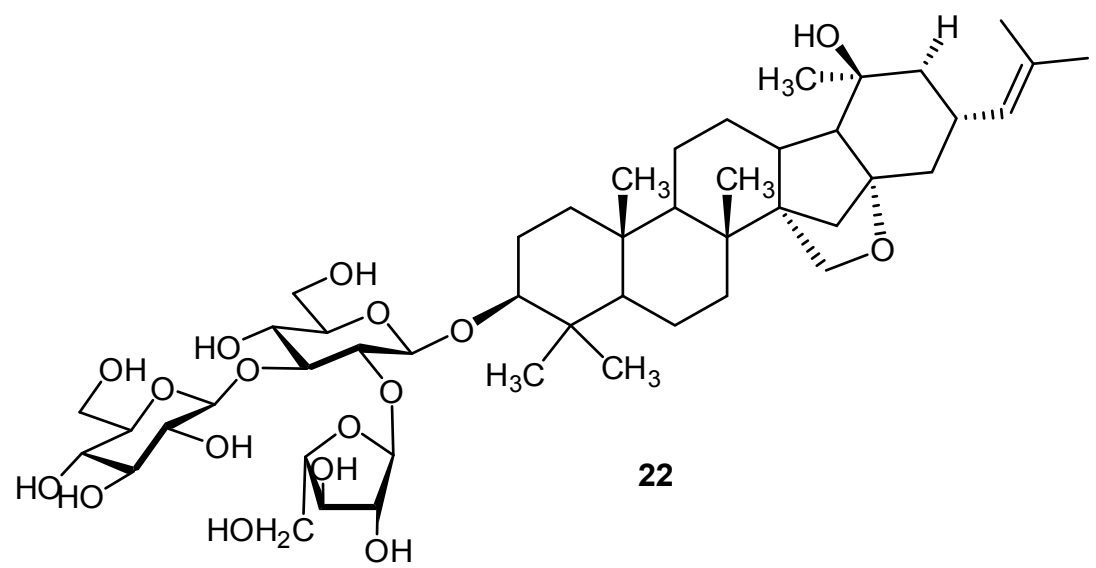

Figure 5. Molecular structure of bacoside A (22).

Recent studies have suggested that bacoside-A might exhibit therapeutic effects against amyloid diseases, such as Alzheimer's disease (AD) [33,34]. More recently Malishev et al. have investigated the interactions between bacoside- $\mathrm{A}$ and the 21-residue amyloidogenic determinant of the prion protein $\operatorname{PrP}_{106-126}$ by spectroscopy and microscopy experiments [35,36]. They evaluated the consequence of bacoside-A/PrP(106-126) interactions upon membrane bilayers (Figure 6). The experimental data revealed acceleration of $\mathrm{PrP}_{106-126}$ fibril formation in the presence of lipid bilayers. Importantly, they found that the enhanced fibrillation of the peptide, induced by bacoside- $\mathrm{A}$, went in parallel with significant reduced membrane interactions and bilayer disruption, demonstrating a direct relationship between externally-induced accelerated fibrillation and inhibition of membrane interactions (Figure 6), indicating bacoside-A (22) as a potential therapeutic agent for TSE and amyloid diseases.
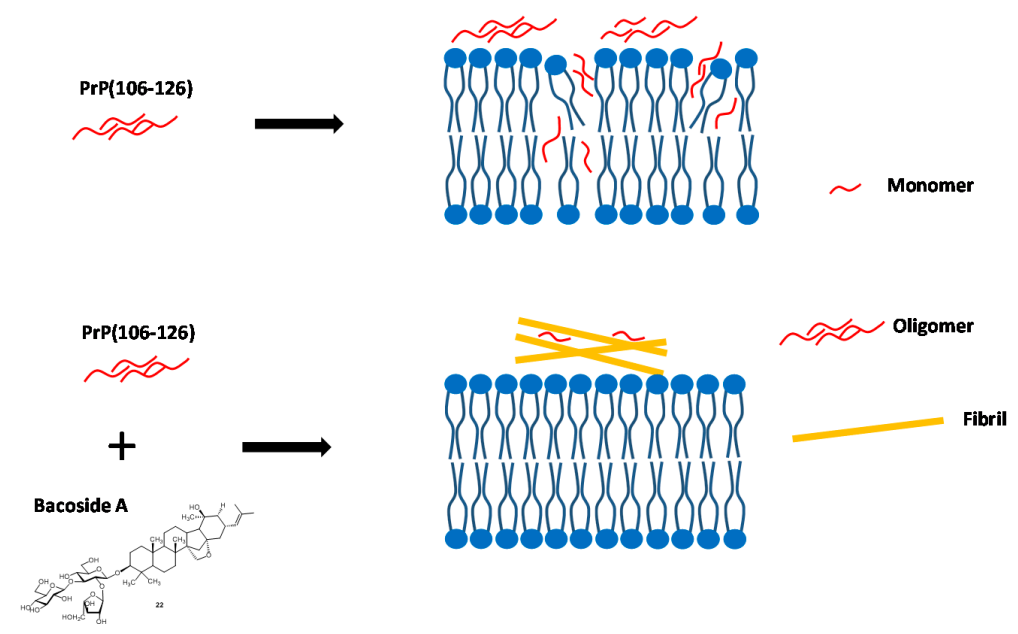

Figure 6. Schematic model for the activity of Bacoside-A; up: $\operatorname{PrP}_{106-126}$ alone forms abundant pre-fibril aggregates which interact with, and disrupt membrane bilayers; down: when $\operatorname{PrP}_{106-126}$ is pre-incubated with bacoside-A, fibrillation is accelerated resulting in lower abundance of membrane-active species (adapted from [30]).

\subsection{Aromatic Scaffolds with Nitrogen Containing Six-Membered Ring Heterocycles}

\subsubsection{Pyridine Dicarbonitrile Derivatives}

Pyridine dicarbonitrile derivatives were firstly published in 2000 as a new class of rationally designed leads with activity against $\mathrm{PrP}^{\mathrm{Sc}}$ replication in $\mathrm{PrP}^{\mathrm{Sc}}$-infected mouse neuroblastoma cells (ScN2a) [37]. In particular compound 23 (Figure 7) was reported to inhibit $\mathrm{PrP}^{\mathrm{Sc}}$ formation in ScN2a 
cells in a dose-dependent manner, with an $\mathrm{IC}_{50}$ of $18.0 \mu \mathrm{M}$ in ScN2a cells, and low levels of toxicity [37]. It has been proposed that it may bind to a chaperone required itself to bind to $\operatorname{PrP}$ for its conversion into $\mathrm{PrP}^{\mathrm{Sc}}$, consequently inhibiting this conversion [37,38].<smiles>N#Cc1c(N)nc(Sc2ccccc2N)c(C#N)c1-c1ccco1</smiles>

23<smiles>N#Cc1c(N)nc(SCc2ccccc2)c(C#N)c1-c1cccs1</smiles>

24<smiles>CCN(CC)CCSc1nc(N)c(C#N)c(-c2ccccc2Cl)c1C#N</smiles>

25

Figure 7. Three pyridine dicarbonitrile derivatives with in vitro anti-prion activity.

In 2006, Reddy and co-workers focused on improving the activity of compound 23 through the development and evaluation of a small library of pyridine dicarbonitrile derivatives [39]. After performing docking studies with a proposed binding site model for compound selection, 45 structurally diverse compounds were synthesized by a one-pot three-component coupling reaction, herein illustrated in Scheme 3 for compound 24, the most promising compound in this study.<smiles>N#CC[N+]#N</smiles>

B

Proposed reaction mechanism:<smiles>N#CC[N+]#N</smiles><smiles>N#CC(C#N)=Cc1cccs1</smiles><smiles>N=C(Br)C(=Cc1cccs1)C(=N)Br</smiles><smiles>[R18]=C[14CH2]NCCC#N</smiles><smiles>N#Cc1c(Br)nc(N)c([18O])c1-c1cccs1</smiles>

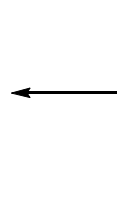<smiles>N#CC1=C(N)NC([Se])=C(C#N)C1c1cccs1</smiles>

Scheme 3. (A) One-pot synthesis of pyridine dicarbonitrile derivative 24; (B) Proposed reaction mechanism. Reagents and conditions: (a) EtOH, reflux piperidine, $3 \mathrm{~h}$, then air-exposed overnight $(19 \%)[39]$. 
Reaction optimization involved the study of the optimum aldehyde/thiol/malononitrile ratio, which was found to be 1:1:2, as well as the best solvent, the best catalytic base and the ideal reaction duration. Mechanistically, as depicted in Scheme 3B, during the first $3 \mathrm{~h}$ of reaction in ethanol under reflux, the initial base-catalyzed attack of a malononitrile anion to the aldehyde followed by elimination of water gives an adduct, which subsequently suffers the addition of benzylthiol to give an iminonitrile intermediate. Then, a second molecule of malononitrile is added to promote a cyclization reaction that affords the central dihydropyridine core; from this point, air-derived $\mathrm{O}_{2}$ is required for the aromatization into the final pyridine ring by chemical oxidation. Even though the yields obtained for this one-pot reaction were up to $52 \%$, compound 24 was achieved in only $19 \%$ yield.

Compound 24 successfully interacted with all three $\operatorname{PrP}^{\mathrm{C}}$ forms used in this study: human $\operatorname{PrP}^{\mathrm{C}}$ (huPrPC ; binding affinity at $\left.40 \mu \mathrm{M}, \% \mathrm{RU}_{\max }=55.5\right)$, truncated human $\operatorname{PrP}^{\mathrm{C}}\left(\mathrm{t}-\mathrm{huPrPC}\right.$; $\% R \mathrm{U}_{\max }=$ 28.8) and murine $\operatorname{PrP}^{\mathrm{C}}\left(\mathrm{moPrPC} ; \% \mathrm{RU}_{\max }=52.6\right)$. The analog possessing a 3-chlorophenylthiol at C-4 had a significantly higher affinity towards $\operatorname{PrP}^{\mathrm{C}}$ (huPrPC \% $\mathrm{RU}_{\max }=123.6$; $\mathrm{t}-\mathrm{huPrPC} \% \mathrm{RU}_{\max }=$ 91.8; $\left.\operatorname{moPrP}^{\mathrm{C}} \% \mathrm{RU}_{\max }=72.2\right)$; however, it was found to be toxic. Nevertheless, compound 24 was more potent than the lead compound 23 in $\mathrm{PrP}^{\mathrm{Sc}}$-infected mouse brain mesodermal (SMB) cells, and presented a high association/dissociation response ratio, which is ideal when looking for a potential new drug candidate.

Overall, most pyridine dicarbonitrile derivatives possessing the benzylsulfanyl moiety displayed some level of affinity towards $\operatorname{PrP}^{\mathrm{C}}$. Through the evaluation of all synthesized analogs, Reddy and co-workers concluded that the substituent at $\mathrm{C}-4$ of the central pyridine core of pyridine dicarbonitriles does not influence the binding to $\operatorname{PrP}^{\mathrm{C}}$ as much as the substituent at C-6. In fact, this had been predicted in prior docking poses where the thioether moiety was placed deep inside the hypothetical pocket, whereas the substituent at C-4 was generally placed towards the opening of the cavity.

Compound 25 (Figure 7) was published in a subsequent report by May et al. presenting a thorough structure-activity relationship study on pyridine dicarbonitrile derivatives bearing amine substituents at C-6 and furan or halobenzene substituents at C-4 [38]. The synthetic approach towards designed derivatives was quite distinct from the previous one, and is herein illustrated for compound $\mathbf{2 5}$ in Scheme 4 .

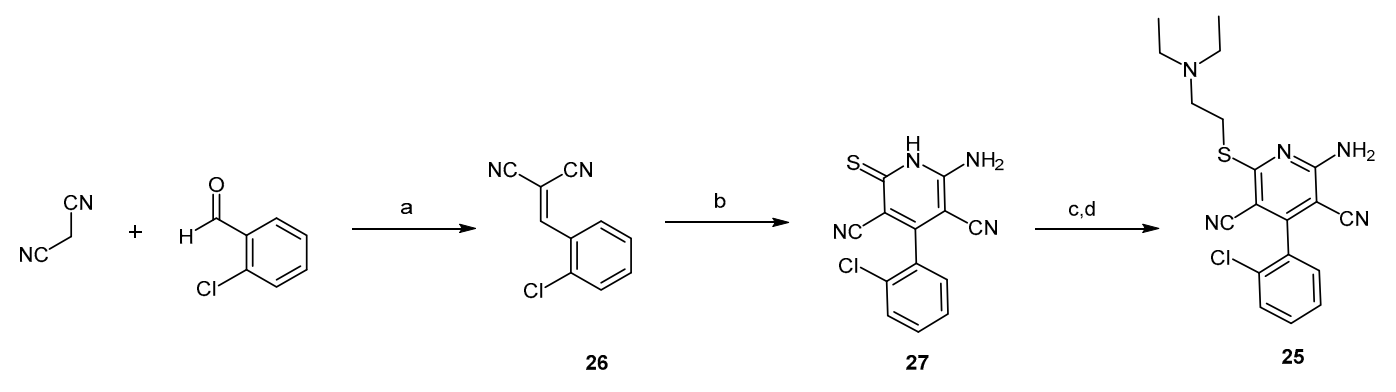

Scheme 4. Synthesis of pyridine dicarbonitrile derivative 25. Reagents and conditions: (a) $\beta$-alanine, EtOH, r.t., 72 h; (b) 2-cyanoacetamide, piperidine, EtOH, reflux, 8 h; (c) 10\% KOH, DMF, r.t., 1 min; (d) (diethylamino) alkyl halide, r.t., $5 \mathrm{~h}$ [38].

Firstly, a $\beta$-alanine-catalysed Knoevenagel condensation afforded the arylidene malononitrile 26, which was subsequently converted into intermediate 27 by reacting with a molecule of 2-cyanoacetamide, in the presence of piperidine, under reflux. Then, after treatment with $10 \% \mathrm{KOH}$ in dimethylformamide (DMF), the haloamine was added to form the desired sulfanyl moiety, thus affording the final compound 25. Although the yields for each reaction step are not specified, final compounds were obtained in $10-70 \%$ overall yield.

Most of these pyridine dicarbonitrile derivatives were not toxic up to $25 \mu \mathrm{M}$ and exhibited $\mathrm{EC}_{50}$ values below $15 \mu \mathrm{M}$ in ScNa2 cells. Moreover, they were generally more active than compound 24 (Figure 7) which, in this study, presented no activity up to $25 \mu \mathrm{M}$. Compounds with tertiary 
alkyl amines at C-6 were generally more active than those bearing primary amine moieties, whereas meta-substituted halobenzenes at C-4 were found to be preferable to furan-substituted compounds or to the corresponding para-substituted analogs. Among all synthesized pyridine dicarbonitrile derivatives, compound 25 was found to be the most promising, with an $\mathrm{EC}_{50}$ value of $5.5 \mu \mathrm{M}$ in ScNa2 cells. Moreover, it presented high water solubility and a good permeability rate in a standard parallel artificial membrane permeability assay (PAMPA) $(\log P e=-6.0 \pm 0.1)$, indicating a good pharmacokinetic profile. However, no in vivo data are available up to this point.

\subsubsection{Piperazine Derivatives}

Based on the previously described neuroprotective activity and ability of the 2,5-diketopiperazine scaffold to modulate protein-protein interactions [40], Bolognesi and co-workers have generated a small library of compounds bearing different aromatic and heteroaromatic substituents in positions 3 and 6 of a central 3,6-dimethylpiperazine-2,5-dione core [41]. The authors envisioned that a planar, symmetrical molecule with aromatic end groups would be ideal to optimize the desired anti-aggregating properties and, in 2010, presented compound 28 (Figure 8) as a new anti-prion lead for further development.

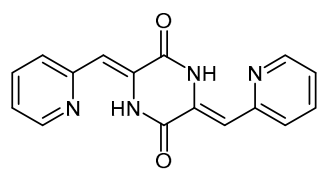

28

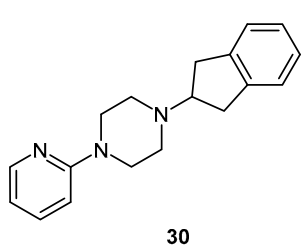

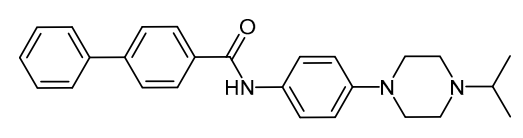

29

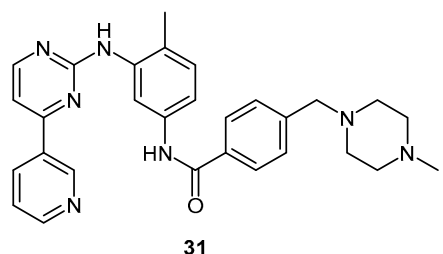

Figure 8. Four piperazine derivatives with anti-prion activity.

Compound 28 inhibited $\mathrm{PrP}^{\mathrm{Sc}}$ accumulation in $\mathrm{PrP}^{\mathrm{Sc}}$-mouse hypothalamus (ScGT1) cells with an $\mathrm{EC}_{50}$ value of $4.1 \mu \mathrm{M}$, while maintaining approximately $75 \%$ cell viability at this concentration. Mechanistic studies focusing on aggregation kinetics revealed that this molecule acts by interacting directly with recombinant prion protein $(\mathrm{recPrP})$ to inhibit its conversion into the pathological $\mathrm{PrP}^{\mathrm{Sc}}$-like conformer and, interestingly, while the corresponding 3- and 4-pyridyl analogs were roughly ten times less active against $\mathrm{PrP}^{\mathrm{Sc}}$ accumulation, compounds presenting benzene, furan, thiophene or quinolone moieties did not exhibit any activity.

The straightforward synthesis of compound 28 involved only one reaction step (Scheme 5). In this reaction, two equivalents of picolinaldehyde were mixed with one equivalent of the commercially available 1,4-diacetylpiperazine-2,5-dione dissolved in DMF, in the presence of triethylamine. A double aldol-condensation at room temperature gave compound 28 in $64 \%$ yield, affording exclusively the desired $(Z, Z)$-isomer.<smiles>CC(=O)N1CC(=O)N(C(C)=O)CC1=O</smiles>

Scheme 5. Synthesis of diketopiperazine 28. Reagents and conditions: (a) TEA, DMF, r.t., 16 h (64\%) [41]. 
The isopropylpiperazine derivative 29 (Figure 8) was later published by $\mathrm{Li}$ et al. as the most promising compound of a small library of optimized arylamides with anti-prion activity, which were developed based on a moderately active piperazine arylamide derivative [42]. Here, the piperazine ring is placed in one of the extremities of the molecule, thus contrasting with Bolognesi's rationale in which the diketopiperazine was the core moiety acting as the linker between two identical pyridine groups. The synthesis of this amide bearing the $N$-alkyl piperazine ring is very straightforward and involves only one reaction step, namely the standard coupling between a carboxylic acid and an arylamine carried out in the presence of the uranium salt $O$-(7-azabenzotriazol-1-yl)- $N, N, N^{\prime}, N^{\prime}$-tetramethyluronium hexafluorophosphate (HATU) as an acid activating reagent and $\mathrm{N}, \mathrm{N}$-diisopropylethylamine (DIPEA), in anhydrous DMF, at room temperature gave compound 29 in $66 \%$ yield (Scheme 6).

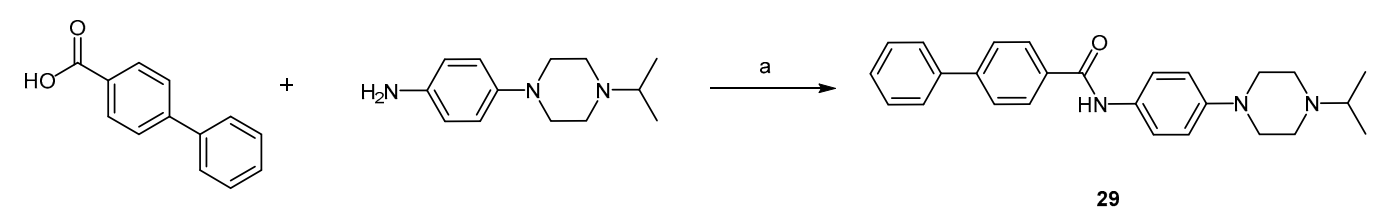

Scheme 6. Synthesis of piperazine derivative 29. Reagents and conditions: (a) HATU, DIPEA, anhydrous DMF, r.t., 12 h (66\%) [42].

The initially conducted structure-activity relationship studies revealed that the biphenyl group linked to the carbonyl of the amide functionality led to more potent compounds than those bearing only one aromatic ring. The piperazine moiety was regarded as an important feature for the maintenance of compound solubility and thus was kept throughout this series of derivatives. Furthermore, 4-biphenyl analogs were preferable to their 3-biphenyl congeners, and compounds containing large $N$-alkyl moieties in the piperazine ring were more potent than those containing smaller $N$-alkyl groups.

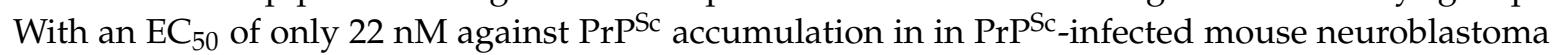
(ScN2a-cl3) cells, compound 29 stood out among this series of derivatives and was found to be 100-fold more potent than the original lead compound. It displayed acceptable metabolic stability in mouse liver microsomes $\left(t_{1 / 2}>60 \mathrm{~min}\right)$ and good brain exposure upon oral administration in mice, thus coming across as a promising lead for further development. However, the in vivo evaluation of this compound to confirm whether the nanomolar range potency observed in vitro is indeed transposable to TSE in vivo models is still lacking.

Compound 30 (Figure 8), on the other hand, was published by Leidel and colleagues as a piperazine derivative with activity in $\mathrm{PrP}^{\mathrm{Sc}}$-infected mice [43]. This molecule was identified after high-throughput screening of 10,000 compounds in SMB cells, where four piperazine derivatives emerged as a new class of $\mathrm{PrP}^{\text {res }}$ conversion/amplification inhibitors. Noteworthy, a significant decrease in $\mathrm{PrP}^{\text {res }}$ formation was not achieved by compound $\mathbf{3 0}$ in a cell-free assay but it was shown to be very potent when tested in mouse neuroblastoma (N2a) cells, displaying an $\mathrm{IC}_{50}$ of $0.4 \mu \mathrm{M}$. Moreover, proteasome activity was not affected in its presence, indicating that it does not influence cellular trafficking or processing of $\operatorname{PrP}^{\mathrm{C}}$. Taken together, these results suggest an indirect inhibitory mechanism of action for compound 30, in which it probably targets misfolding or aggregation co-factors present in the cell-based assay, but absent when using only the purified prion protein. Alternatively, it may act by inducing cellular PrPres clearance. Anyhow, this piperazine derivative successfully prolonged the incubation time in $\mathrm{PrP}^{\mathrm{Sc}}$-infected C57BL/6 mice from 144 to 157 days when administered via an intraperitoneal injection, while a direct analog with a lower $\mathrm{IC}_{50}$ and bearing a 3-chlorophenyl moiety, instead of the 2-pyridyl group, did not.

This study succeeded to illustrate in vivo effects of piperazine derivatives against TSEs, and provided important hints on the potential anti-prion mechanism of action of these types of compounds. It is relevant to note that another piperazine derivative, compound 31 (Figure 8), was found to enhance the clearance of $\mathrm{PrP}^{\mathrm{Sc}}$ in $\mathrm{ScN} 2 \mathrm{a}$ cells, with an $\mathrm{IC}_{50}$ of $0.1 \mu \mathrm{M}$ [44]. Interestingly, this compound is a 
well-known tyrosine kinase inhibitor indicated for the treatment of chronic myeloid leukaemia, and was shown to strongly activating the lysosomal degradation of $\mathrm{PrP}^{\mathrm{Sc}}$, without affecting the biosynthesis or localization of $\mathrm{PrPC}$. These results are consistent and clarify the findings regarding the mechanism of action of the piperazine derivative 30 .

Several possible synthetic routes for compound 31, also known as 5TI571 or Imatinib, were reported since the early 1990s [45-47]. Scheme 7 shows one of the most recently published methodologies involving eight reaction steps with an excellent overall yield of 37\% [48]. In this synthesis, the commercially available acetylpyridine was firstly enaminated and subsequently converted into the pyrimidyl amine 33 in the presence of guanidine nitrate (Scheme 7A). In parallel, after bromination of $p$-nitrotoluene, the so formed intermediate 34 was coupled to 33 using $\mathrm{CuI}$ as catalyst in a ligand assisted Ullmann-type $N$-arylation reaction. Subsequent reduction of the nitro group gave the arylamine 35 in 69\% over two reaction steps (Scheme 7B). Finally, after full chlorination of 4-(hydroxymethyl)benzoic acid by $\mathrm{SOCl}_{2}$, compound 35 was coupled to the so formed acid chloride in the presence of triethylamine, affording amide 36 in 93\% yield (Scheme 7C). Further $N$-alkylation of 1-methylpiperazine under reflux gave the final product, compound 31, in 91\% yield.

A

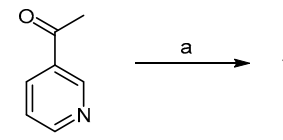

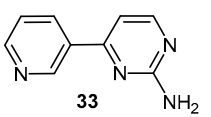

32

33

B
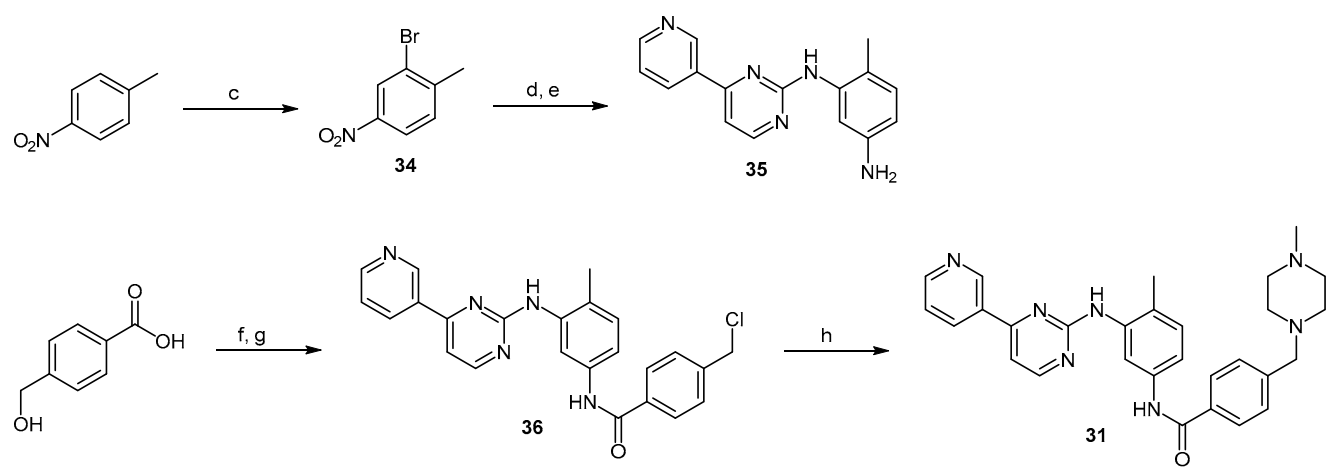

Scheme 7. Synthesis of piperazine derivative 31 by the reaction steps presented in (A-C). Reagents and conditions: (a) xylene, $\left(\mathrm{CH}_{3}\right)_{2} \mathrm{NCH}\left(\mathrm{OCH}_{3}\right)_{2}$, reflux, $20 \mathrm{~h}(93 \%)$; (b) guanidine nitrate, $\mathrm{NaOH}, n$-butanol, reflux, $12 \mathrm{~h}(86 \%)$; (c) $\mathrm{Br}_{2}, \mathrm{Fe}, 80^{\circ} \mathrm{C}, 1.5 \mathrm{~h}(90 \%)$; (d) 33, DMEDA, CuI, $\mathrm{K}_{2} \mathrm{CO}_{3}$, dioxane, $100{ }^{\circ} \mathrm{C}, 20 \mathrm{~h}$ (82\%); (e) $\mathrm{N}_{2} \mathrm{H}_{4} \cdot \mathrm{H}_{2} \mathrm{O} / \mathrm{FeCl}_{3}, \mathrm{MeOH}$, reflux, 6-8 h (84\%); (f) $\mathrm{SOCl}_{2}, \mathrm{DCM}$, reflux, $5 \mathrm{~h} \mathrm{(87 \% );} \mathrm{(g)} \mathrm{35,} \mathrm{THF,}$ TEA, $0{ }^{\circ} \mathrm{C}, 3 \mathrm{~h}$ (93\%); (h) 1-methylpiperazine, reflux, $3 \mathrm{~h}(91 \%)$ [48].

Even though piperazine derivatives did not show evidence of disease-modifying effects against TSEs so far, the above studies highlight some chemical features that may be important in future structure optimization approaches, namely the presence of an amide bond together with at least two aromatic rings and, conceivably, pyridine and pyrimidine moieties. However, additional in vivo studies are required for a better understanding of these requirements.

\subsubsection{Acridine Derivatives}

Quinacrine is one of the most known compounds presenting anti-prion properties and many analogs have been synthesized and studied over the last two decades. In 2001 Prusiner et al. reported that tricyclic derivatives of acridine and phenothiazine exhibited half-maximal inhibition of $\mathrm{PrPSc}$ formation at effective concentrations in scrapie-infected neuroblastoma ( $\mathrm{ScN} 2 \mathrm{a})$ cells [49]. The EC 50 values for chlorpromazine was $3 \mu \mathrm{M}$, whereas quinacrine was 10 times more potent (Figure 9), suggesting that they may be candidates for the treatment of CJD and prion diseases. 


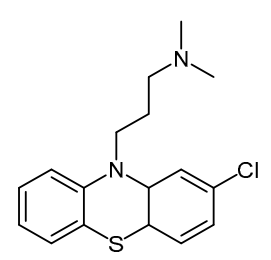

Chlorpromazine

$\mathrm{EC}_{50}=3 \mu \mathrm{M}$

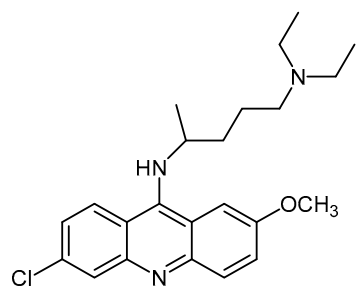

Quinacrine

$\mathrm{EC}_{50}=0.3 \mu \mathrm{M}$

Figure 9. Structure of acridine analogs active for inhibition of $\mathrm{PrP}^{\mathrm{Sc}}$ in scrapie-infected neuroblastoma (ScN2a) cells.

For the synthesis of quinacrine and their analogs, the corresponding anthranilic acids are used as starting materials by applying Ullmann-Jourdan reaction or Buchwald Hartwig amination [50] (Scheme 8). Copper-catalyzed Ullmann-Jourdan reaction [51] is applied to substituted 2-chlorobenzoic acids and the corresponding aniline derivatives yielding the anthranilic acids in moderate yields. However, the scope of the reaction is limited to electron-rich anilines and electron-deficient benzoic acids, leading to yield decrease. Using a palladium-catalyzed Buchwald-Hartwig amination seems to be a more robust method for the synthesis of anthranilic acids. Reaction of methyl 2-iodobenzoates and anilines using $\mathrm{Pd}(\mathrm{ac})_{2}$, bis-[2-diphenylphosphino)phenyl]ether (DPEPhos) and $\mathrm{Cs}_{2} \mathrm{CO}_{3}$ as base, and subsequent hydrolysis gave the corresponding acids [50] (Scheme 8).<smiles>O=C(O)c1cc[R1]cc1Cl</smiles><smiles>[R]c1ccc(N)cc1C</smiles><smiles>[R]c1ccc(Nc2ccccc2C(=O)O)cc1</smiles><smiles>COC(=O)c1ccccc1I</smiles><smiles>[R]c1cccc(N)c1</smiles><smiles>[R]c1ccc(Nc2ccccc2C(=O)O)cc1</smiles>

Scheme 8. General synthetic routes for the synthesis of $N$-phenylanthranilic acids. Reagents and conditions: (a) $\mathrm{Cu}$, py, amyl alcohol, (b) $\mathrm{Pd}(\mathrm{ac})_{2}$, DPEPhos, $\mathrm{Cs}_{2} \mathrm{CO}_{3}$, toluene, (c) aq. $\mathrm{NaOH}$, acetone.

In order to obtain the acridine scaffold, the resulting anthranilic acids are easily transformed into the corresponding 9-chloroacridines by reaction with $\mathrm{POCl}_{3}$ (Scheme 9).<smiles>[R]c1ccc(Nc2ccccc2C(=O)O)cc1</smiles>

Scheme 9. Ring closure procedure to achieve 9-chloroacridines.

Quinacrine derivatives are obtained from 9-chloroacridines and the corresponding amino spacer compound by reaction with phenol which acts as a catalyst at high temperature (Scheme 10). 

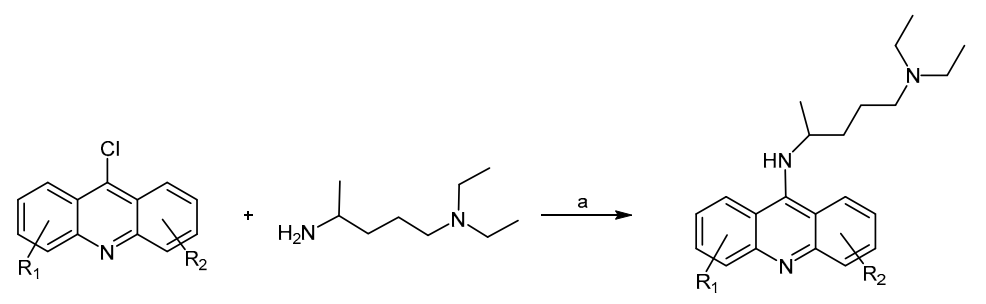

Scheme 10. Synthesis of quinacrine derivatives. Reagents and conditions: (a) phenol, $100{ }^{\circ} \mathrm{C}$.

In 2003, Vogtherr et al. identified the binding site of quinacrine at the C-terminal helix of human prion protein (hPrP) using NMR spectroscopy [52] Tyr225, Tyr226 and Gln227 residues of hPrP helix $\alpha 3$ turned to be the responsible of the interaction with quinacrine. $K_{D}$ value was of $4.6 \mu \mathrm{M}, 4$ orders of magnitude weaker than the $\mathrm{EC}_{50}$ value found for $\mathrm{PrP}^{\mathrm{Sc}}$ inhibition in the cell culture assay [49], probably due to a specific enrichment of this drug in cell organelles.

In spite of the inhibition effectiveness of quinacrine, the lack of efficacy was attributed to inadequate accumulation of quinacrine in the brain, due to its removal by P-glycoprotein (Pgp) which is an efflux protein found in the blood brain barrier [53]. Indeed, when quinacrine was administered to prion-infected mice deficient in the genes encoding Pgp, brain levels of quinacrine were significantly increased [53,54]. Since quinacrine failed to extend the survival of prion-infected animals, authors speculated that continuous quinacrine treatment promoted the formation of drug resistant prions. This phenomenon could have contributed to the lack of in vivo efficacy of quinacrine. In spite of its limitations, quinacrine structural modification has yielded analogs with more potent in vitro anti-prion activity. Thus, other quinacrine derivatives with different substituents $R_{1}$ and $R_{2}$ and different spacers have been synthesized and their biological activity tested in the last two decades. Authors as Nguyen et al. showed that nature of side chain influenced compound cell-based potency, PAMPA permeability and binding affinity to $\mathrm{hPrP}_{121-231}$ when compared to quinacrine [55]. Several promising analogs were found with a more favorable anti-prion profile than quinacrine, in terms of potency and activity across different prion-infected murine cell models. Analogs 37-39 depicted in Figure 10 have shown sub-micromolar activities on several prion-infected mouse neuroblastoma cell lines, including the more resistant F3 where host cells were stably infected with a human prion strain. In particular, Nguyen Thi et al. found that piperazin analog 37 had $\mathrm{EC}_{50}$ values ranging from 0.1 to $0.7 \mu \mathrm{M}$ on all cell models, being able to clear $\mathrm{PrP}^{\mathrm{Sc}}$ at non-toxic concentrations of 1.2-2.5 $\mu \mathrm{M}$, and presenting more activity than quinacrine in terms of $\mathrm{EC}_{50}$ values [56]. Behavior of analog 7 appeared to be unusual, showing $\mathrm{EC}_{50}$ values of 0.13 and $0.19 \mu \mathrm{M}$ on ScN2a and F3 cell models respectively (Figure 10 and Table 1).
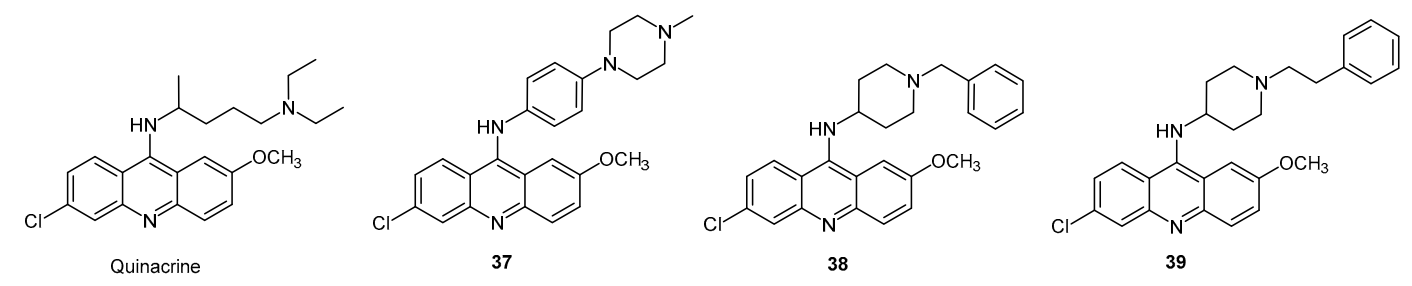

Figure 10. Quinacrine and analogs 37-39 with anti-prion acitivity against $\mathrm{PrP}^{\mathrm{Sc}}$ in different cell lines. 
Table 1. In vitro anti-prion activities of quinacrine and compounds 37-39 on murine neuroblastoma cells infected mouse adapted scrapie strains (ScN2a and N167) and a human prion strain (F3), binding responses of test compounds to $\mathrm{hPrP}_{121-231}$ by SPR, permeability by PAMPA-BBB assay, $\log \mathrm{D}$ and efflux ratio across wild type MDCK-MDR1 cell monolayers.

\begin{tabular}{|c|c|c|c|c|c|c|}
\hline Compound & $\begin{array}{c}\mathrm{EC}_{50}(\mu \mathrm{M}) \\
\mathrm{ScN} 2 \mathrm{a}\end{array}$ & $\begin{array}{c}\mathrm{EC}_{50}(\mu \mathrm{M}) \\
\mathrm{N} 167\end{array}$ & $\begin{array}{c}\mathrm{EC}_{50}(\mu \mathrm{M}) \\
\mathrm{F} 3\end{array}$ & $\begin{array}{c}\text { Binding to } \\
\mathrm{hPrP}_{121-231}(\% \mathrm{RU} \text { max) }\end{array}$ & $\begin{array}{c}\text { Permeability } \\
\text { PAMPA-BBB } \\
\text { Assay }\left(\log D_{7.4}\right)\end{array}$ & $\begin{array}{l}\text { Efflux Ratio * } \\
\text { MDCK-MDR1 }\end{array}$ \\
\hline Quinacrine & 0.23 & 0.59 & 1.88 & 87.3 & 1.89 & 5 \\
\hline 37 & 0.10 & 0.42 & 0.68 & 120.3 & 3.36 & 2.4 \\
\hline 38 & 0.42 & 0.49 & 0.80 & 67.5 & 3.75 & - \\
\hline 39 & 0.13 & 0.23 & 0.19 & 169.5 & 3.41 & - \\
\hline
\end{tabular}

* Ratio of apparent permeability from the basolateral (B) to apical (A) compartment, to apparent permeability from apical (A) to basolateral (B) compartments. Efflux ratio $\frac{1}{4} \operatorname{Papp}(\mathrm{B} / \mathrm{A}) / \operatorname{Papp}(\mathrm{A} / \mathrm{B})$.

In general, potent and broad ranging anti-prion activities were found in the presence of side chains with aromatic residues substituted with basic functionalities. These structures also have shown a decreased effective permeability in PAMPA-BBB by increasing partition coefficient $\log \mathrm{D}_{7.4}$, but kept within the permeability range of CNS compounds. Interestingly, compound 37 crossed the permeability P-glycoprotein assay (MDCK-MDR1) barrier with an efflux ratio that is half that of quinacrine (Table 1), indicating that it may be a weaker Pgp substrate.

Other quinacrine analogs with non-aromatic and basic side chains exhibited strong binding affinities for $\mathrm{hPrP}_{123-231}$ and good PAMPA permeabilities. Unfortunately, anti-prion activities were limited to ScN2a and did not extend to other cell models [55].

The synthesis of analog 37 was carried out by a sequence of three steps (Scheme 11). Buchwald-Hartwig amination of 1-iodo-4-nitrobenzene with 1-methylpiperazine in the presence of a palladium acetate $/ 2,2^{\prime}$-bis(diphenylphosphino)-1,1'binaphthalene (BINAP) catalyst generated compound 41 in $95 \%$ yield. Catalytic hydrogenation of the nitro group gave the corresponding amine to react with 6,9-dichloro-2-methoxyacridine in refluxing ethanol affording anti-prion compound 37 in $65 \%$ yield [56].

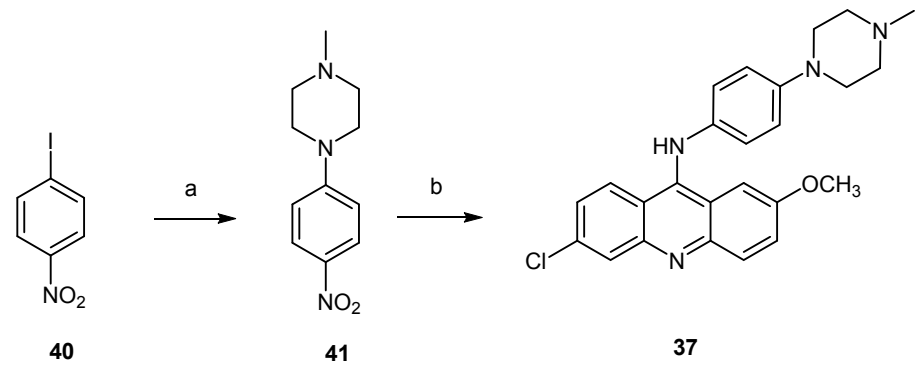

Scheme 11. Synthesis of quinacrine analog 37. Reagents and conditions: (a) amine, $\mathrm{Pd}(\mathrm{OAc})_{2}, \mathrm{BINAP}$, $\mathrm{Cs}_{2} \mathrm{CO}_{3}$, anhydrous toluene, $120^{\circ} \mathrm{C}, 95 \%$; (b) (i) $\mathrm{H}_{2}, \mathrm{Pd} / \mathrm{C}$; (ii) 6,9-dichloro-2-methoxyacridine, ethanol, reflux, $24 \mathrm{~h}, 65 \%$ over the two steps.

In 2003, Cohen et al. disclosed bis(acridine) analogs as an alternative to the acridine-based compounds [57]. They postulated that covalent dimers of quinacrine could be more potent inhibitors of prion replication due to an increased local concentration of the active moiety. Thus, dimeric acridine compounds were synthesized exhibiting a ten-fold higher activity than the respective monomeric compounds. The best results were obtained with the three bis(acridine) analogs 42-44 (Figure 11) that showed half-maximal inhibition of $\mathrm{PrP}^{\mathrm{Sc}}$ formation in $\mathrm{ScN} 2 \mathrm{a}$ cells at 40, 25, and $30 \mathrm{nM}$, respectively, and were not cytotoxic to uninfected neuroblastoma cells at concentrations of $500 \mathrm{nM}$. 


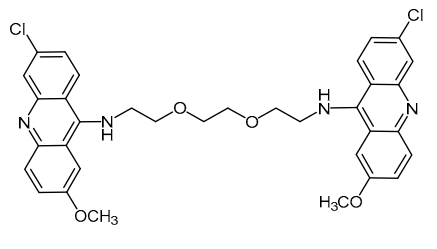

42

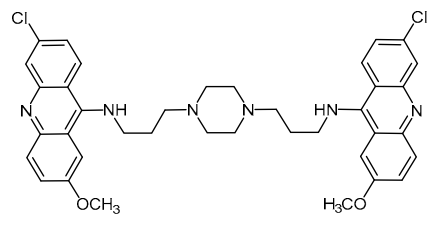

43

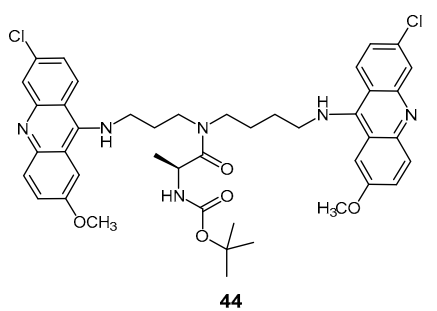

Figure 11. Bis(acridine) compounds $\mathbf{4 2 - 4 4}$ with anti-prion activity.

Structure-activity analysis revealed that spacer length and structure are determinant for inhibition of prion replication in cultured scrapied cells [57]. Compound $\mathbf{4 2}$ showed improved activity which could result from additional hydrogen-bonding interactions between the heteroatoms of the linker and the target receptor. Synthesis of bis(acridines) 42-44 [58,59] was carried out by reacting polyamines with 3 equiv. of 6,9-dichloro-2-methoxyacridine in DMF at reflux, in the presence of potassium carbonate as an inorganic base (Scheme 12A). In the case of compound 44, a side chain central secondary amino group reacted with a carboxylic acid in the presence of bromotripyrrolidinophosphonium hexafluorophosphate (Py-BroP) to give the amide functionality [59] (Scheme 12B).

A

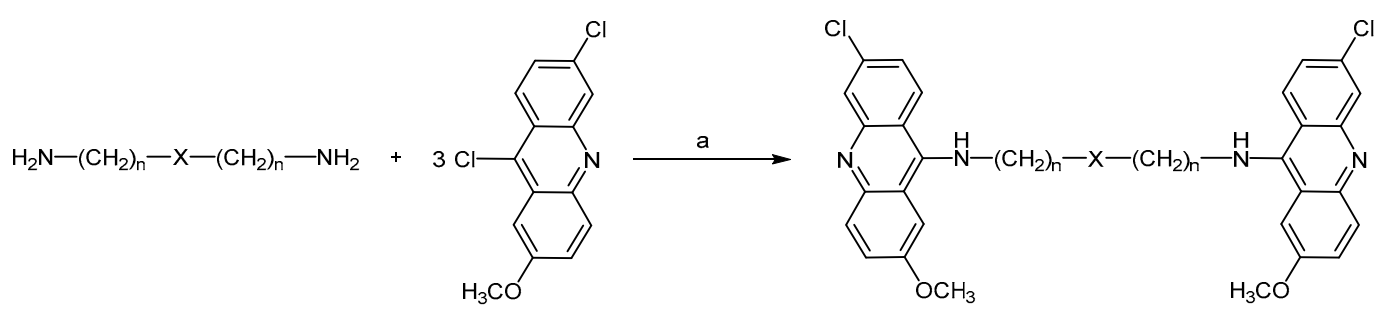

B
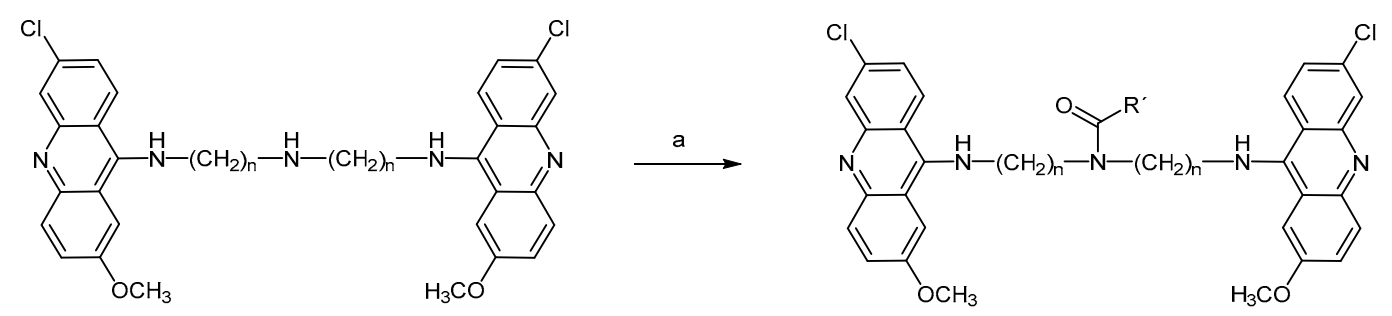

Scheme 12. (A). General synthesis of bis(acridines). Reagents and conditions: (a) $\mathrm{K}_{2} \mathrm{CO}_{3}, \mathrm{DMF}$; (B). Preparation of bis(acridines) bearing a central amide group. Reagents and conditions: (a) $\mathrm{RCOOH}$, PyBrop, DIEA, DMF.

Bongarzone et al. [60] evaluated a small library of bis(acridine) analogs, bearing a 2,5-diamino-1,4-benzoquinone moiety as spacer component, against prion infection. The most active one acting on prion replication in the submicromolecular range was 45 containing the 6-chloro-1,2,3,4-tetrahydroacridine moiety (Figure 12), and showing an $\mathrm{EC}_{50}$ of $0.17 \mu \mathrm{M}$ on ScGT1 cells, which was lower than that displayed by reference compound 42 ( $\mathrm{EC}_{50}=0.32 \mu \mathrm{M}$ on ScGT1). 


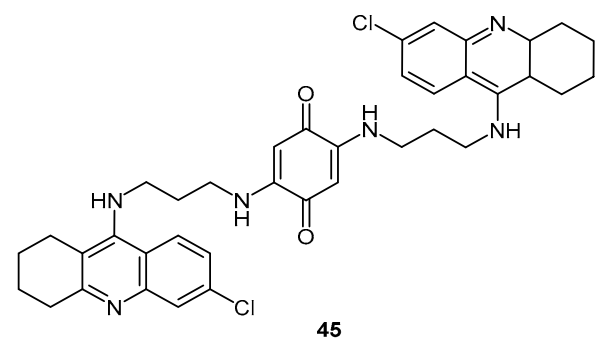

Figure 12. Compound 45 structure with $\mathrm{EC}_{50}=0.17 \mu \mathrm{M}$ on ScGT1 cells.

Compound 45 was synthesized starting from 6,9-dichloro-1,2,3,4-tetrahydroacridine by reaction with sodium iodide, followed by addition of a large excess of diamine at $120{ }^{\circ} \mathrm{C}$ for $5 \mathrm{~h}$ to generate the $\mathrm{N}$-substituted diamine 47 in $50 \%$ yield (Scheme 13), whose reaction with 2,5-dimethoxy-1,4-benzoquinone at $60^{\circ} \mathrm{C}$ for $5 \mathrm{~h}$ gave 45 in $87 \%$ yield [60].

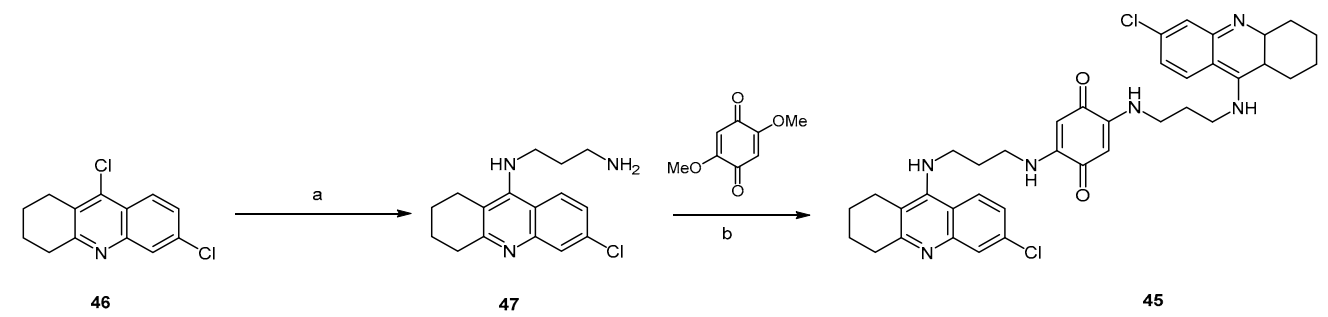

Scheme 13. Synthesis of compound 45. Reagents and conditions: (a) i. NaI, $120{ }^{\circ} \mathrm{C}(1 \mathrm{~h})$; ii. Propane-1,3-diamine, $5 \mathrm{~h}, 120^{\circ} \mathrm{C}, 50 \%$; (b) EtOH, $5 \mathrm{~h}, 60^{\circ} \mathrm{C}, 87 \%$ yield.

More recently Galdeano et al. [61] developed a family of huprine-tacrine heterodimers demonstrating a potent inhibition of human acetylcholinesterase (AChE) activity, in vitro neutralization of the pathological chaperoning effect of $A C h E$ toward $\beta$-amyloid peptide $(A \beta)$ and prion protein aggregation. These heterodimers were able to cross the blood brain barrier in ex vivo experiments with OF1 mice. The general structure of these huprine-tacrine heterodimers is presented in Figure 13.

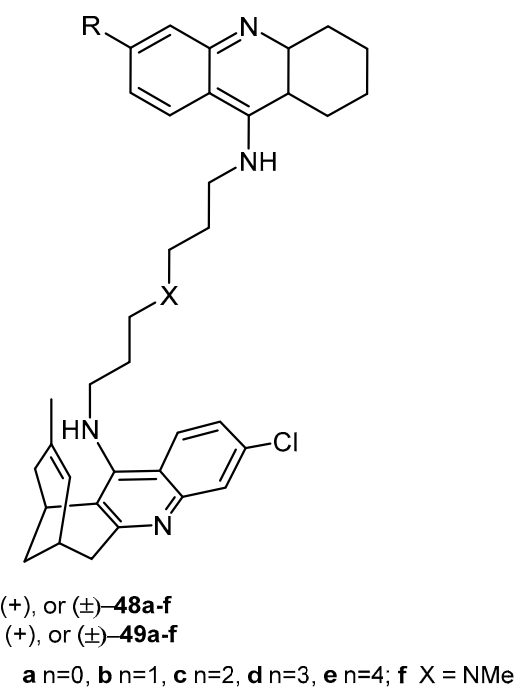

Figure 13. General huprine-tacrine heterodimer structure. 
Enantiopure (-)-48b and (-)-49b showed a 5-6-fold more potent inhibitory effect $\left(\mathrm{IC}_{50}=1.33\right.$ and $2.04 \mathrm{nM}$ respectively) towards hAChE than their dextrorotatory homologs. All the huprine-tacrine heterodimers, at $100 \mu \mathrm{M}$, turned out to be potent inhibitors of the AChE-induced $\mathrm{PrP}_{106-126}$ aggregation with percentages of inhibition higher than $80 \%$ but no significant differences between compounds bearing an unsubstituted or chloro-substituted tacrine unit or between enantiomers were found.

Thus, alkylation of tacrine [62] with 1,9-dibromoheptane 50 in the presence of $\mathrm{KOH}$ in DMSO [63] gave bromoalkyltacrine $\mathbf{5 1 b}$. Alkylation of racemic huprine $\mathrm{Y}$ with $\mathbf{5 1 b}$ under similar reaction conditions afforded the heterodimer (-)-48b in 13\% isolated yield [64] (Scheme 14).

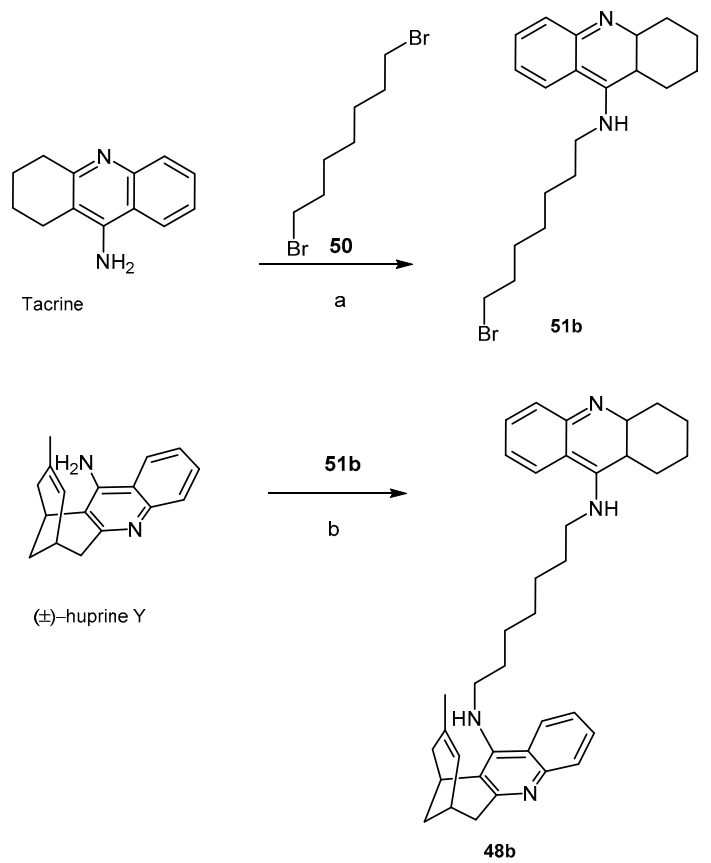

Scheme 14. Synthesis of compound $\mathbf{4 8 b}$. Reagents and conditions: KOH, DMSO, 4 A MS. (a) 2 h; (b) 3 days, 13\% isolated yield over the two steps.

Quinacrine has been reported to be an important prion inhibitor [65] However this compound did not increase the survival in a murine model of prion disease [49] and in high doses led to liver damage without therapeutic efficacy in humans affected with CJD.

Interestingly, a shared mode of action between acridines and aminoquinolines, whose core structure is embodied in acridines, has been discussed [66]. Aminoquinolines with anti-prion activity were also reported by Macedo and co-workers $[67,68]$. These aminoquinoline derivatives have been developed ten years earlier as potential antimalarial drugs. The hypothesis that the aminoquinoline scaffold could also act against $\mathrm{PrP}^{\mathrm{Sc}}$ formation was based on a previous publication reporting the PrPres-inhibitory activity of the aminoquinoline derivative mefloquine (52, Figure 14), despite its lack of efficacy in Tg7 mice challenged with $263 \mathrm{~K}$ brain homogenates [69]. By studying these compounds, the authors aimed at gaining new insights on the minimum structure required for anti-prion efficacy, while trying to improve the therapeutic potential of both quinacrine and mefloquine. Compounds 53 and 54 (Figure 14) emerged as the most promising molecular entities with the aminoquinoline scaffold, with $\mathrm{IC}_{50}$ values of $0.2 \mu \mathrm{M}$ and $0.1 \mu \mathrm{M}$, respectively, for the inhibition of the Syrian hamster prion protein ShaPrP $109-149$ aggregation. 


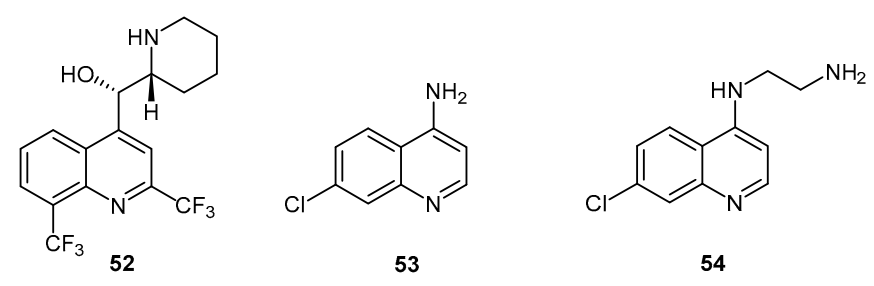

Figure 14. Aminoquinoline derivatives 52-54 with anti-prion activity.

By comparing the activity of all analogs studied by Macedo et al., it becomes clear that the primary amine present in both compounds $\mathbf{5 3}$ and $\mathbf{5 4}$ is an important feature for activity, particularly in the case of the latter [67]. In fact, while $N$-methylation of 53 led to an increase in $\mathrm{ShaPrP}_{109-149}$ aggregation from $8.4 \%$ to $38.6 \%$ at $1 \mu \mathrm{M}, N$-alkylation of compound 54 drastically increased the aggregation of ShaPrP $\mathrm{P}_{109-149}$ to $82 \%$. Moreover, the replacement of the primary amine by a hydroxy group also led to a dramatic decrease in activity, thus excluding the role of the primary amine as a hydrogen bond donor or acceptor in the affinity of these types of compounds towards the target protein.

These compounds definitively need to be further investigated to be considered as anti-prion leads for further development. Indeed, as evidenced by the studies presented and discussed in previous sections, the best inhibitors of $\operatorname{PrP}$ aggregation in cell-free assays are not necessarily the best compounds in cell-based assays, demonstrating that in vitro activity does not assure significant in vivo effects.

\subsection{Aromatic Scaffolds Bearing Five-Membered Ring Heterocycles as Core Structure}

\subsubsection{Diphenylpyrazole and Analogs}

In addition to piperazine derivatives (30, Figure 8), Leidel and co-workers identified diphenylpyrazoles as another class of promising compounds with anti-prion activity in vivo [70]. In a high throughput screening study against SMB and ScN2a cells conducted in 2011, compound 55 (Figure 15) stood out, exhibiting $\mathrm{IC}_{50}$ values of $0.6 \mu \mathrm{M}$ and $1.2 \mu \mathrm{M}$, respectively. When compared to similar compounds also evaluated in this report, the methyl group is recognized as a key motif for the enhanced activity in SMB cells, but not in ScN2a; conversely, when the fluorine atom is replaced by a bromine, the activity drops in both cell lines. Compound 55 did not influence $\operatorname{PrP}^{\mathrm{C}}$ expression or proteasome activity in ScN2a cells, and did not display any effect in a cell-free assay. The exact mechanism of action remains, for now, undisclosed. Yet, this diphenylpyrazole successfully prolonged the incubation time by 42 days in Tga20 mice challenged with the RML prion strain upon oral treatment, and increased survival time by 20 days in $\mathrm{PrPSC}^{\mathrm{Si}}$-ifected C57BL/ 6 mice in a prophylactic approach. The $p$-fluoro analog 56 (Figure 15) was later tested on SMB cells and presented an $\mathrm{IC}_{50}$ of only $0.1 \mu \mathrm{M}$, but no in vivo studies have been published so far [43].
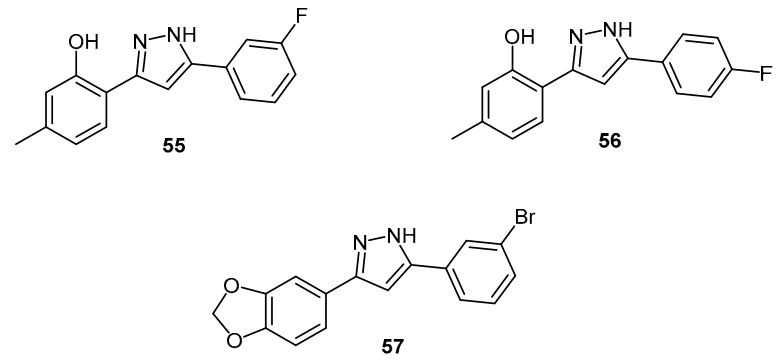

Figure 15. Three diphenylpyrazole derivatives (55-57).

Just two years later, compound $\mathbf{5 7}$ was identified by Wagner et al. another diphenylpyrazole with anti-prion activity [71]. After screening 20,000 structurally diverse compounds, the 
benzylidene-benzohydrazide unit came across as a potential lead chemical scaffold and, once optimized into the diphenylpyrazole core, a library of 150 diphenylpyrazole derivatives was prepared. The synthetic methodology is herein exemplified for compound 57: briefly, after condensing the adequate ester and acetophenone starting materials in the presence of sodium hydride to afford de diketone intermediate, the pyrazole core is formed following treatment with hydrazine in ethanol, under reflux (Scheme 15). Compound 57, also known as Anle138b, was obtained by this approach in $77 \%$ overall yield [71].

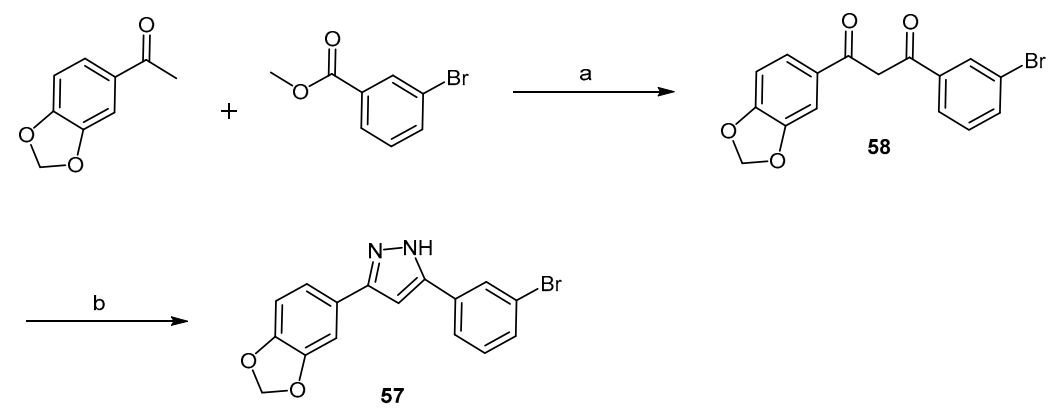

Scheme 15. Synthesis of Anle138b (57). Reagents and conditions: (a) $\mathrm{NaH}, \mathrm{DMSO}, \mathrm{THF}, 10{ }^{\circ} \mathrm{C}$, then r.t., $15 \mathrm{~h}(87 \%)$ (b) $\mathrm{H}_{2} \mathrm{~N}-\mathrm{NH}_{2} \cdot \mathrm{H}_{2} \mathrm{O}, \mathrm{EtOH}$, reflux, $3 \mathrm{~h}(89 \%)$ [71].

In this study published in 2013, Anle138b (57) was reported to be an amyloid oligomer modulator able to inhibit $\mathrm{PrP}^{\mathrm{Sc}}$ formation in a cell-free protein misfolding cyclic amplification (PMCA) in vitro assay in $84 \%$. Moreover, it was found to block the accumulation of $\mathrm{PrP}^{\mathrm{Sc}}$ and neuronal cell death in mice infected with different $\mathrm{PrP}^{\mathrm{Sc}}$ strains $\left(\mathrm{EC}_{50}=7.3 \mu \mathrm{M}\right.$ for the murine $\mathrm{RML}$ prion strain or $7.1 \mu \mathrm{M}$ for the vCJD human prion strain), while $\mathrm{PrP}^{\mathrm{C}}$ expression was not affected.

Importantly, neuronal cell death was found to correlate with the rate of $\mathrm{PrP}^{\mathrm{Sc}}$ amplification and not with the absolute levels of $\mathrm{PrP}^{\mathrm{Sc}}$. Compound 57 permeates BBB, is orally available and, interestingly, it also inhibits the aggregation of $\alpha$-synuclein ( $\alpha$-syn), an amyloid protein involved in the pathophysiology of Parkinson's disease (PD). Indeed, amyloid proteins such as $\mathrm{PrPSc}^{\mathrm{Sc}} \alpha$-syn and Alzheimer's amyloid $\beta$ 1-42 $\left(\mathrm{A} \beta_{1-42}\right)$ share common structural features underpinning their similar aggregation-prone behavior [72]. This molecule was thus proposed to act transversally against amyloids, being potentially useful against different protein misfolding diseases [71].

Since then, Anle138b (57) has been and continues to be studied due to such promising results against amyloid protein aggregation. In agreement with Wagner's results, it was found to increase survival in a mouse model of PD by 66 days [73]. Moreover, it showed affinity towards aggregated tau protein, which is implicated in the pathology of both PD and AD, while inhibiting tau aggregation in vitro and in vivo [74]. It prevented synapse and neuronal loss in tau transgenic PS19 mice, effectively increasing survival of these animals [74]. Hence, Anle138b seems to be not only a promising new lead against TSEs, but also against other diseases caused by amyloid proteins.

Villa et al. studied the neuroinflammatory role of ciclooxigenase (COX) activity, and its potential targeting for anti-prion therapies by comparing ketoprofen and celecoxib (Figure 16), preferential inhibitors of COX1 and COX2, respectively, on $\mathrm{PrP}_{90-231}$-induced microglial activation. Celecoxib, but not ketoprofen significantly reverted the growth arrest as well as NO and prostaglandine PGE2 secretion induced by $\operatorname{PrP}_{90-231}$, indicating that $\operatorname{PrP}_{90-231}$ pro-inflammatory response in microglia is mainly dependent on COX2 activation [75]. 
<smiles>CC(C(=O)O)c1cccc(C(=O)c2ccccc2)c1</smiles><smiles>Cc1ccc(-c2cc(C(F)(F)F)nn2-c2ccc(S(N)(=O)=O)cc2)cc1</smiles>

Figure 16. Structures of ketoprofen and celecoxib.

Synthesis of celecoxib is based on Claisen condensation of acetophenone with ethyl trifluoroacetate providing the adduct 59 in good yield. Reaction with (4-sulfamoylphenyl)hydrazine hydrochloride gave exclusively the desired regioisomer celecoxib in $46 \%$ yield [76] (Scheme 16).

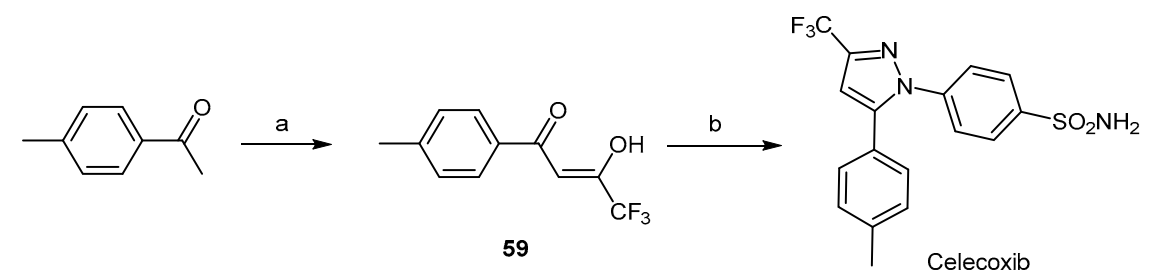

Scheme 16. Synthesis of celecoxib. Reagents and conditions: (a) 25\% NaOMe/MeOH, MTBE, ethyl trifluoroacetate, 94\%, (b) (4-sulfamoylphenyl)hydrazine hydrochloride, EtOH, reflux 46\%.

\subsubsection{Thiazolamines and Oxazolamines}

Thiazoles and oxazoles are found in the structure of a wide variety of biologically active molecules. In particular thiazol-5-amines are present in antibiotics [77] and photosensitisers [78]. Heal and co-workers [79] reported the first example of anti-prion activity in compounds of this type. Synthetic 2,4-diphenylthiazol-5-amine and 2,4-diphenyloxazol-5-amine derivatives 60-62 were found to bind $\mathrm{hPrPC}$ and showed potent inhibition of $\mathrm{PrP}^{\mathrm{Sc}}$ formation in infected $\mathrm{SMB}$ cells with $\mathrm{EC}_{50}$ in the range 1.5-20 $\mu \mathrm{M}$ (Figure 17).

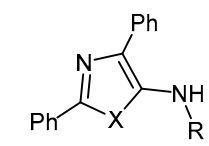

$$
\begin{aligned}
& 60 X=O, R=\text { O-tert-butyl } \\
& 61 X=S, R=C C_{3} \\
& 62 X=O, R=\operatorname{COCF}_{3}
\end{aligned}
$$

Figure 17. Oxazol-5-amine and thiazol-5-amine structures with anti-prion activity.

Preparation of oxazole derivative 60 was carried out starting from 2-phenylglycinonitrile hydrochloride. Reaction with benzoyl chloride afforded the intermediate 63 , whose treatment with triphosgene and tert-BuOH permitted to obtain the target molecule in $22 \%$ overall yield (Scheme 17).

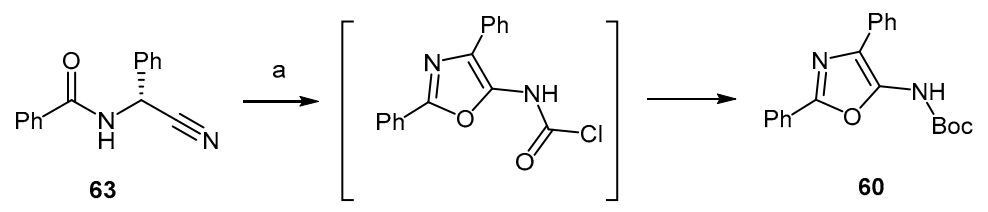

Scheme 17. Synthesis of oxazol-5-amine derivative 60. Reagents and conditions: (a) Triphosgene, DCM, r.t., $15 \mathrm{~min}$, then tert-BuOH, DCM, r.t., $5 \mathrm{~min}, 22 \%$. 
For the synthesis of thiazole 61, D-(-)-phenylglycinamide 64 was reacted with benzoyl chloride in the presence of $N$-ethylmorpholine (NEM) to give $N$-acylglycinamide 65 . Treatment with Lawesson's reagent to provide bis(thioamide) intermediate 45 , and then with trifluoroacetic anhydride (TFAA) gave 61 via a two-step one-pot procedure in 65\% yield [80] (Scheme 18).

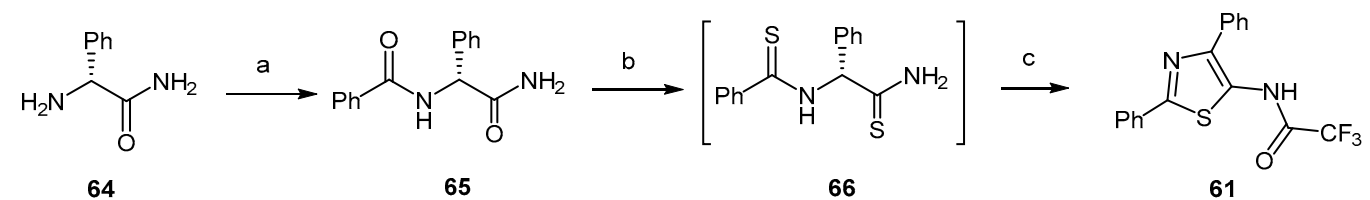

Scheme 18. Synthesis of thiazol-5-amine derivative 61. Reagents and conditions: (a) PhCOCl, py, NEM; (b) Lawesson's reagent; (c) TFAA, DCM.

Thiazol-2-amines are another class of small molecules with anti-prion activity in prion-infected neuroblastoma cell lines. In Figure 18 the structure of some of the most potent anti-prion thiazol-2-amines is illustrated, and also oxazoles, namely compound 68, used by some authors for comparison purposes because it was reported to produce a $\geq 50 \%$ extension of survival in treated animals. Prusiner and co-workers were pioneer identifying thiazol-2-amines as active compounds in $\mathrm{ScN} 2 \mathrm{a}$ cells. The inhibition of $\mathrm{PrP}^{\mathrm{Sc}}$ formation seemed to be the mode of action they postulated for these molecular entities [81]. N-(Methylpyridyl)thiazol-2-amines seemed to confer a more potent effect than analogs with unsubstituted pyridyl groups as suggested by SAR studies. In fact, compound 67 showed the more potent anti-prion activity with an $\mathrm{EC}_{50}$ of $2.5 \mu \mathrm{M}$ in prion-infected neuroblastoma cell lines $(\mathrm{ScN} 2 \mathrm{a})$, than other tested analogs bearing $m$-dihydroxyphenyl and pyridyl groups.
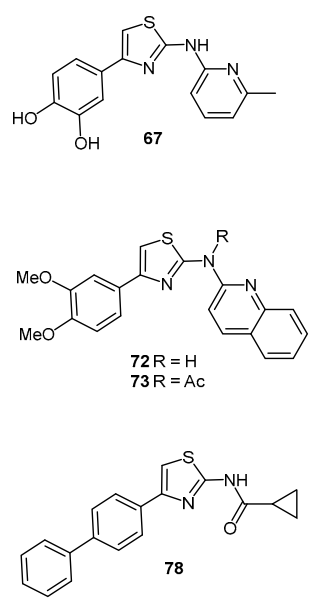
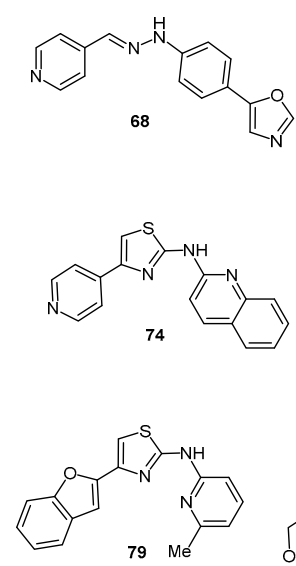
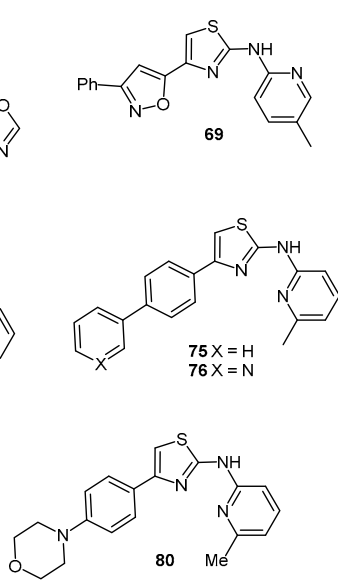
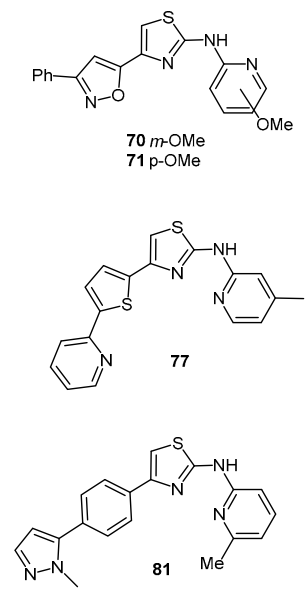

Figure 18. Structure of anti-prion thiazol-2-amines and oxazole 68.

Gallardo-Godoy et al. reported the identification of other thiazol-2-amine lead compounds that are orally absorbed and achieved high brain concentrations in animals [82]. In particular compound 69, embodying also an isoxazole ring, displayed excellent stability to rat liver microsomes in vitro and exhibited an $\mathrm{EC}_{50}$ of $0.94 \mu \mathrm{M}$ in prion-infected neuroblastoma cells ( $\mathrm{ScN} 2 \mathrm{a}-\mathrm{cl} 3$ ), reaching a concentration of $\sim 25 \mu \mathrm{M}$ in mice brain after three days of oral administration. The replacement of 4-methylpyridyl by 3-/4-methoxypyridyl resulted in more potent analogs, namely $70\left(\mathrm{EC}_{50}=0.23 \mu \mathrm{M}\right)$ and $71\left(\mathrm{EC}_{50}=0.25 \mu \mathrm{M}\right)$. Noteworthy, the analogs with a quinoline ring and a diprotected catechol moiety, namely $72\left(\mathrm{EC}_{50}=0.11 \mu \mathrm{M}, 10\right.$-fold more potent than its monocyclic version $)$ and $73\left(\mathrm{EC}_{50}=\right.$ $0.081 \mu \mathrm{M}$ ) were the most potent agents, even more than 74 bearing a pyridyl group. Also the presence of the hydrogen bonding donor, $\mathrm{NH}$, was not determinant for anti-prion activity as shown by the activity of 73 when compared to that of compound 72 (Figure 18). 
Ghaemmaghami et al. [83] reported that $N$-acyl substitution with small groups (e.g., acetamide, cyclopropylamide) was tolerated to keep the inhibitory effect, as confirmed with the activity of compound 78. On the other hand aryl, heteroaryl or aliphatic rings appended to the aromatic ring attached to position 4 of the thiazolamine were tolerated, e.g., compounds $\mathbf{7 9}$ and $\mathbf{8 0 .}$

Regarding brain exposure evaluation, among the thiazoles embodying the quinoline moiety, compound 74 exhibited the highest brain AUC value $(0.02 \mu \mathrm{M}$ after $40 \mathrm{mg} / \mathrm{Kg} /$ day $)$, while a higher brain exposure (1.31 and $0.88 \mu \mathrm{M}$ after $40 \mathrm{mg} / \mathrm{Kg} /$ day, respectively) was found for 78 containing also the benzofurane ring and for $\mathbf{7 1}$ bearing the phenylisoxazole in its structure. However, thiazole $\mathbf{7 5}$ exhibited the highest brain AUC amongst the evaluated thiazolamines $(8.70 \mu \mathrm{M}$ after $40 \mathrm{mg} / \mathrm{Kg} / \mathrm{day})$. Even at the dose of $210 \mathrm{mg} / \mathrm{kg} /$ day, mice receiving 75 or 77 exhibited no adverse clinical or behavioral effects, suggesting that these compounds would be well tolerated on prolonged dosing in an animal model of prion disease. In general thiazolamine analogs exhibited higher exposure in brain than in plasma, suggesting that is not subjected to P-gp mediated efflux.

On the other hand, among in vivo efficacy studies published prior to 2013, arylhydrazone with the oxazole ring, compound 68, was the only agent that produced a $\geq 50 \%$ extension of survival in treated animals compared to controls [84]. Based on this finding, Renslo et al. also determined the full PK profile of 75 and 77 compared to that of hydrazone 68 (Figure 18). They concluded that compound 75 achieved nearly 30-fold higher brain exposure following oral dosing than 68, and also exhibited a much longer half-life, lower clearance, a superior brain/plasma ratio, and greater bioavailability. Compound 77 exhibited the highest volume of distribution of the three compounds. On the other hand 75 and 77 produced no signs of toxicity in mice. In contrast it was found that hydrazone 68 exhibited lethal toxicity at a dose of $150 \mathrm{mg} / \mathrm{Kg}$ /day.

Moreover, the replacement of the terminal phenyl ring in 75 with heteroaromatic or heteroaliphatic rings produced analogs with clearly superior potency in the $\mathrm{ScN} 2 \mathrm{a}-\mathrm{cl} 3$ assay. Thus, the presence of pyridyl in 76, of morpholine in $\mathbf{8 0}$ and pyrazole in $\mathbf{8 1}$ led to analogs of $\mathbf{7 5}$ exhibiting EC $\mathrm{E}_{50}$ values below $100 \mathrm{nM}$, a greater than 10-fold improvement in potency when compared to 75. Compound 76 also exhibited excellent brain exposure in animals, yielding a greater than 20 -fold improvement in brain $\mathrm{AUC} / \mathrm{EC}_{50}$ ratio for $\mathbf{7 6}$ compared to $\mathbf{7 5}$. More promising results were found with a series of cyclopropylamide substituted thiazole analogs, including compound 78, the direct analog of 75, that exhibited potency and in vivo brain exposure superior to 75, with a brain $\mathrm{AUC} / \mathrm{EC}_{50}$ ratio 10-fold higher than that of 75 .

However, thiazolamine-treated mice eventually showed accumulation of $\mathrm{PrPSc}^{\mathrm{S}}$ in their brain and ultimately succumbed to disease. Compound 75 proved to be entirely ineffective against human CJD prions in susceptible transgenic mice expressing human $\operatorname{PrP}^{C}$. Prusiner and co-workers demonstrated that the eventual failure of thiazolamines can be accounted for by treatment-induced selection of thiazolamine-resistant prion strains [85].

To comprehend the mechanism of action of thiazolamines it has been suggested that they might interfere with the formation of new $\mathrm{PrPSc}^{\mathrm{S}}$ in the cell, either directly by interference in the misfolding/assembly process or indirectly by modulating endogenous cellular clearance mechanisms [83]. However recent findings supported by X-Ray structure have shown that flexible, unstructured regions of $\mathrm{PrP}^{\mathrm{C}}$ contribute to forming a cryptic small molecule binding site revealing direct interactions between thiazolamine and $\mathrm{PrP}^{\mathrm{C}}$ [86].

The synthesis of thiazol-2-amine analogs was carried out by the Hantzsch-type condensation of bromomethyl ketones with thioureas (Scheme 19). Synthesis of compound 69 started with reaction of the commercially available (5-methylpyridin-2-yl)amine with phenyl isothiocyanate in acetone under reflux, dissolved in $\mathrm{MeOH}$ and hydrolyzed by treatment with $1 \mathrm{~N} \mathrm{NaOH}$ at $80^{\circ} \mathrm{C}$ to afford thiourea 82 in $65 \%$ yield. Reaction with the commercially available 2-bromo-1-(3-phenylisoxazol-5-yl)ethanone under reflux for $4 \mathrm{~h}$ gave 69 isolated in $65 \%$ yield. 


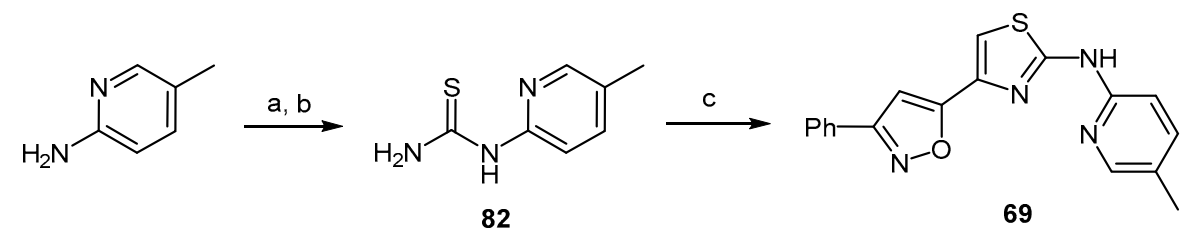

Scheme 19. Synthesis of thiazol-2-amine 69. Reagents and conditions: (a) PhSCN, acetone, reflux, 65\%, (b) $\mathrm{NaOH}, \mathrm{MeOH}$, reflux; (c) 2-bromo-1-(3-phenylisoxazol-5-yl)ethanone, $\mathrm{EtOH}$, reflux, 65\%.

\subsubsection{Thiazolidines}

Thiazolidines intervention in neuroinflammation-like responses, induced in microglia by $\mathrm{PrP}_{90-231}$, has also been explored. Microglia are CNS resident immune cells that comprise approximately $10-12 \%$ of glial cells in the brain and predominate in the grey matter. Although microglia form the first line of protection for neural parenchyma, and their uncontrolled activation may be toxic to neurons due to release of reactive oxygen $\left(\mathrm{H}_{2} \mathrm{O}_{2}\right.$, or $\left.\mathrm{O}_{2}{ }^{-}\right)$and nitrogen (NO) species, inflammatory cytokines, and prostaglandins (PGE2) [87-89]. AD patients show increased concentration of PGE2 in the cerebrospinal fluid and upregulated cyclooxygenase-2 (COX-2) in the brain; moreover, the deletion of PGE2 receptors result in neuroprotective effects in mouse models of AD [90,91]. Thus, being the activity of COXs the rate-limiting step in the conversion of arachidonic acid into prostaglandins, it was hypothesized that the neuronal injury induced by glial activation in AD and prion diseases can be reduced by non-steroidal anti-inflammatory drug (NSAIDs) treatment [92,93].

Recently, to study the possible role of NSAIDs in preventing amyloid-driven neuroinflammation, Villa et al. have demonstrated that $\mathrm{PrP}_{90-231}$ induces PGE2 release from microglia through the activation of COX-2, since this effect was selectively inhibited by celecoxib but not by ketoprofen, a prevalent COX-1 blocker [75]. Later on, the same authors searched for novel compounds able to inhibit glial cell activation induced by neuroinflammatory stimuli, such as $\mathrm{PrP}_{90-231}$ and lipopolysaccharide LPS. They tested a small library of 2,3-diaryl-1,3-thiazolidin-4-one derivatives structurally related to celecoxib (Figure 19), found to possess anti-inflammatory activity in animal models [94].

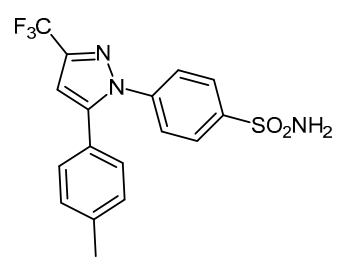

Celecoxib

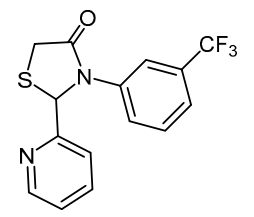

85

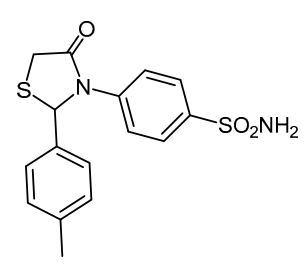

83

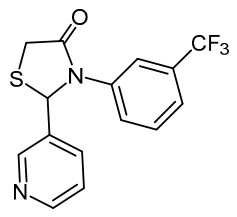

86

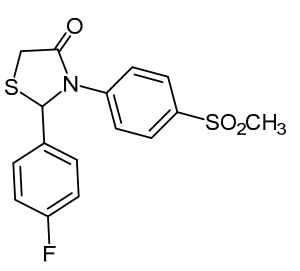

84

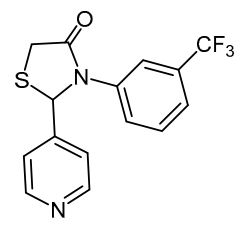

87

Figure 19. Chemical structures of celecoxib and the 2,3-diaryl-1,3-thiazolidin-4-one derivatives.

Thiazolidin-4-one 83 (Figure 19) inhibits microglia activation more efficiently than all other tested thiazolidines and celecoxib, whose structure embodies a pyrazole (see pyrazole section), lowering both iNOS and COX-2 activity, and reducing reactive oxygen species (ROS) release. These properties lead to the ability of $\mathbf{8 3}$ to revert neuroinflammation-like responses in mixed astrocyte and microglia induced by $\mathrm{PrP}_{90-231}$ and LPS. 
Compound 83 was obtained by synthesizing the corresponding Schiff base 88 (Scheme 20) [95]. Reaction of 4-methylbenzaldehyde with 4-aminophenylsulfonamide under reflux followed by addition of $\alpha$-sulfanylacetic acid maintaining the same conditions gave compound 83 in 36\% overall yield (Scheme 20).
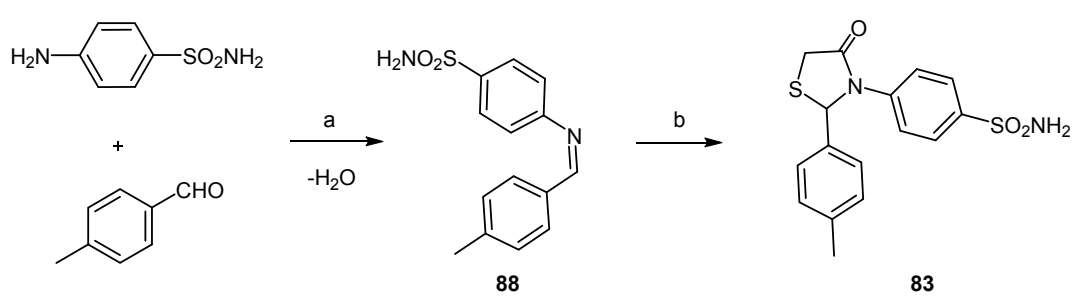

Scheme 20. Synthesis of thiazolidin-4-one 83. Reagents and conditions: (a) benzene, reflux, Dean-Stark apparatus; (b) $\mathrm{HSCH}_{2} \mathrm{COOH}$, reflux, 36\% (two steps).

\subsubsection{Polythiophenes}

Five-membered heterocycle ring polymers as thiophenes have been investigated as anti-prion compounds. Herrmann et al. [96] administered to the brain of prion-infected mice luminescent conjugated polythiophenes (LCPs) varying in the number of polyphene moieties, the number and distribution pattern of carboxyl groups (e.g., compounds 89-96, Figure 20). They found that anti-prion activity required a minimum of five thiophene rings bearing regularly spaced carboxyl side groups. Solid-state NMR analyses and molecular dynamics simulations revealed that anionic side chains interact with complementary, regularly spaced cationic amyloid residues of model prions.

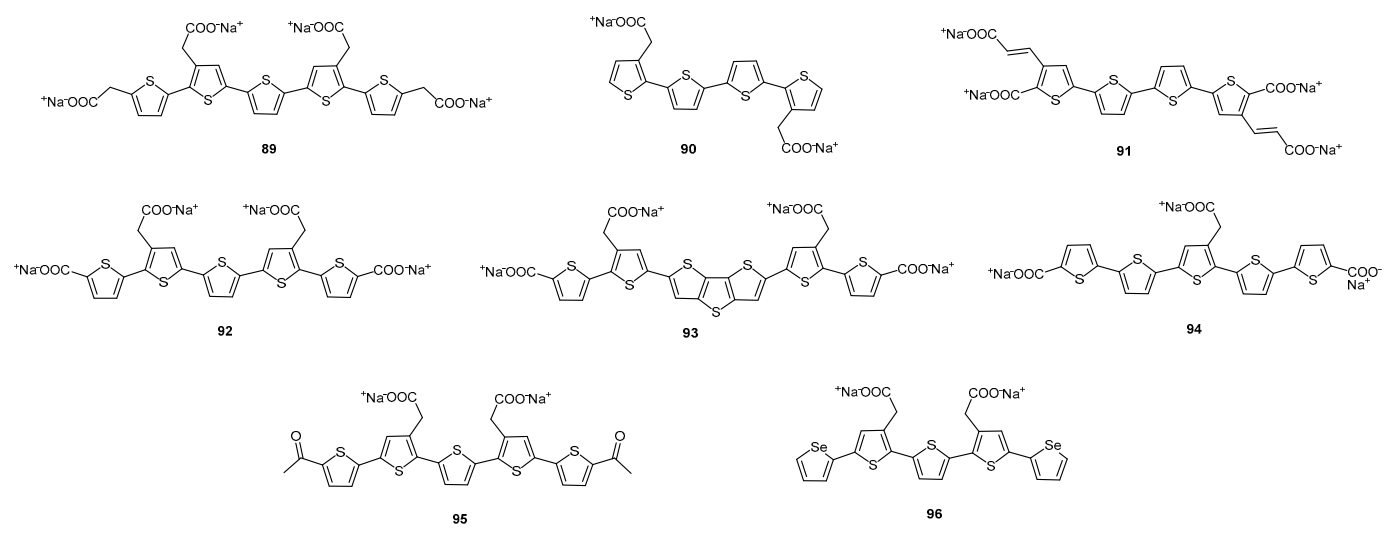

Figure 20. Polythiophene structures 89-96 studied in prion-infected mice.

While five thiophene moieties were required for the minimal generic anti-amyloid LCP pharmacophore, as mentioned above, anionic side groups linked to the terminal thiophene rings is determinant for activity. Finally the periodicity of the anionic side groups also controlled the anti-prion properties, with the most effective pattern of regioregular charges being ca. $5 \AA-10 \AA-5 \AA$ as in compound $\mathbf{8 9}$.

Reduced PrP deposition was confirmed by immunohistochemistry in brainstems of mice treated with 89 and was associated to a conspicuous reduction in vacuolation and astrocytosis. In addition, the increased survival of 89 -treated mice, even when administered to preterminally scrapie-sick mice, suggested that LCPs may attenuate $\mathrm{PrP}^{\mathrm{Sc}}$ toxicity, but confirmation remains open because it cannot be directly quantified. Compound 89 was synthesized [97] using the route represented in Scheme 21. Intermediate $\mathbf{9 9}$ was prepared by Suzuki cross-coupling conditions from brominated thiophene $\mathbf{9 7}$ and boronic acid 98 . After esterification, an overall yield of $71 \%$ over the two steps was obtained. Bromination of $\mathbf{9 9}$ with $\mathrm{N}$-bromosuccinimide afforded the key precursor $\mathbf{1 0 0}$ in $\mathbf{7 3} \%$ yield, whose 
coupling to 101 yielded methyl ester pentamer 102, giving compound 89 by hydrolysis, quantitatively (Scheme 21).

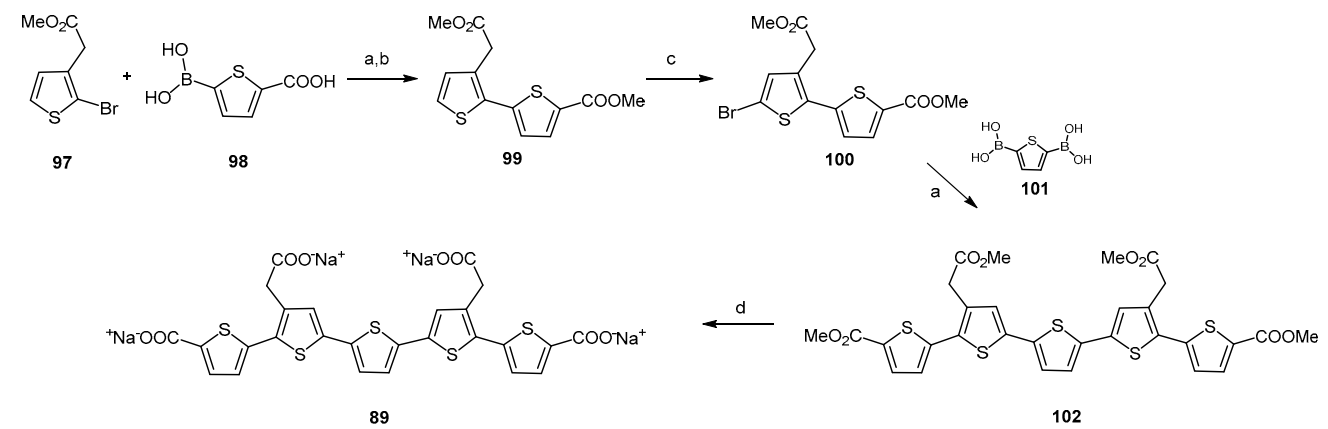

Scheme 21. Synthesis of compound 89. Reagents and conditions: (a) 1,4-dioxane/MeOH, PEPPSI ${ }^{\mathrm{TM}}-\mathrm{IPr}$, $\mathrm{K}_{2} \mathrm{CO}_{3}, 70{ }^{\circ} \mathrm{C}, 20 \mathrm{~min}$; (b) $\mathrm{MeOH}, \mathrm{H}_{2} \mathrm{SO}_{4}, 70{ }^{\circ} \mathrm{C}, 16 \mathrm{~h}$; (c) NBS, DMF, $0{ }^{\circ} \mathrm{C}$ to r.t., $16 \mathrm{~h}$; (d) $\mathrm{NaOH}(1 \mathrm{M})$, 1,4-dioxane, $60{ }^{\circ} \mathrm{C}, 16 \mathrm{~h}$.

\subsubsection{Carbazoles}

Compounds 103 and 104 (Figure 21) are clearly distinct in terms of their chemical structure; yet, it is interesting to note the presence of key common elements in both structures: the number of hydrogen bond donors and acceptors, a nitrogen-containing five-membered ring, aromatic rings-one of which substituted with a fluorine atom, as well as a free hydroxy group. Compound $\mathbf{1 0 3}$ was also identified as a promising anti-prion scaffold by Kimura and co-workers in 2011 [98].

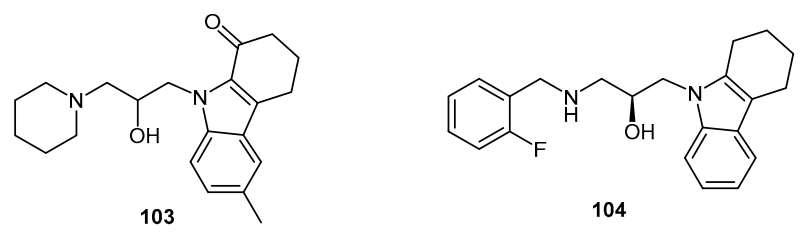

Figure 21. Two carbazole derivatives 103, 104 with anti-prion activity.

Compound 104 was developed inspired on compound 103 (Figure 21), previously reported for its affinity towards $\mathrm{PrP}^{\mathrm{C}}$ while displaying an $\mathrm{IC}_{50}$ of $8.54 \mu \mathrm{M}$ against PrPres accumulation in GT1-7 cells infected with Fukoka 1 (FK-1) [98]. It was synthesized together with a library of fortyseven dihydrocarbazole analogs and derivatives, which were subsequently tested to allow a comprehensive structure-activity relationship study on the activity of the lead compound.

Among the most relevant conclusions drawn by the authors, the fused three-ring system was found to be crucial for the desired effect. Indeed, when the 1,2,3,4-tetrahydrocarbazole moiety was replaced by either a pyrrole, indole or 4,5,6,7-tetrahydroindole unit, the anti-prion activity was lost. Carbazoles and 2,3,4,9-tetrahydrocarbazoles, however, were able to retain the desired effects to the same extent as compound $\mathbf{1 0 3}$. The hydroxy group was also found to be critical for activity by acting as hydrogen bond donor; what's more, by replacing the original piperidine by secondary amines such as the one in compound 104, the anti-prion activity was further enhanced. The secondary amine function is indeed thought to interact with the target by acting as a hydrogen bond donor, while the hydrophobicity conferred by the $N$-linked substituent seems to be an important requirement. $O$-halobenzyl substituents in this position proved to be the most effective ones.

Compounds were firstly prepared as racemic mixtures containing both $(R)$ - and $(S)$-enantiomers, following a similar synthetic route here presented for the lead compound 103 (Scheme 22A). Herein, the starting material-in this case the 6-methyl-2,3,4,9-tetrahydro- $1 \mathrm{H}$-carbazol-1-one unit-was treated with sodium hydride followed by addition of epichlorhydrin in DMF at $25^{\circ} \mathrm{C}$. Subsequent epoxide opening by piperidine in ethanol then gave the final product in good overall yield [98]. 
A<smiles>Cc1ccc2[nH]c3c(c2c1)CCCC3=O</smiles>

B

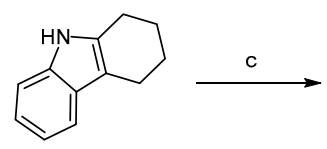<smiles>Cc1ccc2c(c1)CCCC2=O</smiles><smiles>c1ccc2c(c1)c1c(n2CC2CO2)CCCC1</smiles>
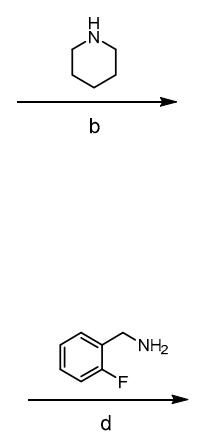

106
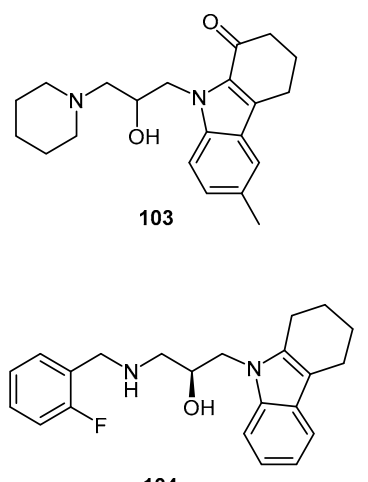

104

Scheme 22. Synthesis of carbazole derivatives 103 (A) and 104 (B). Reagents and conditions: (a) (1) NaH, DMF, $0{ }^{\circ} \mathrm{C}$, then $25^{\circ} \mathrm{C}, 1 \mathrm{~h}$; (2) epichlorhydrin, DMF, $0{ }^{\circ} \mathrm{C}$, then $25^{\circ} \mathrm{C}, 12 \mathrm{~h}$; (b) EtOH, reflux, $12 \mathrm{~h}(51 \%$ over two reaction steps); (c) NaH, DMF, $0{ }^{\circ} \mathrm{C}$, then $25^{\circ} \mathrm{C}, 1 \mathrm{~h}$; (2) S-epichlorhydrin, DMF, $0{ }^{\circ} \mathrm{C}$, then $25^{\circ} \mathrm{C}, 12 \mathrm{~h}$; (d) EtOH, reflux, $12 \mathrm{~h}$ (60\% over two reaction steps) [98].

In order to compare the individual contributions of each enantiomer constituting the most active mixture tested in this study, $(S)$ - or ( $R$ )-epichlorhydrin was, accordingly, used (Scheme 22B) [98]. Containing a 2,3,4,9-tetrahydro- $1 H$-carbazole unit as the main core, and a $o$-fluorobenzyl group linked to the secondary amine, compound $\mathbf{1 0 4}$ then arose as the most promising one of this series, with an $\mathrm{IC}_{50}$ of $1.11 \mu \mathrm{M}$ against PrPres in GT1-7 cells infected with FK-1. It was found to be twice as potent as its $(R)$-enantiomer, eight times more potent than the lead compound 103, and in vivo studies are currently taking place to assess whether it may, or not, deliver more encouraging results than those observed for some of the previously presented molecules. It would be interesting to compare those results, for instance, with the effects exhibited by GN8 (107, Figure 22) in vivo, since both compounds displayed identical $\mathrm{IC}_{50}$ values in the same cellular disease model.

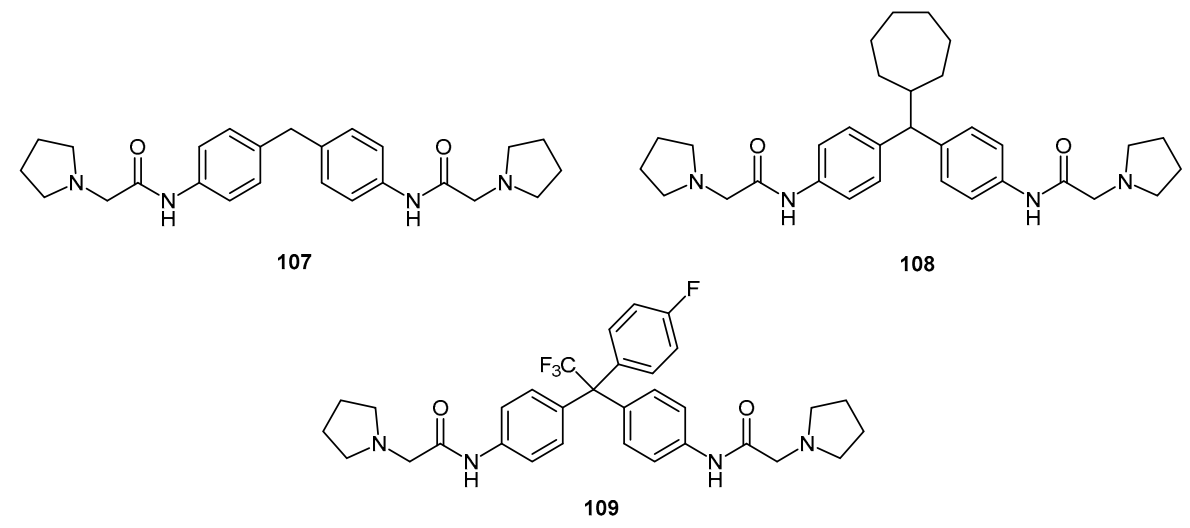

Figure 22. GN8 (107) and two derivatives 108, 109 with anti-prion activity.

\subsubsection{GN8 and Derivatives}

$N, N^{\prime}$-[methylenebis(4,1-phenylene)]bis[2-(pyrrolidin-1-yl)acetamide] (GN8, 107, Figure 22) was discovered in 2007 by Kuwata and co-workers and, with an $\mathrm{IC}_{50}$ of $1.35 \mu \mathrm{M}$, significantly reduced the levels of $\mathrm{PrP}^{\mathrm{Sc}}$ in a mouse neuronal cell line (GT1-7) infected with the Fukuoka-1 (FK-1) prion strain [99]. This compound also improved the incubation time of $\mathrm{PrP}^{\mathrm{Sc}}$-infected mice up to 18 days when administered subcutaneously, and was found to stabilize $\mathrm{PrP}^{\mathrm{C}}$ mostly by binding to its $\mathrm{C}$-terminal domain and, possibly, by interacting with the C-terminal region of the GPI-anchored $\mathrm{PrP}^{\mathrm{C}}$ [99].

$\mathrm{PrP}^{\mathrm{C}}$ is highly conserved in mammals and, therefore, GN8 is therefore strain-independent. This constitutes a relevant advantage in regard to previously described anti-prion compounds that act 
by targeting $\mathrm{PrPSc}^{\mathrm{Sc}}$. Furthermore, this compound is easily accessed in only two reaction steps, with excellent overall yield (Scheme 23).<smiles>CCC(=O)CCC(=O)Nc1ccc(Cc2ccc(NC(=O)CBr)cc2)cc1</smiles>

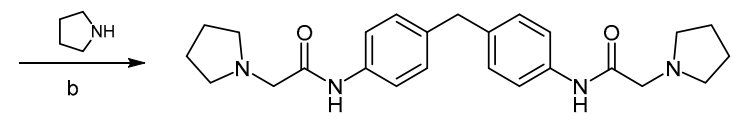

107

Scheme 23. Synthesis of GN8. Reagents and conditions: (a) Py, DMAP, DCM, $0{ }^{\circ} \mathrm{C}$, then $25^{\circ} \mathrm{C}, 3 \mathrm{~h}(93 \%)$; (b) $\mathrm{K}_{2} \mathrm{CO}_{3}, \mathrm{THF}, 25^{\circ} \mathrm{C}$, then $60{ }^{\circ} \mathrm{C}, 12 \mathrm{~h}(88 \%)[100]$.

First, treatment of 4,4'-methylenedianiline with two equivalents of 2-bromoacetyl bromide in the presence of pyridine and dimethylaminopyridine (DMAP) gives intermediate $\mathbf{1 1 0}$. Then, subsequent di- $\mathrm{N}$-alkylation by pyrrolidine in THF at $60^{\circ} \mathrm{C}$ affords the desired product [100].

In 2011 Kimura et al. developed a series of GN8 analogs ultimately aiming at defining structural requirements for the activity of the lead compound [100]. Sixtyfour analogs were synthesized, two of which—compounds 108 and 109 (Figure 22)—displayed improved activity when compared to the prototype structure, both with an $\mathrm{IC}_{50}$ of $0.51 \mu \mathrm{M}$ in GT1-7 cells infected with FK-1. The synthesis of these compounds involved an additional reaction step for the formation of the dianiline precursor, which is exemplified for compound 109 in Scheme 24. In this reaction, 2,2,2-trifluoro-1-(4-fluorophenyl)ethan-1-one was dissolved in a solution of aniline hydrochloride in aniline at high temperature to afford intermediate $\mathbf{1 1 1}$ in moderate yield. Then, as previously described in the synthesis of GN8 (Scheme 23), two consecutive $N$-alkylation reactions gave the final compound in $65 \%$ yield.
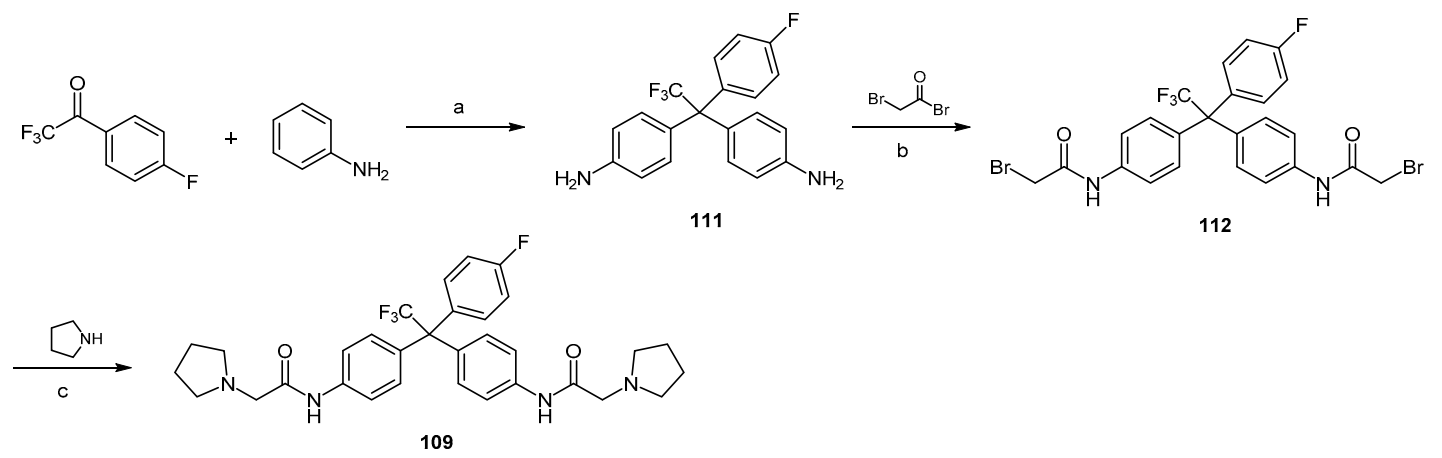

Scheme 24. Synthesis of GN8 derivative 109. Reagents and conditions: (a) $\mathrm{PhNH}_{3} \mathrm{Cl}, 25^{\circ} \mathrm{C}$, then $140{ }^{\circ} \mathrm{C}$, $48 \mathrm{~h}$ (41\%); (b) Py, DMAP, DCM, $0{ }^{\circ} \mathrm{C}$, then $25^{\circ} \mathrm{C}, 3 \mathrm{~h}$; (c) $\mathrm{K}_{2} \mathrm{CO}_{3}, \mathrm{THF}, 25{ }^{\circ} \mathrm{C}$, then $60{ }^{\circ} \mathrm{C}, 12 \mathrm{~h}(65 \%$ over two reaction steps) [100].

Overall, the conclusions of this study indicate that the structure of GN8 as a whole is essential for activity, as the deletion of either both pyrrolidines, or the full 2-(1-pyrrolidinyl)acetyl moieties conduct to a decrease in anti-prion activity. Moreover, $N$-methylation of the amide function leads to the same result. Indeed, it is supposed that the amide N-H groups and nitrogen atoms of the pyrrolidine units are crucial in the affinity towards $\mathrm{PrP}^{\mathrm{C}}$, acting as hydrogen bond donor and acceptor groups, respectively. In contrast, the carbonyl groups are seemingly less important. All compounds in which the central methylene bridge in GN8 was replaced by other linkers, including compounds 108 and 109, exhibited improved activity when compared to the lead structure. $\mathrm{PrP}^{\mathrm{C}}$ levels were not affected by 
these compounds; however, conformational analysis showed that substituents at the benzylic position confer structural rigidity to the molecule, placing both phenyl groups in the right orientation and thus favouring the access to the binding site of $\mathrm{PrP}^{\mathrm{C}}$. Yet, these substituents do not establish additional interaction points to the $\mathrm{PrP}^{\mathrm{C}}$ structure. Compounds 108 and 109 did not present any toxicity at $2 \mu \mathrm{M}$ in a cell-based assay and therefore constitute a promising class of anti-prion compounds for further development against TSEs.

\subsection{Aryl Scaffolds Linked to Nitrogen Containing Functional Groups}

\subsubsection{Congo Red Analogs}

Congo Red (CR, 113, Figure 23) was found to inhibit the formation of $\mathrm{PrP}^{\mathrm{Sc}}$ in cell-free assays back in 1983, and later to prevent the formation and accumulation of $\mathrm{PrP}^{\mathrm{Sc}}$ in ScN2a cells [101,102]. However, it has a relevant lack of specificity and poor blood brain barrier permeability [103,104]. Importantly, the central benzidine moiety-which is released into the bloodstream after cleavage by gut and intestinal enzymes-has a relevant carcinogenic potential [105]. Since Rudyk and co-workers have shown that this moiety can actually be replaced by less toxic units without losing the desired activity, some research groups have joined efforts to design and develop new CR analogs with improved pharmacological profiles [106]. In 2004, Sellerajah and colleagues defined a strategy for the accomplishment of this task [107]. Previous work had already pointed towards both symmetrical parts of the lead molecule as being necessary for activity; additionally, the sulfonate groups could be replaced by carboxyl groups without causing a significant loss in activity $[106,108]$. Sellerajah and colleagues then envisioned that by replacing both diazo groups with bioisosteric equivalents such as amide bonds, the molecule could be prevented from being metabolized into the carcinogenic benzidine unit [107]. After synthesis and evaluation of a small library of CR analogs, compound 114 (Figure 23) was elected as the most promising for further development, being able to inhibit the formation of PrPres in SMB cells with an $\mathrm{EC}_{50}$ value between 25 and $50 \mathrm{nM}$. It was significantly more efficient that the lead $\mathbf{1 1 3}$ and was effective in a PrP polymerization assay, which pointed towards a mode of action targeting $\operatorname{PrP}^{\mathrm{C}}$ or the conversion between $\mathrm{PrPC}^{\mathrm{C}}$ into PrPres. Moreover, it displayed an $\mathrm{IC}_{50}$ value between $30 \mu \mathrm{M}$ and $40 \mu \mathrm{M}$ in a cytotoxicity assay against mouse cerebellar neuronal cells, which indicates that this compound has a good therapeutic window.
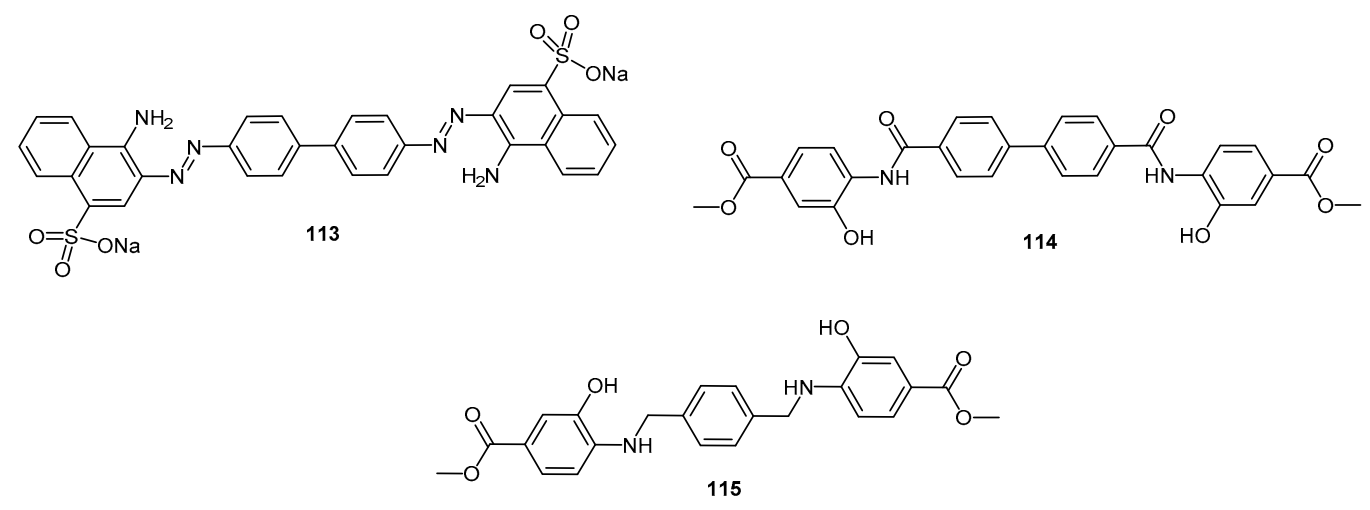

Figure 23. Congo red (113) and two analogs 114, 115 with anti-prion activity.

The synthesis of compound $\mathbf{1 1 4}$ was accomplished through a coupling reaction between (1,1'-biphenyl)-4,4'-dicarbonyl dichloride and methyl 4-amino-3-hydroxybenzoate in the presence of triethylamine, in anhydrous THF at room temperature (Scheme 25) [107]. Using this method, the target compound was obtained in $14 \%$ yield. The authors also described the synthesis starting from the dicarboxylic acid and using $O$-(benzotriazol-1-yl)- $N, N, N^{\prime}, N^{\prime}$-tetramethyluronium tetrafluoroborate 
(TBTU) and DIPEA in dimethylacetamide (DMA) at room temperature for $48 \mathrm{~h}$. However, there was no significant improvement, as the yield was only $10 \%$.

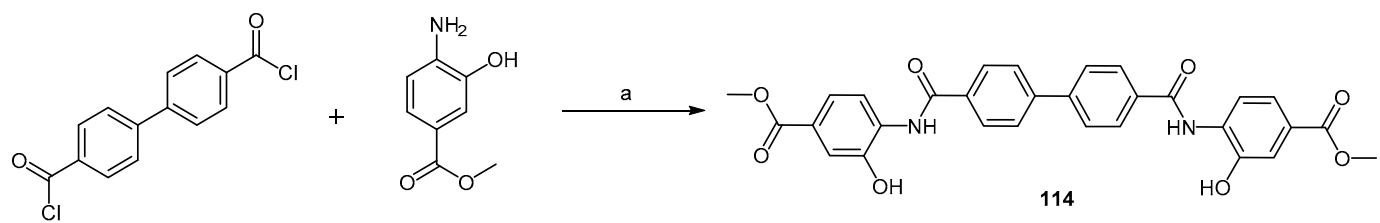

Scheme 25. Synthesis of Congo Red analog 114. Reagents and conditions: (a) TEA, anhydrous THF, $0{ }^{\circ} \mathrm{C}$, $10 \mathrm{~min}$, then rt, $18 \mathrm{~h}(14 \%)$ [107].

With an $\mathrm{EC}_{50}$ value of $75 \mathrm{nM}$, compound 115 (Figure 23) also exhibited tremendous potential in this study, and its synthesis, although involving one additional step, was much more effective than the previous two: after condensation of terephthalaldehyde with methyl 4-amino-3-hydroxybenzoate in ethanol at $55{ }^{\circ} \mathrm{C}$ to afford the imine intermediate 116, a $\mathrm{NaBH}_{4}$-promoted reduction in DCM and $\mathrm{MeOH}$ at room temperature gave the desired product in $49 \%$ yield (Scheme 26) [107].

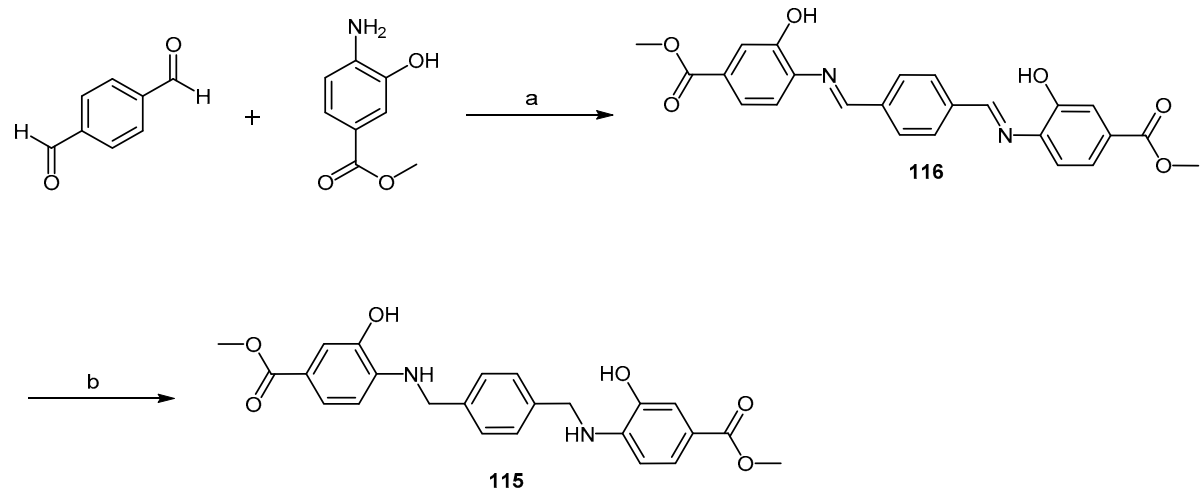

Scheme 26. Synthesis of Congo Red analog 115. Reagents and conditions: (a) EtOH, $55{ }^{\circ} \mathrm{C}, 5 \mathrm{~h}(76 \%)$; (b) DCM, $\mathrm{NaBH}_{4}, \mathrm{MeOH}$, r.t., 12 h (49\%) [107].

The ester moieties in both compounds 114 and 115 were initially conceived based on the hypothesis that they would be readily hydrolysed by esterase enzymes in the brain. Thus, the hydroxy groups were placed in the molecules to assure sufficient aqueous solubility [107]. However, the corresponding free carboxylic acid metabolites were not tested regarding their anti-prion activity in this study, and thus it is not known whether this rationale is, indeed, valid. Yet, in 2007, Webb et al. published a study showing the results of a set of mechanistic tests to verify the mode of action of both compounds, which were later named WSP677 and WSP740, respectively [109]. In this report, proteasome activity was shown to be increased by the interaction of these compounds with PrP. After $24 \mathrm{~h}$, with one single treatment of $1 \mu \mathrm{M}$ of compound SMB cells were "cured" based on the detectable levels of PrPSc. Remarkably, CD-1 mice inoculated with SMB cell extracts containing compound 115 presented no symptoms after 400 days after inoculation. This implies that the agent of disease transmission was eliminated by the action of this compound. However, compound $\mathbf{1 1 4}$ did not exhibit the same effects. These data not only place compound $\mathbf{1 1 5}$ in a lead position for the development of new molecules for the treatment of TSEs, but also reflect the discrepancy between in vitro and in vivo effects when dealing with anti-prion therapies.

\subsubsection{Sulfonated Arylamides}

Suramin is a polysulfonated aromatic urea (Figure 24), discovered in the 60's to treat African sleeping sickness [110]. More recently it has been described as modulator of $\operatorname{PrP}^{\mathrm{C}}$ expression, 
with the ability to modify biochemical properties of $\operatorname{PrP}^{\mathrm{C}}$ including solubility and its half-life [111]. Kiachopoulos and co-workers described how suramin induces misfolding of the cellular prion protein and interferes with the propagation of infectious scrapie prions [112]. Gilch et al. characterised the effects of suramin on prion biogenesis in cell culture and in vivo models. They reported suramin inhibiting de novo formation of $\mathrm{PrP}^{\mathrm{Sc}}$ by inducing intracellular $\mathrm{PrP}^{\mathrm{C}}$ aggregates which are targeted from Golgi/Trans Golgi Network (TGN) compartments to a lysosomal degradation pathway [113].
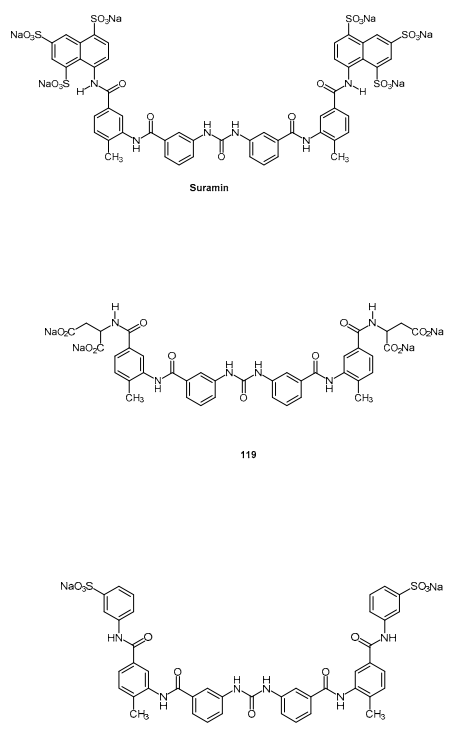

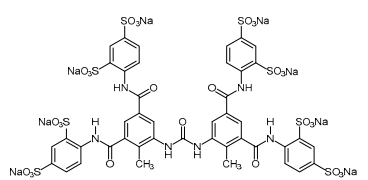

${ }^{117}$

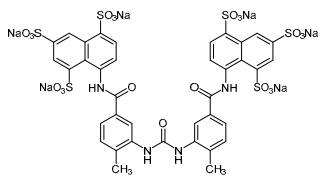

120

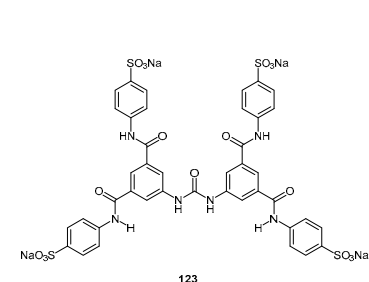

123
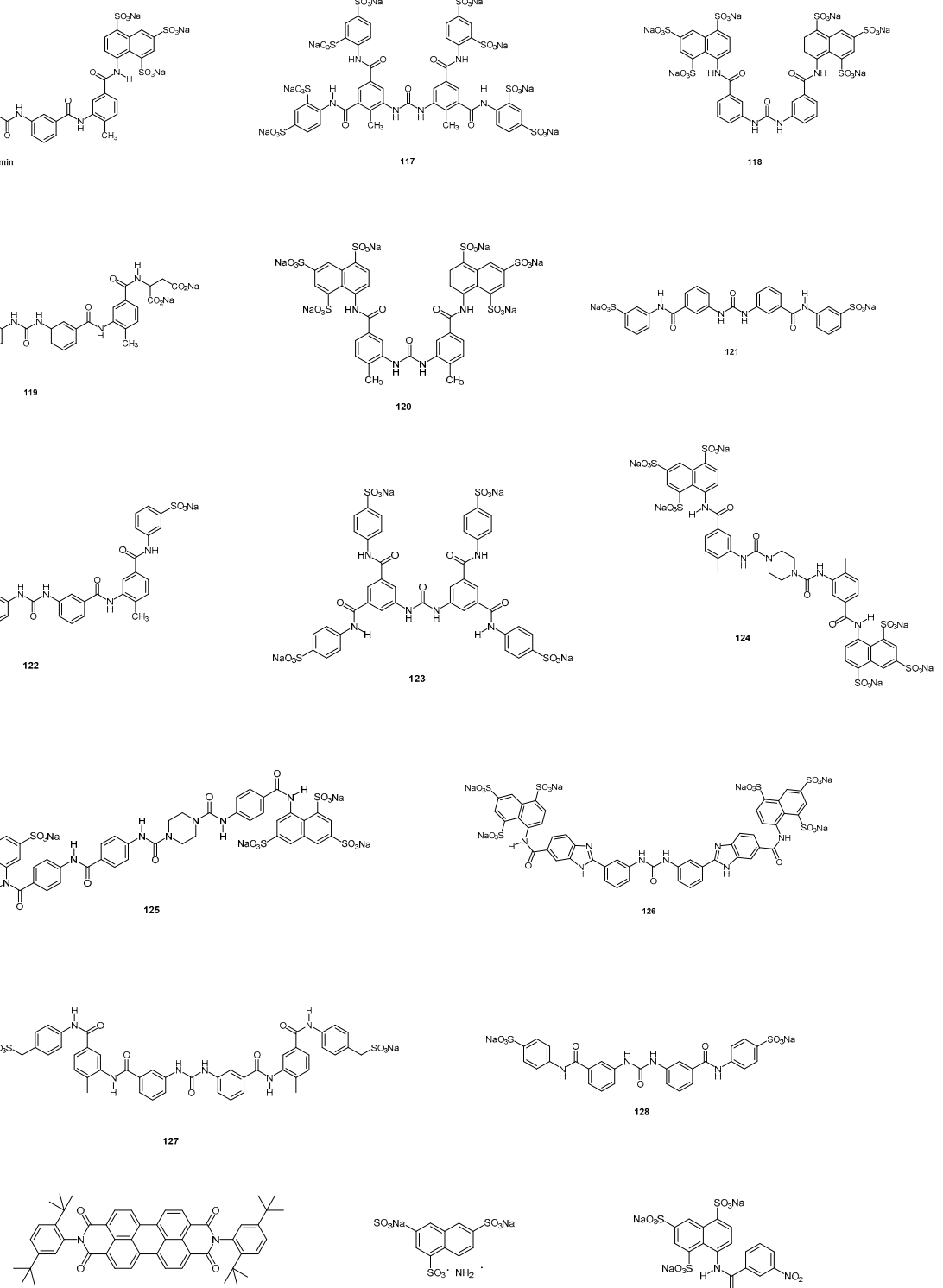

129

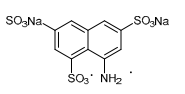

130

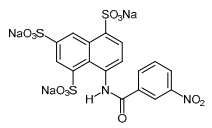

Figure 24. Suramin-related structures tested for anti-prion activity.

All these previous findings have led to the evaluation of new suramin-related compounds developed by Nunziante and co-workers [111] (Figure 24). Among the compounds tested, only those with symmetrical bipolar structure and sulfonic acid groups showed potent inhibition of $\mathrm{PrPSc}^{\mathrm{Sc}}$ synthesis. Two half-molecules lacking symmetrical structure had no effect on $\operatorname{PrP}^{\mathrm{Sc}}$ accumulation. Uncharged compounds did not have activity, despite their symmetrical aromatic structure. Effective compounds induced aggregation of $\mathrm{PrP}^{\mathrm{C}}$ and reduced its half-life without affecting $\mathrm{PrP}^{\mathrm{C}}$ cell surface expression, which was crucial for their activity. The effect of these suramin derivatives on $\mathrm{PrP}^{\mathrm{Sc}}$ was determined in prion-infected neuroblastoma cells (3F4-ScN2a) using a solubility assay and proteinase 
K (PK) treatment followed by immunoblot analysis. The accumulation of PKresistant material was completely eliminated after treatment with suramin and with compounds 117, 118, 120, 122, 123, 124, 125, and 126. Substances with carbonic or phosphonic acid substitutions, 119 and 121 respectively, showed no activity or only mild inhibitory effects on $\mathrm{PrP}^{\mathrm{Sc}}$. No PrP signal was detected in cells incubated with 128 owing to the strong toxicity of the compound. Asymmetric and uncharged drugs $\left(129,130\right.$ and 131) were ineffective in reducing the amount of $\mathrm{PrP}^{\mathrm{Sc}}$, and did not show any effect on $\mathrm{PrPC}^{\mathrm{C}}$ solubility.

On the other hand, when cells were subjected to a solubility assay, the immunoblot analysis revealed aggregation of $\operatorname{PrP}$ when cells were exposed to suramin and to compounds 117, 119, 122, 123 and 124.

Nunziante et al. [111] also examined the influence of suramin analogs on the cellular localization of PrP by confocal microscopy. After treatment of wtN2a cells with 117 or 118, the PrP signal at the cell surface was still consistent with that detected in untreated cells. In addition, 117 and 118 also induced increased partitioning of PrP in intracellular compartments. This intracellular PrP population was mainly present in lysosomes. These results showed that, in contrast to suramin, these derivatives did not interfere with the cell surface expression of $\operatorname{PrPC}^{\mathrm{C}}$.

As an example of arylamide synthesis, Scheme 27 shows the synthetic route to obtain compound 118 [114]. 3-Nitrobenzoyl chloride 132 was reacted with compound $\mathbf{1 3 3}$ in a biphasic mixture of toluene and water at acid pH for 6 hours affording the amide 134 in 83\% yield. Reduction of nitro group by hydrogenation generated compound $\mathbf{1 3 5}$ in 98\% yield. Finally, reaction of $\mathbf{1 3 5}$ with phosgene gave suramin derivative $\mathbf{1 1 8}$ in $85 \%$ yield.

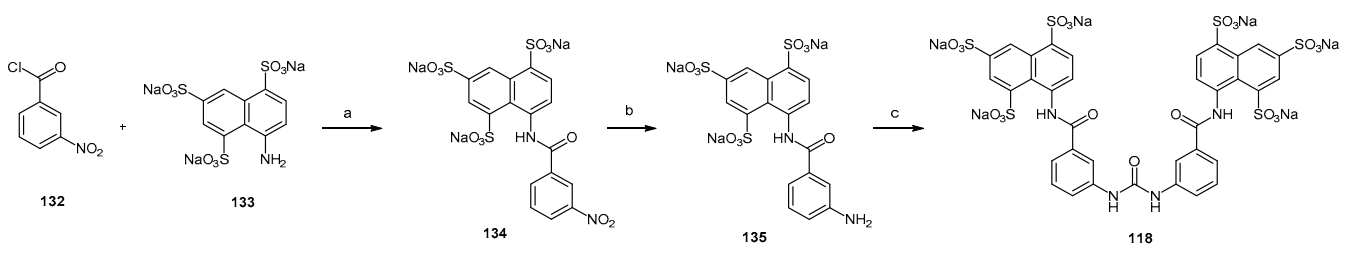

Scheme 27. Synthesis of compound 118. Reagents and conditions: (a) toluene, r.t,. 6 h, $83 \%$, (b) Pd (10\%) on charcoal, $\mathrm{H}_{2} \mathrm{O}, 4$ bar $\mathrm{H}_{2}$, rt, overnight, $98 \%$, (c) $\mathrm{H}_{2} \mathrm{O}$, phosgene $(20 \%)$ in toluene, r.t., $6 \mathrm{~h}, 85 \%$.

\subsection{Polyphenols}

This structurally diverse family of compounds, the polyphenols, are often found as the major plant components responsible for their medicinal properties. Their bioactivity against neurodegeneration is mainly due to their antioxidant [115-119], anti-inflammatory [120,121], and anti-amyloidogenic [122-124] effects. Polyphenols mode of action includes inhibition of intracellular kinases activity [125], binding to cell surface receptors [126], and modifying cell membrane functions [127]. These natural drugs are potent therapeutic agents exhibiting pharmacological properties against Alzheimer's disease and dementia, multiple sclerosis, ischemic stroke, Parkinson's and Huntington's disease [128].

Rauter and co-workers reported the potent acetylcholinesterase (AChE) inhibitory activity of Salvia sclareoides extracts, a spontaneous plant growing in Iberia (Figure 25A) [129]. Plant extracts also delayed prion propagation in a cell-based screening assay [130], and the prion binding properties were then evaluated by NMR measurements [131]. The $n$-butanol extract turned out to bind to the cellular form of human prion protein in a specific manner, causing conformational perturbation in three different regions of the protein including the highly dynamic N-terminal region (Figure 25B). The authors found out that the major extract component was rosmarinic acid, and NMR measurements have shown its interaction with the Alzheimer's disease (AD) amyloid oligomers A $\beta 1-42$, with aromatic protons being mostly involved in the binding (Figure 25C) [132]. Interestingly, a new binding site of rosmarinic acid to AChE was also discovered by the authors, namely the binding site B in Figure 25D [133], opening the way to the development of new drugs based on rosmarinic acid as 
scaffold, aiming to innovate the standard therapy to treat AD patients with donepezil, rivastigmine and galantamine. The search for new AChE inhibitors is encouraged as this cholinesterase is able to accelerate amyloid formation [134]. Indeed $\mathrm{PrP}^{\mathrm{C}}$ decrease also accelerates $\mathrm{A} \beta$ formation and it was reported that its fate in ageing may be related to the mechanisms involved in neurodegeneration, affecting also $\mathrm{AD}$ [135], but the role of $\mathrm{PrPC}^{\mathrm{C}}$ on $\mathrm{AD}$ is not yet fully understood. Noteworthy, prions are amyloid forming proteins and the discovery of anti-amyloidogenic compounds against AD may also be an added-value discovery for the combat of prion diseases.
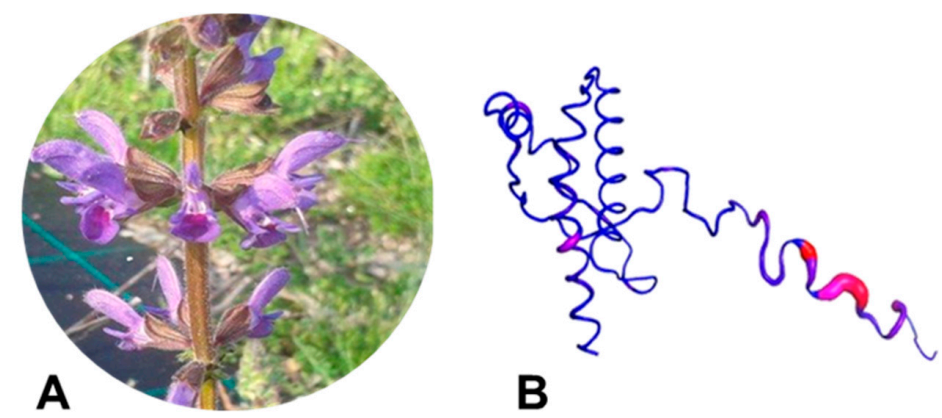

B
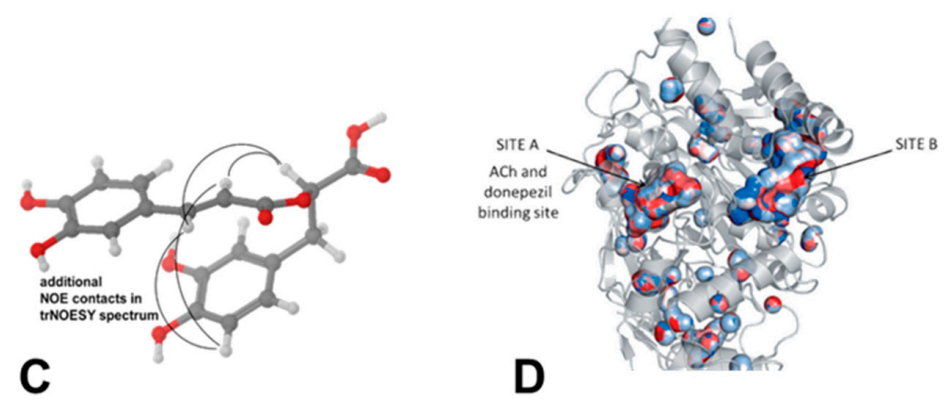

Figure 25. (A) Salvia sclareoides; (B) Structure of huPrP $91-231$ indicating residues affected by S. sclareoides butanol extract, where the color and thickness of the ribbon indicates increased interaction. Residues affected: 93-112 in the unstructured N-terminal region of $\operatorname{PrPC}, 130-187$ comprising the two strands of the beta sheet, helix 1 and the beginning of helix 2, and 205-225 in helix 3 at the C-terminus of the structured domain [131]; (C) Rosmarinic acid interacts with $\mathrm{A} \beta_{1-42}$, and the aromatic protons are mostly involved in the binding, as detected by NMR experiments [132]; (D) Depiction of acetylcholinesterase binding site A for donepezil, a drug in the market to treat $\mathrm{AD}$ and that of the newly discovered binding site B for rosmarinic acid [133].

Caughey et al. screened 2000 compounds covering drugs and natural products for the inhibition of $\mathrm{PrPSc}^{\mathrm{Sc}}$ in $\mathrm{ScN} 2 \mathrm{a}$ cells infected with scrapie strain RML or 22L [136]. While 40 compounds showed $\mathrm{IC}_{50 \mathrm{~s}}$ below $10 \mu \mathrm{M}, 17$ of them, depicted in Figure 15, were the most potent ones, having $\mathrm{IC}_{50 \mathrm{~s}}$ below 1 $\mu \mathrm{M}$ against both strains. It was also found that many of them were natural without observed toxicity. Quinacrine and lovastatin were previously identified as $\mathrm{PrP}^{\mathrm{Sc}}$ inhibitors $[137,138]$. Tannic acid 84, a constituent of foods, turned to be the most potent inhibitor, even better than quinacrine, with $\mathrm{IC}_{50}$ 100 nM.

The compounds were also evaluated in a solid-phase cell-free (SP-CFC) hamster PrP conversion assay. Only polyphenols 136, katacine 137 and $2^{\prime \prime \prime}$-bisepigallocatechin digallate 138 inhibited the cell-free reaction, and their $\mathrm{IC}_{50}$ values were near $100 \mathrm{nM}$. Epigallocatechin 139 and epicatechin 140 were not $\mathrm{PrP}^{\mathrm{Sc}}$ inhibitors, with molecular weights of about 300, although their 3-monogallate derivatives were effective, namely 141 and 142. Noteworthy, compound 143, embodying a double bond in the central ring with a higher hydroxylation pattern than 139 and 140, presented inhibitory properties, demonstrating that changing flavan-type structure by a planar highly hydroxylated flavonol analog had important effects on polyphenol inhibitory efficacy. All other compounds 145-156, with 
a diversity of highly substituted core structures, namely steroid, glycosylated triterpene, aromatics and heteroaromatics, did not show inhibitory activity in the SP-CFC reaction at concentrations up to $100 \mu \mathrm{M}$.

In addition, Rambold et al. [139] identified 142 and its diastereoisomer 144 (Figure 26) as potent drugs to interfere with the formation of $\mathrm{PrP}^{\mathrm{Sc}}$ in $\mathrm{ScN} 2 \mathrm{a}$ cells. Noteworthy 141, with the same configuration as 90 but differing in the hydroxylation pattern, interfered with $\mathrm{PrP}^{\mathrm{Sc}}$ accumulation efficiently at $200 \mu \mathrm{M}$ concentration while only $50 \mu \mathrm{M}$ were needed to have the same effect with $\mathbf{9 0}$. The additional hydroxy group at the trihydroxyphenyl side chain of $\mathbf{1 4 2}$ clearly increases its activity when compared to that of $\mathbf{1 4 1}$. To test for a direct interaction with PrP, isothermal titration calorimetry (ITC) experiments were carried out using $\mathrm{rPrP}_{90-232}$ showing the lack of interaction of 141 with $\mathrm{rPrP}_{90-232}$. While 142 had a $K_{D}$ of $130 \mathrm{nM}$ and a $\Delta \mathrm{H}$ of $-43 \mathrm{~kJ}$, no changes in enthalpies with 141 were observed, indicating absence of binding. In addition, compounds 139 and 140 both without the gallate side chain, did not interfere with $\mathrm{PrP}^{\mathrm{Sc}}$ propagation, endorsing, as reported by Kocisko et al. [136] the gallate side chain as essential for activity.
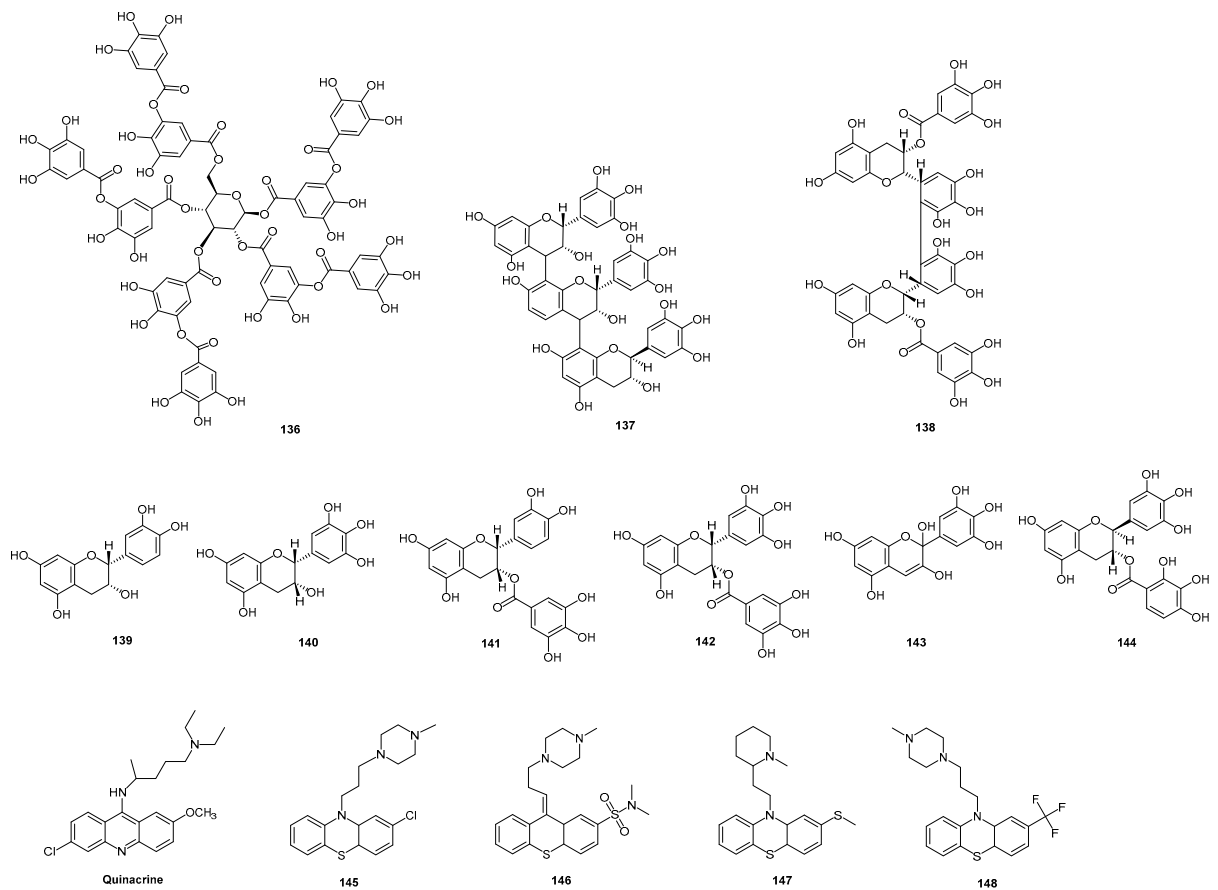

146

147

148
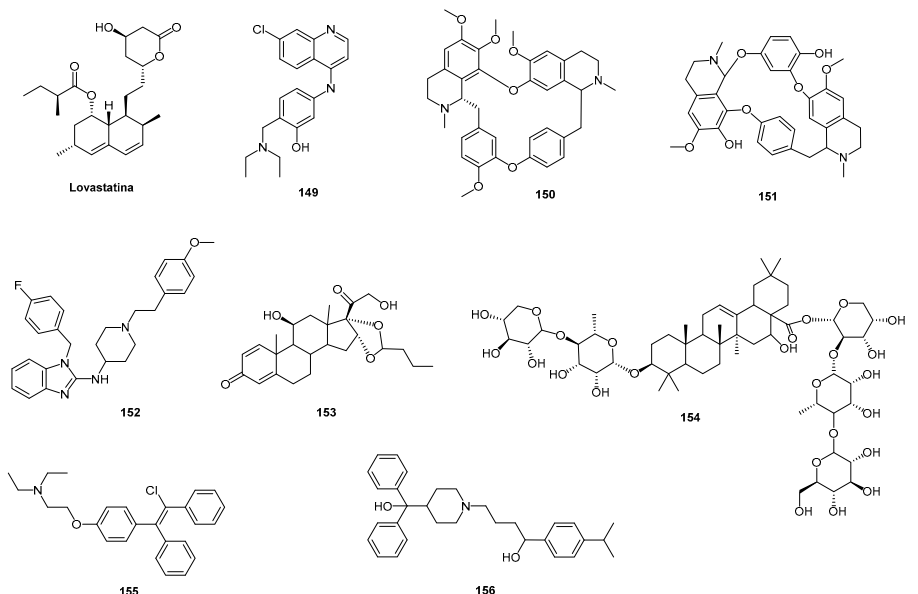

156

Figure 26. Structure of compounds 136-156 studied against both the RML and 22 L scrapie strains [136] and $\mathrm{rPrP}_{90-232}$ [139]. 
Some polyphenols may not be the best candidates to cross the blood brain barrier for their water solubility, but these molecular entities may be useful by preventing TSE disease. However, radiolabeled epigallocatechin gallate (EGCG) has been detected in mouse brains after oral administration [140].

More recently, Fuchigami and co-workers evaluated the potential of radioiodinated flavonoids (flavone 157, chalcone 158 and aurone 159) and styryl chromones against $\mathrm{PrP}^{\mathrm{Sc}}$ (Figure 27) by single photon emission computed tomography (SPECT) imaging of $\operatorname{PrP}^{\mathrm{Sc}}$ [141].

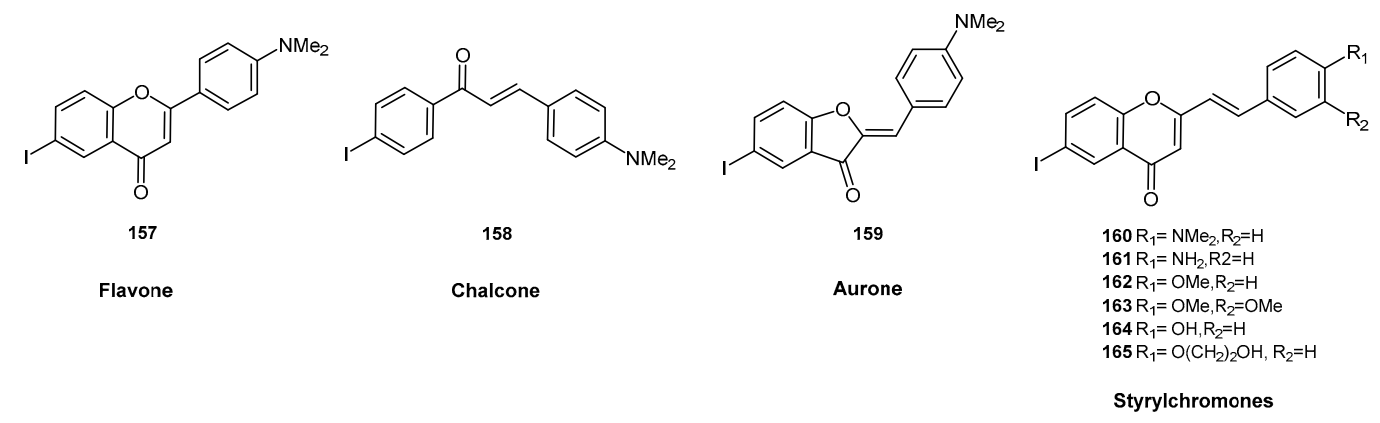

Figure 27. Radioiodinated flavonoids 157-159 and styrylchromones 160-165 tested by SPECT imaging of $\mathrm{PrPSc}$.

In vitro binding assays using recombinant mouse $\operatorname{PrP}(\mathrm{rMoPrP})$ aggregates revealed that $\mathbf{1 6 0}$ had higher in vitro binding affinity $\left(K_{D}=24.5 \mathrm{nM}\right.$ and capacity $B_{\max }=36.3 \mathrm{pmol} / \mathrm{nmol}$ as total density of protein in a sample of tissue) than the three flavonoids $\left(\mathrm{K}_{\mathrm{d}}=201 \mathrm{nM}\right.$ and capacity $\mathrm{B}_{\max }=11.2 \mathrm{pmol} / \mathrm{nmol}$ for $157, \mathrm{~K}_{\mathrm{D}}=246 \mathrm{nM}$ and capacity $\mathrm{B}_{\max }=16.7 \mathrm{pmol} / \mathrm{nmol}$ for 158 , and $K_{D}=125 \mathrm{nM}$ and capacity $B_{\max }=34.9 \mathrm{pmol} / \mathrm{nmol}$ for 159$)$. On the other hand fluorescent imaging using brain sections from mouse-adapted bovine spongiform encephalopathy (mBSE)-infected mice demonstrated that $\mathbf{1 6 0}$ labelled $\mathrm{PrP}^{\mathrm{Sc}}$-positive prion deposits in the mice brain. Fuchigami et al. were pioneers describing in vivo imaging of $\mathrm{PrP}^{\mathrm{Sc}}$ deposits in the mBSE-infected mice brain observing high accumulation of the two methoxy derivatives $\left[{ }^{125} \mathrm{I}\right] 162$ and $\left[{ }^{125} \mathrm{I}\right] 163$ by in vitro fluorescence and autoradiography experiments. These derivatives showed binding for $\mathrm{rMoPrP}$ aggregates with $\mathrm{K}_{\mathrm{i}}=20.8$ and $26.6 \mathrm{nM}$ respectively.

Radiochemical synthesis of compound 162 was carried out by an iododestannylation reaction of corresponding tributyltin derivative 166 to give compound 162 in $35-44 \%$ radiochemical yield and with a radiochemical purity of $98 \%$ as depicted in Scheme 28 .

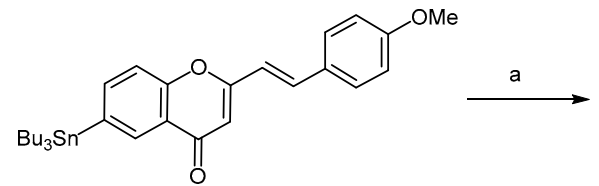

166

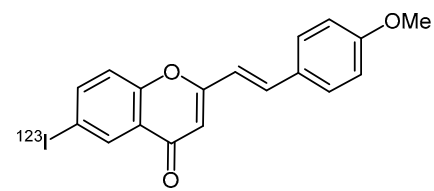

162

Scheme 28. Synthesis of radiolabeled compound 162. Reagents and conditions: $\left[{ }^{123} \mathrm{I}\right] \mathrm{NaI}, \mathrm{H}_{2} \mathrm{O}_{2}, \mathrm{HCl}$, $\mathrm{EtOH}$, r.t., $10 \mathrm{~min}$.

Other natural polyphenols, structurally based on stilbenes or cinnamic acid derivatives, have shown anti-prion activity, as resveratrol and curcumin. Resveratrol [systematic name: (E)-5-(4-hydroxystyryl)benzene-1,3-diol, Figure 28] is produced by grapes, mulberries, and nuts, when attacked by pathogens [142]. Over the past couple of decades, resveratrol has been extensively investigated showing health benefits in neuroprotection, cardioprotection, hepatoprotection, antiinflammation, and cancer prevention [143]. Its neuroprotective properties are not restricted to AD or Parkinson's diseases being also demonstrated its anti-prion efficacy. Jeong et al. [144] 
revealed the neuroprotective effects of resveratrol in prion disease demonstrating the prevention of $\mathrm{PrP}_{106-126}$-induced neuronal cell death by activating autophagy. They tested the influence of resveratrol treatment on $\mathrm{PrP}_{106-126}$-induced apoptosis in neuronal cells (SH-SY5Y cells and SK-N-SH cell lines) by exposing cells to resveratrol with and without $\operatorname{PrP}_{106-126}$. Treatment of neuronal cells with $\operatorname{PrP}_{106-126}$, without resveratrol, resulted in neurotoxicity, however, resveratrol treatment prevented $\mathrm{PrP}_{106}$-126-induced apoptosis in a dose-dependent manner. These results were confirmed by examination of Lactate dehydrogenase assay (LDH) and TUNEL assay [144]. Later on, same authors showed that Sirtuin 1 (Sirt1), a class III histone deacetylase that mediates the protective effects of neurons in neurodegenerative disorders [145], induces autophagy preventing prion peptide neurotoxicity [146].

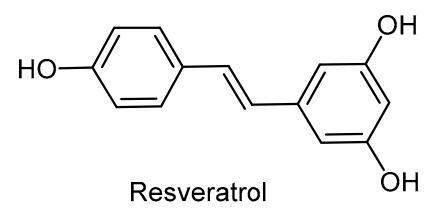

Figure 28. Structure of resveratrol with anti-prion properties.

Wang and co-workers [147] evaluated the treatment of SMB-S15 cells with Sirt1 activators. In the presence of resveratrol, significant reduced levels of $\mathrm{PrP}^{\mathrm{Sc}}$ were dectected.

To address the anti-prion acitivity of resveratrol, Wang et al. [148] tested the inhibitory activity of resveratrol on prion accumulation in vitro and prion inefectivity in vivo using scrapie-infected cell line SMB-S15. They demonstrated that the amounts of PrPSc in SMB-S15 cells decreased in a dose-dependent manner in the presence of resveratrol, with $\mathrm{EC}_{50}=0.61 \mu \mathrm{M}$. The removal of $\mathrm{PrP}^{\mathrm{Sc}}$ in SMB-S15 cells by resveratrol seemed to be irreversible as no $\mathrm{PrP}^{\mathrm{Sc}}$ signals could be detected in the resveratrol-treated cells after withdrawal of the drug. Moreover, infectivity of SMB-S15 cells on the sensitive rodent CD1 mice was eradicated after exposing to resveratrol for 1 week.

Several synthetic approaches have been described for the synthesis of resveratrol, carried out by Wittig [149] or Horner-Wadsworth-Emmons reactions [150], Perkin condensations [151], and also through metal-catalysed processes, such as cross-metathesis [152] or cross-coupling reactions [153,154]. The most recent synthesis of resveratrol has been carried out by El-Deeb et al. [155] and is shown in Scheme 29. They synthesized resveratrol in five steps with a $62 \%$ overall yield. The key step is the oxidation of 5-methylcyclohexane-1,3-dione 167 to 3,5-dimethoxytoluene 168 by hemiacetal formation and subsequent dehydration using ethylene and $\mathrm{Pd} / \mathrm{C}$ in $\mathrm{MeOH}$ at $120{ }^{\circ} \mathrm{C}$ (Scheme 29). Then, bromination with NBS in $\mathrm{CH}_{3} \mathrm{CN}$ was carried out to generate compound 169 in $91 \%$ yield. Compound 169 was converted in the corresponding aldehyde $\mathbf{1 7 0}$ and the phosphonate 171 to follow two different methodologies as depicted in Scheme 29 for the trans double bond formation. They applied the Horner-Wadsworth-Emmons reaction employing on one hand, the reaction of 3,5-dimethoxybenzaldehyde 170 with diethyl 4-methoxybenzylphosphonate and, on the other hand, 4-methoxybenzaldehyde with diethyl 3,5-dimethoxybenzylphosphonate 171. Both routes gave protected resveratrol in high yield (95 and 96\%, respectively) which was later demethylated with the combination of $\mathrm{AlCl}_{3}$ and $\mathrm{i}-\mathrm{Pr}_{2} \mathrm{NH}$ giving resveratrol in $85 \%$ yield (Scheme 29). 


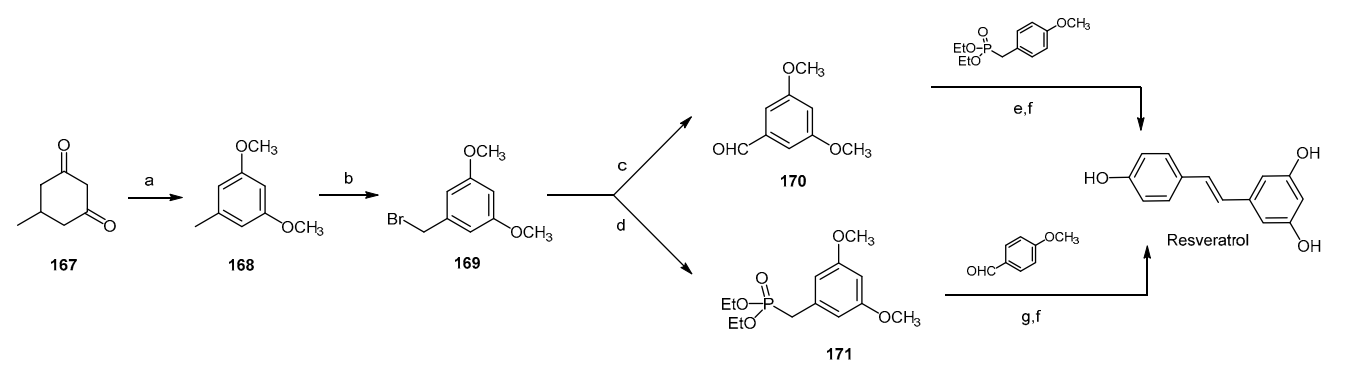

Scheme 29. Synthesis of resveratrol. Reagents and conditions: (a) $\mathrm{MeOH}, \mathrm{Pd} / \mathrm{C}$, ethylene, $130{ }^{\circ} \mathrm{C}, 1 \mathrm{~h}$, $86 \%$, (b) NBS, $\mathrm{CH}_{3} \mathrm{CN}, 25^{\circ} \mathrm{C}, 1 \mathrm{~h}, 91 \%$, (c) hexamethylenetetramine, $\mathrm{H}_{2} \mathrm{O}$, reflux, $12 \mathrm{~h}, 99 \%$, (d) $\mathrm{P}(\mathrm{OEt})_{3}$, $80{ }^{\circ} \mathrm{C}, 12 \mathrm{~h}, 100 \%$, (e,g) NaH, THF, $28{ }^{\circ} \mathrm{C}, 3 \mathrm{~h}, 95 \%$ and $94 \%$ respectively, (f) $\mathrm{AlCl}_{3}, \mathrm{iPr}_{2} \mathrm{NH}$, toluene, $110{ }^{\circ} \mathrm{C}, 4 \mathrm{~h}, 85 \%$.

Curcumin [systematic name: 1,7-bis(4-hydroxy-3-methoxyphenyl)hepta-1,6-diene-3,5-dione], (Figure 18) is the main pigment derived Curcuma longa that has been identified as an inhibitor of prion fibril formation [156,157] with the ability to cross the blood brain barrier [158]. Curcumin, having an unique conjugated structure including two methoxylated phenols and an enol form of diketone shows a typical radical trapping ability as a chain breaking antioxidant (Figure 29). Structurally, curcumin is similar to Congo red, which is toxic and a poor brain penetrant. However, curcumin does not present apparent toxicity resulting in a promising drug as anti-TSE agent.

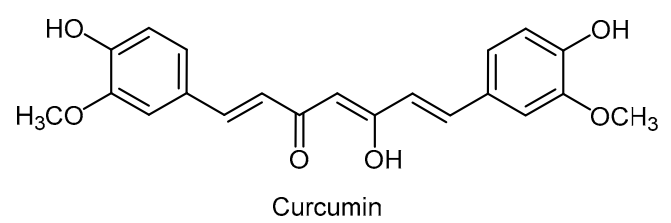

Figure 29. Structure of curcumin with anti-prion properties.

Caughey and co-workers have found that curcumin inhibits the accumulation of $\operatorname{PrP}^{\mathrm{Sc}}$ in scrapie-infected neuroblastoma (scNB) cells [156]. Hafner-Bratkovic et al. showed that this polyphenol binds only to non-native forms of $\operatorname{PrP}$, avoiding prion fibril formation without affecting native $\operatorname{PrP}$ [157]. Lin's lab investigated the anti-amyloidogenic and antioxidant effects of curcumin on the behavior of recombinant murine $\operatorname{PrP}(\mathrm{mPrP})$ in a cell-free environment and in murine neuroblastoma (N2a) cells [159]. They evaluated the effect of curcumin on the amyloid formation of $\mathrm{mPrP}$, based on the kinetics of amyloid formation by fluorescence intensity of thioflavin T. ThT-fluorescence increased significantly, but in the presence of curcumin only a weak increase was detected. Analysis of transmission electron microscopy (TEM) images showed mPrP fibrils growing in the absence of curcumin, while in its presence the length of the fibrils was shorter. To investigate the effect of curcumin in cells, they first confirmed the disruption of cell membranes in erythrocytes from mouse blood. Mouse erythrocytes are typically oval and biconcave but when the erythrocytes were co-incubated with $\mathrm{mPrP}$ fibrils, cells of wrinkled morphology were formed. However treatment of the erythrocytes with curcumin together with or prior to fibril incubation reduced membrane damage.

Viability of N2a cells turned to increase $33 \%$ by treatment with curcumin prior to the co-incubation with amyloid fibrils. An apoptosis assay confirmed that fibril-induced apoptosis was largely weakened when N2a cells were treated with curcumin prior to the fibril treatment. On the other hand, since curcumin is widely applied for its antioxidant properties, it has been investigated its effect on the (ROS) level [159] of N2a cells infected with $\mathrm{mPrP}$ fibrils. They found out that $\mathrm{mPrP}$ fibril-induced ROS could be completely eliminated by treatment with $2.5 \mu \mathrm{M}$ of curcumin prior to co-incubation with $\mathrm{mPrP}$ fibrils, suggesting that curcumin is involved in the ROS-related signal transduction pathways. 
The major processes of practical utility for the preparation of curcumin follow Pabon's route [160]. This method involves the reaction of vanillin (4-hydroxybenzaldehyde), acetylacetone and $\mathrm{B}_{2} \mathrm{O}_{3}$ in the presence of tributhyl borate and buthylamine. The reaction is carried out in ethyl acetate at r.t. affording curcumin in $80 \%$ yield (Scheme 30 ).<smiles>COc1cc(C=O)ccc1O</smiles><smiles>CC(=O)CC(C)=O</smiles><smiles>COc1cc(/C=C/C(=O)/C=C(O)/C=C/c2ccc(O)c(OC)c2)ccc1O</smiles>

Scheme 30. Synthesis of curcumin. Reagents and conditions: (a) $\mathrm{B}_{2} \mathrm{O}_{3},(\mathrm{BuO})_{3} \mathrm{~B}, n-\mathrm{BuNH}_{2}, \mathrm{AcOEt}$, r.t., $80 \%$ yield.

As shown so far, polyphenols are potent therapeutic agents with a broad range of pharmacological effects, however their biological activity is not completely clear. These compounds modulate many biological pathways and alter functions of different proteins including membrane proteins [161-163] pathways. This characteristic of perturbating cell membrane is believed to be the reason for their multiple functions, instead of specific binding to proteins [164] and there is little evidence for direct binding to some of their numerous effector proteins [165].

Amongst the polyphenols mentioned in this section EGCG, resveratrol and curcumin have been described by Ingolfsson et al. [164] to alter bilayer properties and modify membrane protein function. Curcumin displays essentially all known Pan Assay Interference Compounds (PAINS)-type behavior $[164,166]$. It contains catechol units which are recognizable PAINS motifs interfereing in biological events through different mechanisms [167]. Resveratrol, like many phenols, is readily oxidized and can form reactive quinones [168] which are also PAINS motifs.

The promiscuous activity of these entities should lead us to use them cautiously as control compounds and leave open the challenge to continue structure optimization to investigate their specificity of binding to proteins considered key to the control of neurodegeneration.

\section{Concluding Remarks}

Prion and Alzheimer's diseases share being protein misfolding disorders. These diseases are fatal, and the latter accounts for most cases of dementia. It is a much more prevalent amyloid disorder than TSEs and, to this point, no effective disease-modifying therapies have been successfully developed. After continuous drug flops in pivotal clinical trials for AD, a new hope has risen since the recent discovery of $\operatorname{PrP}^{\mathrm{C}}$ as a high-affinity binding partner of amyloid $\beta(\mathrm{A} \beta)$ oligomers, which are the key pathophysiological toxic entities causing neuronal death in AD patients [169]. In fact, post-mortem examinations of brain tissue derived from $\mathrm{AD}$ patients have led to the identification of high molecular mass assemblies of $\mathrm{A} \beta$ oligomers and $\mathrm{PrP}^{\mathrm{C}}$ [170]. Moreover, in contrast with $\mathrm{AD}$ transgenic mice, $\mathrm{PRNP}^{-/-}$mice with $\mathrm{A} \beta$ plaques do not exhibit hippocampal impairment of synaptic plasticity and associated suppression of cognitive function [171]. These data suggest that $A \beta$ oligomer toxicity in $\mathrm{AD}$ may in fact be mediated by $\mathrm{PrP}^{\mathrm{C}}$, and encourage further research focusing on protein-protein interaction inhibitors (PPII) to block the assembly of $\mathrm{A} \beta-\mathrm{PrP}^{\mathrm{C}}$ aggregates in the treatment of $\mathrm{AD}$. By exploring the molecular entities able to intervene with the common mechanisms of prion assembly and prion-promoted neurodegeneration, perhaps in the future new efficacious therapeutic approaches will be achievable and somehow adjustable to all human prions.

Acknowledgments: The European Union is gratefully acknowledged for the support of the project entitled "Diagnostic and Drug Discovery Initiative for Alzheimer's Disease" (D3i4AD), FP7-PEOPLE-2013-IAPP, GA 612347. Fundação para a Ciência e a Tecnologia is also acknowledged for the support of the project UID/Multi/0612/2013 (to CQB), and for the Ph.D. grant SFRH/BD/93170/2013 (to Ana M. Matos).

Conflicts of Interest: The authors declare no conflict of interest. 


\section{References}

1. Aguzzi, A.; Heikenwalder, M.; Polumenidou, M. Insights into prion strains and neurotoxicity. Nat. Rev. Mol. Cell Biol. 2007, 8, 552-561. [CrossRef] [PubMed]

2. Prusiner, S.B. Prions. Proc. Natl. Acad. Sci. USA 1998, 95, 13363-13383. [CrossRef] [PubMed]

3. Kim, H.J.; Choi, H.S.; Park, J.H.; Kim, M.J.; Lee, H.G.; Petersen, R.B.; Kim, Y.S.; Park, J.B.; Choi, E.K. Regulation of RhoA activity by the cellular prion protein. Cell Death Dis. 2017, 8, e2668. [CrossRef] [PubMed]

4. Shi, F.; Yang, Y.; Wang, T.; Kouadir, M.; Zhao, D.; Hu, S. Cellular prion protein promotes neuronal differentiation of adipose-derived stem cells by ppregulating miRNA-124. J. Mol. Neurosci. 2016, 59, 48-55. [CrossRef] [PubMed]

5. Slapšak, U.; Salzano, G.; Amin, L.; Abskharon, R.N.; Ilc, G.; Zupančič, B.; Biljan, I.; Plavec, J.; Giachin, G.; Legname, $\mathrm{G}$. The $\mathrm{N}$ terminus of the prion protein mediates functional interactions with the neuronal cell adhesion molecule (NCAM) fibronectin domain. Biol. Chem. 2016, 291, 21857-21868. [CrossRef] [PubMed]

6. Soto, G.; Satani, N. The intricate mechanisms of neurodegeneration in prion diseases. Trends Mol. Med. 2012, 17, 14-24. [CrossRef] [PubMed]

7. Bradley, R.; Liberski, P.P. Bovine spongiform encephalopathy (BSE): The end of the beginning or the beginning of the end? Folia Neuropathol. 2004, 42, 55-68. [PubMed]

8. Cordeiro, Y.; Ferreira, N.C. New approaches for the selection and evaluation of anti-prion organic compounds. Mini Rev. Med. Chem. 2015, 15, 84-92. [CrossRef] [PubMed]

9. Carroll, J.A.; Striebel, J.F.; Rangel, A.; Woods, T.; Phillips, K.; Peterson, K.E.; Race, B.; Chesebro, B. Prion strain differences in accumulation of $\mathrm{PrP}^{\mathrm{Sc}}$ on neurons and glia are associated with similar expression profiles of neuroinflammatory genes: Comparison of three prion strains. PLoS Pathog. 2016, 12, e1005551. [CrossRef] [PubMed]

10. Morales, R.; Abid, K.; Soto, S. The prion strain phenomenon: Molecular basis and unprecedented features. Biochim. Biophys. Acta 2007, 1772, 681-691. [CrossRef] [PubMed]

11. Kocisko, D.A.; Engel, A.L.; Harbuck, K.; Arnold, K.M.; Olsen, E.A.; Raymond, L.D.; Vilette, D.; Caughey, B. Comparison of protease-resistant prion protein inhibitors in cell cultures infected with two strains of mouse and sheep scrapie. Neurosci. Lett. 2005, 388, 106-111. [CrossRef] [PubMed]

12. Snow, A.D.; Wight, T.N.; Nochlin, Y.; Koike, K.; Kimata, S.J.; De Armond, S.B.; Prusiner, S.B. Immunolocalization of heparin sulfate proteoglycans to the prion protein amyloid plaques of Gerstmann-Straussler syndrome, Creutzfeldt-Jakob disease and scrapie. Lab. Investig. 1990, 63, 601-611. [PubMed]

13. Horonchik, L.; Tzaban, S.; Ben-Zaken, O.; Yedidia, Y.; Rouvinski, A.; Papy-Garcia, D.; Barritault, D.; Vlodavsky, I.; Taraboulos, A. Heparan sulfate is a cellular receptor for purified infectious prions. J. Biol. Chem. 2005, 280, 17062-17067. [CrossRef] [PubMed]

14. Capila, I.; Linhardt, R.J. Heparin-protein interactions. Angew. Chem. Int. Ed. Engl. 2002, 41, $391-412$. [CrossRef]

15. Caughey, B.; Brown, K.; Raymond, G.J.; Katzenstein, G.E.; Thresher, W. Binding of the protease-sensitive form of prion protein PrP to sulfated glycosaminoglycan and congo red [corrected]. J. Virol. 1994, 68, 2135-2141. [PubMed]

16. Warner, R.G.; Hundt, C.; Weiss, S.; Turnbull, J.E. Identification of the heparan sulfate binding sites in the cellular prion protein. J. Biol. Chem. 2002, 277, 18421-18430. [CrossRef] [PubMed]

17. Perez, M.; Wandosell, F.; Colaco, C.; Avila, J. Sulphated glycosaminoglycans prevent the neurotoxicity of a human prion protein fragment. Biochem. J. 1998, 335, 369-374. [CrossRef] [PubMed]

18. Ouidja, M.-O.; Petit, E.; Kerros, M.-E.; Ikeda, Y.; Morin, C.; Carpentier, G.; Barritault, D.; Bruge're-Picoux, J.; Deslys, J.-P.; Adjou, K.; et al. Structure-activity studies of heparan mimetic polyanions for anti-prion therapies. Biochem. Biophys. Res. Commun. 2007, 363, 95-100. [CrossRef] [PubMed]

19. Kirby, L.; Birkett, C.R.; Rudyk, H.; Gilbert, I.H.; Hope, J. In vitro cell-free conversion of bacterial recombinant PrP to PrPres as a model for conversion. J. Gen. Virol 2003, 84, 1013-1020. [CrossRef] [PubMed]

20. Teruya, K.; Wakao, M.; Sato, M.; Hamanaka, T.; Nishizawa, K.; Funayama, Y.; Sakasegawa, Y.; Suda, Y.; Doh-ura, K. Heparinase I-specific disaccharide unit of heparin is a key structure but insufficient for exerting anti-prion activity in prion-infected cells. Biochem. Biophys. Res. Commun. 2015, 460, 989-995. [CrossRef] [PubMed] 
21. Saito, A.; Wakao, M.; Deguchi, H.; Mawatari, A.; Sobel, M.; Suda, Y. Towards the assembly of heparin and heparan sulfate oligosaccharide libraries: efficient synthesis of uronic acid and disaccaride building blocks. Tetrahedron 2010, 66, 3951-3962. [CrossRef] [PubMed]

22. Caughey, B.; Baron, G.S. Prions and their partners in crime. Nature 2006, 443, 803-810. [CrossRef] [PubMed]

23. Caughey, B.; Raymond, G.J. Sulfate polyanion inhibition of scrapie-associated PrP accumulation in cultured cells. J. Virol. 1993, 67, 643-650. [PubMed]

24. Gabizon, R.; Meiner, Z.; Halimi, M.; Ben-Sasson, S.A. Heparin-like molecules bind differentially to prion-proteins and change their intracellular metabolic fate. J. Cell Physiol. 1993, 157, 319-325. [CrossRef] [PubMed]

25. Caughey, B.; Brown, K.; Raymond, G.J.; Katzenstein, G.E.; Thresher, W. Binding of the protease-sensitive form of $\operatorname{PrP}$ (prion protein) to sulfated glycosaminoglycan and congo red. J. Virol. 1994, 68, 4107, (Erratum of [15]).

26. Yamaguchi, S.; Nishida, Y.; Sasaki, K.; Kambara, K.; Kim, C.-L.; Ishiguro, N.; Nagatsuka, T.; Uzawa, T.; Horiuchi, M. Inhibition of PrPSc formation by synthetic $O$-sulfated glycopyranosides and their polymers. Biochem. Biophys. Res. Commun. 2006, 349, 485-491. [CrossRef] [PubMed]

27. Sasaki, K.; Nishida, Y.; Uzawa, H.; Kobayashia, K. N-Acetyl-6-sulfo-D-glucosamine as a Promising Mimic of N-Acetyl Neuraminic Acid. Bioorg. Med. Chem.Lett. 2003, 13, 2821-2823. [CrossRef]

28. Nishizawa, K.; Oguma, A.; Kawata, S.Y.; Teruya, K.; Dohura, K. Efficacy and Mechanism of a Glycoside Compound Inhibiting Abnormal Prion Protein Formation in Prion-Infected Cells: Implications of Interferon and Phosphodiesterase 4D-Interacting Protein. J. Virol. 2014, 88, 4083-4099. [CrossRef] [PubMed]

29. Charvériat, M.; Reboul, M.; Wang, Q.; Picoli, C.; Lenuzza, N.; Montagnac, A.; Nhiri, N.; Jacquet, E.; Guèritte, F.; Lallemand, J.-Y.; et al. New inhibitors of prion replication that target the amyloid precucrsor. J. Gen. Vir. 2009, 90, 1294-1301.

30. Malishev, R.; Nandi, S.; Kolusheva, S.; Shaham-Niv, S.; Gazit, E.; Jelinek, R. Bacoside-A, an anti-amyloid natural substance, inhibits membrane disruption by the amyloidogenic determinant of prion protein through accelerating fibril formation. Biochim. Biophis. Acta 2016, 1858, 2208-2214. [CrossRef] [PubMed]

31. Limpeanchob, S.; Jaipan, S.; Rattanakaruna, W.; Phrompittayarat, K. Ingkaninan. Neuroprotective effect of Bacopa monnieri on beta-amyloid-induced cell death in primary cortical culture. J. Ethnopharmacol. 2008, 120, 112-117.

32. Bammidi, S.R.; Volluri, S.S.; Chippada, S.C.; Avanigadda, S.; Vangalapati, M. A review on pharmacological studies of Bacopa monniera. J. Chem. Biol. Phys. Sci. 2001, 1, 250.

33. Apetz, N.; Munch, G.; Govindaraghavan, S.; Gyengesi, E. Natural Compounds and Plant Extracts as Therapeutics against Chronic Inflammation in Alzheimer's Disease-A Translational Perspective, CNS \& Neurological Disorders-Drug Targets (Formerly Current Drug Targets-CNS \& Neurological Disorders). CNS Neurol. Disord. Drug Targets 2014, 13, 1175-1191. [PubMed]

34. Holcomb, L.A.; Dhanasekaran, M.; Hitt, A.-R.; Young, K.A.; Riggs, M.; Manyam, B.V. Bacopa monniera extract reduces amyloid levels in PSAPP mice. J. Alzheimers Dis. 2006, 9, 243-251. [CrossRef] [PubMed]

35. Miura, M.; Yoda, M.; Takaku, N.; Hirose, T.; Takeuchi, H. Clustered negative charges on the lipid membrane surface induce $\beta$-sheet formation of prion protein fragment 106-126. Biochemistry 2007, 46, 11589-11597. [CrossRef] [PubMed]

36. Tagliavini, F.; Prelli, F.; Verga, L.; Giaccone, G.; Sarma, R.; Gorevic, P.; Ghetti, B.; Passerini, F.; Ghibaudi, E.; Forloni, G. Synthetic peptides homologous to prion protein residues 106-147 form amyloid-like fibrils in vitro. Proc. Natl. Acad. Sci. USA 1993, 90, 9678-9682. [CrossRef] [PubMed]

37. Perrier, V.; Wallace, A.C.; Kaneko, K.; Safar, J.; Prusiner, S.B.; Cohen, F.E. Mimicking dominant negative inhibition of prion replication through structure-based drug design. Proc. Natl. Acad. Sci. USA 2000, 97, 6073-6078. [CrossRef] [PubMed]

38. May, B.C.H.; Zorn, J.A.; Wiktop, J.; Sherrill, J.; Wallace, A.C.; Legname, G.; Prusiner, S.B.; Cohen, F.E. Structure-activity relationship study of prion inhibition by 2-aminopyridine-3,5-dicarbonitrile-based compounds: Parallel synthesis, bioactivity and in vitro pharmacokinetics. J. Med. Chem. 2007, 50, 65-73. [CrossRef] [PubMed]

39. Reddy, T.R.K.; Mutter, R.; Heal, W.; Guo, K.; Gillet, V.J.; Pratt, S.; Chen, B. Library design, synthesis and screening: Pyridine dicarbonitriles as potential prion disease therapeutics. J. Med. Chem. 2006, 49, 607-615. [CrossRef] [PubMed] 
40. Niida, A.; Tanigaki, H.; Inokuchi, E.; Sasaki, Y.; Oishi, S.; Ohno, H.; Tamamura, H.; Wang, Z.; Peiper, S.C.; Kitaura, K.; et al. Stereoselective synthesis of 3,6-disubstituted-3,6-dihydropyridin-2-ones as potential diketopiperazine mimetics using organocopper-mediated anti-S $\mathrm{S}_{\mathrm{N}} 2^{\prime}$ reactions and their use in the preparation of low-molecule CXCR4 antagonists. J. Org. Chem. 2006, 71, 3942-3951. [CrossRef] [PubMed]

41. Bolognesi, M.L.; Ai Tran, H.N.; Staderini, M.; Monaco, A.; López-Cobeñas, A.; Bongarzone, S.; Biarnés, X.; López-Alvarado, P.; Cabezas, N.; Caramelli, M.; et al. Discovery of a class of diketopiperazines as antiprion compounds. ChemMedChem 2010, 5, 1324-1334. [CrossRef] [PubMed]

42. Li, Z.; Rao, S.; Gever, J.R.; Widjaja, K.; Prusiner, S.B.; Silber, B.M. Towards optimization of arylamides as novel, potent, and brain-penetrant antiprion lead compounds. ACS Med. Chem. Lett. 2013, 4, 647-650. [CrossRef] [PubMed]

43. Liedel, F.; Eiden, M.; Geissen, M.; Hirschberger, T.; Tavan, P.; Giese, A.; Kretzschmar, H.A.; Schätzl, H.; Groschup, M.H. Piperazine derivatives inhibit $\mathrm{PrP} / \mathrm{PrP} \mathrm{P}^{\mathrm{res}}$ propagation in vitro and in vivo. Biochem. Biophys. Res. Commun. 2014, 445, 23-29. [CrossRef] [PubMed]

44. Ertmer, A.; Gilch, S.; Yun, S.W.; Flechsig, E.; Klebl, B.; Stein-Gerlach, M.; Klein, M.A.; Schätzl, H.M. The tyrosine kinase inhibitor STI571 induces cellular clearance of $\mathrm{PrP}^{\mathrm{Sc}}$ in prion-infected cells. J. Biol. Chem. 2004, 279, 41918-41927. [CrossRef] [PubMed]

45. Zimmermann, J.; Caravatti, G.; Mett, H.; Meyer, T.; Müller, M.; Lydon, N.B.; Fabbro, D. Phenylamino-pyrimidine (PAP) derivatives: A new class of potent and selective inhibitors of protein kinase C (PKC). Arch. Pharm. (Weinheim) 1996, 329, 371-376. [CrossRef] [PubMed]

46. Loiseleur, O.; Kaufmann, D.; Abel, S.; Buerger, H.M.; Meisenbach, M.; Schmitz, B.; Sedelmeier, G. N-phenyl-2-pyrimidine-amine Derivatives. PCT EP Appl. WO2003066613 A1, 14 August 2003.

47. Kompella, A.; Bhujanga, R.A.K.S.; Venkaiah, C.N.; Srinivas, R. Process for the Preparation of the Anti-Cancer Drug Imatinib and Its Analoges. PCT IN Appl. WO2004108699 A1, 16 December 2004.

48. Liu, Y.F.; Wang, C.L.; Bai, Y.J.; Jiao, J.P.; Qi, X.L. A facile total synthesis of imatinib base and its analoges. Org. Process Res. Dev. 2008, 12, 490-495. [CrossRef]

49. Korth, C.; May, B.C.H.; Cohen, F.E.; Prusiner, S.B. Acridine and phenothiazine derivatives as pharmacotherapeutics for prion disease. Proc. Natl. Acad. Sci. USA 2001, 98, 9836-9841. [CrossRef] [PubMed]

50. Csuk, R.; Barthel, A.; Raschke, C. Convenient access to substituted acridines by a Buchwald-Hartwig amination. Tetrahedron 2004, 60, 5737-5750. [CrossRef]

51. Hassan, J.; Sevigon, M.; Gozzi, C.; Schulz, E.; Lemaire, M. Aryl-Aryl Bond Formation One Century after the Discovery of the Ullmann Reaction. Chem. Rev. 2002, 102, 1359-1469. [CrossRef] [PubMed]

52. Vogtherr, M.; Grimme, S.; Elshorst, B.; Jacobs, D.M.; Fiebig, K.; Griesinger, K.; Zahn, R. Antimalarial Drug Quinacrine Binds to C-Terminal Helix of Cellular Prion Protein. J. Med. Chem. 2003, 46, 3563-3564. [CrossRef] [PubMed]

53. Huang, Y.; Okochi, H.; May, B.C.H.; Legname, G.; Prusiner, S.B. Quinacrine is mainly metabolized to mono-desethyl quinacrine by CYP3A4/5 and its brain accumulation is limited by P-glycoprotein. Drug Metab. Dispos. 2006, 34, 1136-1144. [CrossRef] [PubMed]

54. Ghaemmaghami, S.; Ahn, M.; Lessard, P.; Giles, K.; Legname, G.; DeArmond, G.J.; Prusiner, S.B. Continuous quinacrine treatment results in the formation of drug-resistant prions. PLoS Pathog. 2009, 5, e1000673. [CrossRef] [PubMed]

55. Nguyen, T.; Sakasegawa, Y.; Doh-ura, K.; Go, M.L. Anti-prion activities and drug-like potential of functionalized quinacrine analogs with basic phenyl residues at the 9-amino position. Eur. J. Med. Chem. 2011, 46, 2917-2929. [CrossRef] [PubMed]

56. Nguyen, T.H.T.; Lee, C.-Y.; Teruya, K.; Ong, W.-Y.; Doh-ura, K.; Go, M.-L. Anti-prion activity of functionalized 9-aminoacridines related to quinacrine. Bioorg. Med. Chem. 2008, 16, 6737-6746. [CrossRef] [PubMed]

57. May, B.C.H.; Fafarman, A.T.; Hong, S.B.; Rogers, M.; Deady, L.W.; Stanley, B.; Prusiner, S.B.; Cohen, F.E. Potent inhibition of scrapie prion replication in cultured cells by bis-acridines. Proc. Natl. Acad. Sci. USA 2003, 100, 3416-3421. [CrossRef] [PubMed]

58. Srivastava, S.; Tewari, S.; Chauhan, P.M.S.; Puri, S.K.; Bhaduri, A.P.; Pandey, V.C. Synthesis of bisquinolines and their in vitro ability to produce methemoglobin in canin hemosylate. Bioorg. Med. Chem. Lett. 1999, 9, 653-658. [CrossRef] 
59. Coste, J.; Frerot, E.; Jouin, P. Coupling N-Methylated Amino Acids Using PyBroP and PyCloP Halogenophosphonium Salts: Mechanism and Fields of Application. J. Org. Chem. 1994, 59, 2437-2446. [CrossRef]

60. Bongarzone, S.; Tran, H.N.A.; Cavalli, A.; Roberti, M.; Carloni, P.; Giuseppe Legname, G.; Bolognesi, M.L. Parallel synthesis, evaluation, and preliminary structure-activity relationship of 2,5-diamino-1,4-benzoquinones as a novel class of bivalent anti-prion compound. J. Med. Chem. 2010, 53, 8197-8201. [CrossRef] [PubMed]

61. Galdeano, C.; Viayna, E.; Sola, I.; Formosa, X.; Camps, P.; Badia, A.; Clos, M.V.; Relat, J.; Ratia, M.; Bartolini, M.; et al. Huprine-tacrine heterodimers as anti-amyloidogenic compounds of potential interest against Alzheimer's and prion diseases. J. Med. Chem. 2012, 55, 661-669. [CrossRef] [PubMed]

62. Gregor, V.E.; Emmerling, M.R.; Lee, C.; Moore, C.J. The synthesis and in vitro acetylcholinesterase and butyrylcholinesterase inhibitory activity of tacrine $\left(\right.$ Cognex $\left.{ }^{\circledR}\right)$ derivatives. Bioorg. Med. Chem. Lett. 1992, 2, 861-864. [CrossRef]

63. Pang, Y.-P.; Quiram, P.; Jelacic, T.; Hong, F.; Brimijoin, S. Highly potent, selective, and low cost bis-tetrahydroaminacrine inhibitors of acetylcholinesterase. J. Biol. Chem. 1996, 271, 23646-23649. [PubMed]

64. Camps, P.; Contreras, J.; Font-Bardia, M.; Morral, J.; Muñoz-Torrero, D.; Solans, X. Enantioselective synthesis of tacrine-huperzine A hybrids. Preparative chiral MPLC separation of their racemic mixtures and absolute configuration assignments by X-ray diffraction analysis. Tetrahedron Asymmetry 1998, 9, 835-849. [CrossRef]

65. Collins, S.J.; Lewis, V.; Brazier, M.; Hill, A.F.; Fletcher, A.;Masters, C.L. Quinacrine does not prolong survival in a murine Creutzfeldt-Jakob disease model. Ann. Neurol. 2002, 52, 503-508.

66. Cope, H.; Mutter, R.; Heal, W.; Pascoe, C.; Brown, P.; Pratt, S.; Chen, B. Synthesis and SAR study of acridine, 2-methylquinoline and 2-phenylquinazoline analogs as anti-prion agents. Eur. J. Med. Chem. 2006, 41, 1124-1143. [CrossRef] [PubMed]

67. Macedo, B.; Kaschula, C.H.; Hunter, R.; van der Merwe, J.D.; Silva, J.L.; Egan, T.J.; Cordeiro, Y. Synthesis and anti-prion activity evaluation of aminoquinoline analogues. Eur. J. Med. Chem. 2010, 45, 5468. [CrossRef] [PubMed]

68. Egan, T.J.; Hunter, R.; Kaschula, C.H.; Marqes, H.M.; Misplon, A.; Walden, J. Structure-function relationships in aminoquinolines: Effect of amino and chloro groups on quinoline-hematin complex formation, inhibition of beta-hematin formation, and antiplasmodial activity. J. Med. Chem. 2000, 43, 283. [CrossRef] [PubMed]

69. Kocisko, D.A.; Caughey, B. Mefloquine, an antimalarial drug with antiprion activity in vitro lacks activity in vivo. J. Virol. 2006, 80, 1044-1046. [CrossRef] [PubMed]

70. Leidel, F.; Eiden, M.; Geissen, M.; Kretzschmar, H.A.; Giese, A.; Hirschberger, T.; Tavan, P.; Schätzl, H.M.; Groschup, M.H. Diphenylpyrazole-derived compounds increase survival time of mice after prion infection. Antimicrob. Agents Chemother. 2011, 55, 4774-4781. [CrossRef] [PubMed]

71. Wagner, J.; Ryazanov, S.; Leonov, A.; Levin, J.; Shi, S.; Schmidt, F.; Prix, C.; Pan-Montojo, F.; Bertsch, U.; Mitteregger-Kretzschmar, G.; et al. Anle138b: A novel oligomer modulator for disease-modifying therapy of neurodegenerative diseases such as prion and Parkinson's disease. Acta Neuropathol. 2013, 125, 795-813. [CrossRef] [PubMed]

72. Guerrero-Muñoz, M.J.; Castillo-Carranza, D.L.; Kayed, R. Therapeutic approaches against common structural features of toxic oligomers shared by multiple amyloidogenic proteins. Biochem. Pharmacol. 2014, 88, 468-478. [CrossRef] [PubMed]

73. Levin, J.; Schmidt, F.; Boehm, C.; Prix, C.; Bötzel, K.; Ryazanov, S.; Leonov, A.; Griesinger, C.; Giese, A. The oligomer modulator anle138b inhibits disease progression in a Parkinson mouse model even with treatment started after disease onset. Acta Neuropathol. 2014, 127, 779-780. [CrossRef] [PubMed]

74. Wagner, J.; Krauss, S.; Shi, S.; Ryazanov, S.; Steffen, J.; Miklitz, C.; Leonov, A.; Kleinknecht, A.; Göricke, B.; Weishaupt, J.H.; et al. Reducing tau aggregates with anle138b delays disease progression in a mouse model of tauopathies. Acta Neuropathol. 2015, 130, 619-631. [CrossRef] [PubMed]

75. Villa, V.; Thellung, S.; Corsaro, A.; Novelli, F.; Tasso, B.; Colucci-D’Amato, L.; Gatta, E.; Tonelli, M.; Florio, T. Celecoxib inhibits prion protein 90-231-mediatedpro-inflammatory responses in microglial cells. Mol. Neurobiol. 2016, 53, 57-72. [CrossRef] [PubMed] 
76. Penning, T.D.; Talley, J.J.; Bertenshaw, S.R.; Carter, J.S.; Collins, P.W.; Docter, S.; Graneto, M.J.; Lee, L.F.; Malecha, J.W.; Miyashiro, J.M.; et al. Synthesis and biological evaluation of the 1,5-diarylpyrazole class of cyclooxygenase-2 inhibitors: Identification of 4-[-5-(4-methylphenyl)-3-(trifluoromethyl)-1H-pyrazol-1-yl]benzenesulfonamide (SC-58635, celecoxib). J. Med. Chem. 1997, 40, 1347-1365. [CrossRef] [PubMed]

77. Hoshino, K.; Ishida, H.; Omovskaya, O.; Dudley, M.; Rleger, R.; Watkins, W.J.; Zhang, J.Z.; Renau, T.E.; Lee, V.J.; Ota, T.; et al. Drug Discharging Pump Inhibitor. Japan Patent JP 2002322054 A, 8 November 2002.

78. Shimada, Y. Thiazolideneacetanilide Photographic Color Couplers. Japan Patent JP 02113070 A, 25 April 1990.

79. Heal, W.; Thompson, M.J.; Mutter, R.; Cope, H.; Louth, J.C.; Chen, B. Library Synthesis and Screening: 2,4-Diphenylthiazoles and 2,4-Diphenyloxazoles as Potential Novel Prion Disease Therapeutics. J. Med. Chem. 2007, 50, 1347-1353. [CrossRef] [PubMed]

80. Thompson, M.J.; Heal, W.; Chen, B. Synthesis of 5-aminothiazoles as building blocks for library synthesis. Tetrahedron Lett. 2006, 47, 2361-2364. [CrossRef]

81. Ghaemmaghami, S.; May, B.C.H.; Renslo, A.R.; Prusiner, S.B. Discovery of 2-aminothiazoles as potent antiprion compounds. J. Virol. 2010, 84, 3408-3412. [CrossRef] [PubMed]

82. Gallardo-Godoy, A.; Gever, J.; Fife, K.L.; Silber, B.M.; Prusiner, S.B.; Renslo, A.R. 2-Aminothiazoles as Therapeutic Leads for Prion Diseases. J. Med. Chem. 2011, 54, 1010-1021. [CrossRef] [PubMed]

83. Ghaemmaghami, S.; Russo, M.; Renslo, A.R. Successes and Challenges in Phenotype-Based Lead Discovery for Prion Diseases. J. Med. Chem. 2014, 57, 6919-6929. [CrossRef] [PubMed]

84. Teruya, K.; Kawagoe, K.; Kimura, T.; Chen, C.J.; Sakasegawa, Y.; Doh-ura, K. Amyloidophilic compounds for prion diseases. Infect. Disord. Drug Targets 2009, 9, 15-22. [CrossRef] [PubMed]

85. Berry, D.B.; Lu, D.; Geva, M.; Watts, J.C.; Bhardwaj, S.; Oehler, A.; Renslo, A.R.; DeArmond, S.J.; Prusiner, S.B.; Giles, K. Drug resistance confounding prion therapeutics. Proc. Natl. Acad. Sci. USA 2013, 110, E4160-E4169. [CrossRef] [PubMed]

86. Baral, P.K.; Swayampakula, M.; Rout, M.K.; Kav, N.N.; Spyracopoulos, L.; Aguzzi, A.; James, M.N. Structural basis of prion inhibition by phenothiazine compounds. Structure 2014, 22, 291-303. [CrossRef] [PubMed]

87. Block, M.L.; Zecca, L.; Hong, J.S. Microglia-mediated neurotoxicity: Uncovering the molecular mechanisms. Nat. Rev. Neurosci. 2007, 8, 57-69. [CrossRef] [PubMed]

88. Minagar, A.; Shapshak, P.; Fujimura, R.; Ownby, R.; Heyes, M.; Eisdorfer, C. Therole of macrophage/microglia and astrocytes in the pathogenesis of threeneurologic disorders: HIV-associated dementia, Alzheimer disease, andmultiple sclerosis. J. Neurol. Sci. 2002, 202, 13-23. [CrossRef]

89. Tribouillard-Tanvier, D.; Race, B.; Striebel, J.F.; Carroll, J.A.; Phillips, K.; Chesebro, B. Early cytokine elevation, PrPres deposition and gliosis in mousescrapie: No effect on disease by deletion of cytokine genes, IL-12p40 andIL-12p35. J. Virol. 2012, 86, 10377-10383. [CrossRef] [PubMed]

90. Liang, X.; Wang, Q.; Hand, T.; Wu, L.; Breyer, R.M.; Montine, T.J.; Andreasson, K. Deletion of the prostaglandin E2 EP2 receptor reduces oxidative damage andamyloid burden in a model of Alzheimer's disease. J. Neurosci. 2005, 25, 10180-10187. [CrossRef] [PubMed]

91. Montine, T.J.; Sidell, K.R.; Crews, B.C.; Markesbery, W.R.; Marnett, L.J.; Roberts, L.J., 2nd; Morrow, J.D. Elevated CSF prostaglandin E2 levels in patients withprobable AD. Neurology 1999, 53, 1495-1498. [CrossRef] [PubMed]

92. Eikelenboom, P.; Bate, C.; Van Gool, W.A.; Hoozemans, J.J.; Rozemuller, J.M.; Veerhuis, R.; Williams, A. Neuroinflammation in Alzheimer's disease and prion disease. Glia 2002, 40, 232-239. [CrossRef] [PubMed]

93. Bate, C.; Kempster, S.; Williams, A. Prostaglandin D2 mediates neuronaldamage by amyloid-beta or prions which activates microglial cells. Neuropharmacology 2006, 50, 229-237. [CrossRef] [PubMed]

94. Villaa, V.; Thellung, S.; Bajetto, A.; Gatta, E.; Robello, M.; Novelli, F.; Tasso, B.; Tonelli, M.; Florio, T. Novel celecoxib analogues inhibit glial production of prostaglandinE2, nitric oxide, and oxygen radicals reverting the neuroinflammatoryresponses induced by misfolded prion protein fragment 90-231 or lipopolysaccharide. Pharmacol. Res. 2016, 113, 500-514. [CrossRef] [PubMed]

95. Vazzana, I.; Terranova, E.; Mattioli, F.; Sparatore, F. Aromatic Schiff bases and 2,3-disubstituted-1,3thiazolidin-4-one derivatives as anti-inflammatory agents. Arkivoc 2004, V, 364-374. 
96. Herrmann, U.S.; Schütz, A.K.; Shirani, H.; Huang, D.; Saban, D.; Nuvolone, M.; Li, B.; Ballmer, B.; Åslund, A.K.O.; Mason, J.J.; et al. Structure-based drug design identifies polythiophenes as anti-prion compounds. Sci. Transl. Med. 2015, 7, 299ra123. [CrossRef] [PubMed]

97. Simon, R.A.; Shirani, H.; Andreas Åslund, K.O.; Marcus Back, M.; Haroutunian, V.; Gandy, S.; Nilsson, K.P.R. Pentameric Thiophene-Based Ligands that Spectrally Discriminate Amyloid-b and Tau Aggregates Display Distinct Solvatochromism and Viscosity-Induced Spectral Shifts. Chem. Eur. J. 2014, 20, 12537-12543. [CrossRef] [PubMed]

98. Kimura, T.; Hosokawa-Muto, J.; Asami, K.; Murai, T.; Kuwata, K. Synthesis of 9-substituted 2,3,4,9-tetrahydro- $1 H$-carbazole derivatives and evaluation of their anti-prion activity in TSE-infected cells. Eur. J. Med. Chem. 2011, 46, 5675-5679. [CrossRef] [PubMed]

99. Kuwata, K.; Nishida, N.; Matsumoto, T.; Kamatari, Y.O.; Hosokawa-Muto, J.; Kodama, K.; Nakamura, H.K.; Kimura, K.; Kawasaki, M.; Takakura, Y.; et al. Hot spots in prion protein for pathogenic conversion. Proc. Natl. Acad. Sci. USA 2007, 104, 11921-11926. [CrossRef] [PubMed]

100. Kimura, T.; Hosokawa-Muto, J.; Kamatari, Y.O.; Kuwata, K. Synthesis of GN8 derivatives and evaluation of their antiprion activity in TSE-infected cells. Bioorg. Med. Chem. Lett. 2011, 21, 1502-1507. [CrossRef] [PubMed]

101. Prusiner, S.B.; McKinley, M.P.; Bowman, K.A.; Bendheim, P.E.; Groth, D.F.; Glenner, C.G. Scrapie prions aggregate to form amyloid-like birefringent rods. Cell 1983, 35, 349-358. [CrossRef]

102. Caspi, S.; Halimi, M.; Yanai, A.; Sasson, S.B.; Taraboulos, A.; Gabizon, R. The anti-prion activity of congo red. Putative mechanism. J. Biol. Chem. 1998, 273, 3484-3489. [CrossRef] [PubMed]

103. Klunk, W.E.; Debnath, M.L.; Pettergrew, J.W. Development of small-molecule probes for the beta-amyloid protein of Alzheimer's disease. Neurobiol. Aging 1994, 15, 691-698. [CrossRef]

104. Klunk, W.E.; Debnath, M.L.; Koros, A.M.C.; Pettergrew, J.W. Chrysamine-G, a lipophilic analog of Congo red, inhibits A beta-induced toxicity in PC12 cells. Life Sci. 1998, 63, 1807-1814. [CrossRef]

105. Talaska, G. Aromatic amines and human urinary bladder cancer: Exposure sources and epidemiology. J. Environ. Sci. Health 2003, 21, 29-43. [CrossRef] [PubMed]

106. Rudyk, H.; Vasiljevic, S.; Hennion, R.M.; Birkett, C.R.; Hope, J.; Gilbert, I.H. Screening Congo Red and its analogs for their ability to prevent the formation of $\mathrm{PrP}^{\mathrm{res}}$ in scrapie-infected cells. J. Gen. Virol. 2000, 81, 1155-1164. [CrossRef] [PubMed]

107. Sellarajah, S.; Lekishvili, T.; Bowring, C.; Thompsett, A.R.; Rudyk, H.; Birekett, C.R.; Brown, D.R.; Gilbert, I.H. Synthesis of analogs of congo red and evaluation of their anti-prion activity. J. Med. Chem. 2004, 47, 5515-5534. [CrossRef] [PubMed]

108. Rudyk, H.; Knaggs, M.H.; Vasiljevic, S.; Hope, J.; Birkett, C.; Gilbert, I.H. Synthesis and evaluation of analogs of Congo red as potential compounds against transmissible spongiform encephalopathies. Eur. J. Med. Chem. 2003, 38, 567-579. [CrossRef]

109. Webb, S.; Lekishvili, T.; Loeschner, C.; Sellarajah, S.; Prelli, F.; Wisniewski, T.; Gilbert, I.H.; Brown, D.R. Mechanistic insights into the cure of prion disease by novel antiprion compounds. J. Virol. 2007, 81, 10729-10741. [CrossRef] [PubMed]

110. Dressel, J.; Oesper, R. The discovery of germanin by Oskar dressel and richard kothe. J. Chem. Educ. 1961, 38, 620-621. [CrossRef]

111. Nunziante, M.; Kehler, C.; Maas, E.; Kassack, M.U.; Groschup, M.; Schatzl, H.M. Charged bipolar suramin derivatives induce aggregation of the prion protein at the cell surface and inhibit $\mathrm{PrPS}^{\mathrm{Sc}}$ replication. J. Cell Sci. 2005, 118, 4959-4973. [CrossRef] [PubMed]

112. Kiachopoulos, S.; Heske, J.; Tatzelt, J.; Winklhofer, K.F. Misfolding of the prion protein at the plasma membrane induces endocytosis, intracellular retention and degradation. Traffic 2004, 5, 426-436. [CrossRef] [PubMed]

113. Gilch, S.; Winklhofer, K.F.; Groschup, M.H.; Nunziante, M.; Lucassen, R.; Spielhaupter, C.; Muranyi, W.; Riesner, D.; Tatzelt, J.; Schatzl, H.M. Intracellular re-routing of prion protein prevents propagation of $\mathrm{PrPSc}^{\mathrm{Sc}}$ and delays onset of prion disease. EMBO J. 2001, 20, 3957-3966. [CrossRef] [PubMed]

114. Ullmann, H.; Meis, S.; Hongwiset, D.; Marzian, C.; Wiese, M.; Nickel, P.; Communi, D.; Boeynaems, J.-M.; Wolf, C.; Hausmann, R.; et al. Synthesis and Structure-Activity Relationships of Suramin-Derived P2Y11 Receptor Antagonists with Nanomolar Potency. J. Med. Chem. 2005, 48, 7040-7048. [CrossRef] [PubMed] 
115. Rice-Evans, C.A.; Miller, N.J.; Paganga, G. Structure antioxidant activity relationships of flavonoids and phenoliacids. Free Radic. Biol. Med. 1996, 20, 933-956. [CrossRef]

116. Pandey, K.B.; Rizvi, S.I. Plant polyphenols as dietary antioxidants in human health and disease. Oxid. Med. Cell Longev. 2009, 2, 270-278. [CrossRef] [PubMed]

117. Kim, H.-S.; Quon, M.J.; Kim, J. New insights into the mechanisms of polyphenols beyond antioxidant properties; lessons from the green tea polyphenol, epigallocatechin 3-gallate. Redox Biol. 2014, 2, 187-195. [CrossRef] [PubMed]

118. Perron, N.R.; Brumaghim, J.L. A review of the antioxidant mechanisms of polyphenol compounds related to iron binding. Cell Biochem. Biophys. 2009, 53, 75-100. [CrossRef] [PubMed]

119. Pignatelli, P.; Ghiselli, A.; Buchetti, B. Polyphenols synergisticall inhibit oxidative stress in subjects given red and white wine. Atherosclerosis 2006, 188, 77-83. [CrossRef] [PubMed]

120. González, R.; Ballester, I.; López-Posadas, R.; Suárez, M.D.; Zarzuelo, A.; Martínez-Augustin, O.; Sánchez de Medina, F. Effects of flavonoids and other polyphenols on inflammation. Crit. Rev. Food Sci. Nutr. 2011, 51, 331-362. [CrossRef] [PubMed]

121. Sergent, T.; Piront, N.; Meurice, J.; Toussaint, O.; Schneider, Y.-J. Anti-inflammatory effects of dietary phenolic compounds in an in vitro model of inflamed human intestinal epithelium. Chem.-Biol. Int. 2010, 188, 659-667. [CrossRef] [PubMed]

122. Ono, K.; Yoshiike, Y.; Takashima, A.; Hasegawa, K.; Naiki, H.; Yamada, M. Potent anti-amyloidogenic and fibril-destabilizing effects of polyphenols in vitro: Implications for the prevention and therapeutics of Alzheimer's disease. J. Neurochem. 2003, 87, 172-181. [CrossRef] [PubMed]

123. Porzoor, A.; Alford, B.; Hügel, H.M.; Grando, D.; Caine, J.; Macreadie, I. Anti-Amyloidogenic Properties of Some Phenolic Compounds. Biomolecules 2015, 5, 505-527. [CrossRef] [PubMed]

124. Viviane, L.; Ngoungoure, N.; Schluesener, J.; Moundipa, P.F.; Schluesener, H. Natural polyphenols binding to amyloid: A broad class of compounds to treat different human amyloid diseases. Mol. Nutr. Food Res. 2015, 59, 8-20.

125. Wright, B.; Moraes, L.A.; Kemp, C.F. A structural basis for the inhibition of collagen-stimulated platelet function by quercetin and structurally related flavonoids. Br. J. Pharmacol. 2010, 159, 1312-1325. [CrossRef] [PubMed]

126. Jacobson, K.A.; Moro, S.; Manthey, J.A.; West, P.L.; Ji, X.-D. Interactions of flavones and other phytochemicals with adenosine receptors. Adv. Exp. Med. Biol. 2002, 505, 163-171. [PubMed]

127. Pawlikowska-Pawlega, B.; Gruszecki, W.I.; Misiak, L. Modification of membranes by quercetin, a naturally occurring flavonoid, via its incorporation in the polar head group. Biochim. Biophys. Acta Biomembr. 2007, 1768, 2195-2204. [CrossRef] [PubMed]

128. Pérez-Hernández, J.; Zaldívar-Machorro, V.J.; Villanueva-Porras, D.; Vega-Ávila, E.; Chavarría, A. Hindawi Publishing Corporation. Oxid. Med. Cell. Long 2016, 8378613. [CrossRef]

129. Rauter, A.P.; Branco, I.; Lopes, R.G.; Justin, J.; Silva, F.V.M.; Noronha, J.P. A new lupene triterpenetriol and anticholinesterase activity of Salvia sclareoides. Fitoterapia 2007, 78, 474-481. [CrossRef] [PubMed]

130. Martins, A.; Araújo, M.E.; Branco, I.; Meireles, M.; Almeida, J.; Sepulveda, C.; Neng, N.; Nogueira, J.; Jacob, P.; Goulart, M.; et al. Evaluation of plant extracts against prion diseases and cancer. In Proceedings of the 42nd IUPAC Congress-Chemistry Solutions, Session for Chemistry for Health—Chemistry in the Food Chain and Health, Glasgow, UK, 2-7 August 2009.

131. Rauter, A.P.; Dias, C.; Martins, A.; Branco, I.; Neng, N.R.; Nogueira, J.M.; Goulart, M.; Filipa, V.M.; Silva, F.V.M.; Justino, J.; et al. Non-toxic Salvia sclareoides Brot. extracts as a source of functional food ingredients: Phenolic profile, antioxidant activity and prion binding properties. Food Chem. 2012, 132, 1930-1935.

132. Airoldi, C.; Sironi, E.; Dias, C.; Marcelo, F.; Martins, A.; Rauter, A.P.; Nicotra, F.; Jimenez-Barbero, J. Natural compounds against Alzheimer's disease: Molecular recognition of A $\beta 1-42$ peptide by Salvia sclareoides extract and its major component, rosmarinic acid, as investigated by NMR. Chem. Asian J. 2013, 8, 596. [CrossRef] [PubMed]

133. Marcelo, F.; Dias, C.; Martins, A.; Madeira, P.J.; Jorge, T.M.; Helena Florencio, M.H.; Cañada, F.J.; Cabrita, E.J.; Jiménez-Barbero, J.; Rauter, A.P. Molecular Recognition of Rosmarinic Acid from Salvia sclareoides Extracts by Acetylcholinesterase: A New Binding Site Detected by NMR Spectroscopy. Chem. Eur. J. 2013, 19, 6641-6649. [CrossRef] [PubMed] 
134. Inestrosa, N.C.; Sagal, J.P.; Colombres, M. Acetylcholinesterase interaction with Alzheimer amyloid beta. Subcell. Biochem. 2005, 38, 299-317. [PubMed]

135. Gasperini, L.; Legname, G. Prion Protein and Aging. Front Cell Dev Biol. 2014, 2, 99-102. [CrossRef] [PubMed]

136. Kocisko, D.A.; Baron, G.S.; Rubenstein, R.; Chen, J.; Kuizon, S.; Caughey, B. New Inhibitors of Scrapie-Associated Prion Protein Formation in a Library of 2,000 Drugs and Natural Products. J. Virol. 2003, 77, 10288-10294. [CrossRef] [PubMed]

137. Doh-Ura, K.; Iwaki, T.; Caughey, B. Lysosomotropic agents and cysteine protease inhibitors inhibit scrapie-associated prion protein accumulation. J. Virol. 2000, 74, 4894-4897. [CrossRef] [PubMed]

138. Taraboulos, A.; Scott, M.; Semenov, M.; Avrahami, D.; Laszlo, L.; Prusiner, S.B.; Avrahami, D. Cholesterol depletion and modification of $\mathrm{COOH}$-terminal targeting sequence of the prion protein inhibit formation of the scrapie isoform. J. Cell Biol. 1995, 129, 121-132. [CrossRef] [PubMed]

139. Rambold, A.S.; Miesbauer, M.; Olschewski, D.; Seidel, R.; Riemer, C.; Smale, L.; Brumm, L.; Levy, M.; Gazit, E.; Oesterhelt, D.; et al. Green tea extracts interfere with the stress-protective activity of $\operatorname{PrP}^{\mathrm{C}}$ and the formation of PrPSc. J. Neurochem. 2008, 107, 218-229. [CrossRef] [PubMed]

140. Suganuma, M.; Okabe, S.; Oniyama, M.; Tada, Y.; Ito, H.; Fujiki, H. Wide distribution of $[3 \mathrm{H}](-)$-epigallocatechin gallate, a cancer preventive tea polyphenol, in mouse tissue. Carcinogenesis 1998, 19, 1771-1776. [CrossRef] [PubMed]

141. Fuchigami, T.; Yamashita, Y.; Kawasaki, M.; Ogawa, A.; Haratake, M.; Atarashi, R.; Sano, K.; Nakagaki, T.; Ubagai, K.; Ono, M.; et al. Characterisation of radioiodinated flavonoid derivatives for SPECT imaging of cerebral prion deposits. Sci. Rep. 2015, 5, 18440. [CrossRef] [PubMed]

142. Walle, T. Bioavailability of resveratrol. Ann. N. Y. Acad. Sci. 2011, 1215, 9-15. [CrossRef] [PubMed]

143. Bhat, K.P.L.; Kosmeder, J.W.; Pezzuto, J.M. Biological effects of resveratrol. Antioxid. Redox Signal. 2001, 3, 1041-1064. [CrossRef] [PubMed]

144. Jeong, J.-K.; Moon, M.-H.; Bae, B.-C.; Lee, Y.-J.; Seol, J.-W.; Kang, H.-S.; Kim, J.-S.; Kang, S.-J.; Park, S.-Y. Autophagy induced by resveratrol prevents human prion protein-mediated neurotoxicity. Neurosci. Res. 2012, 73, 99-105. [CrossRef] [PubMed]

145. Seo, J.S.; Moon, M.-H.; Jeong, J.K.; Seol, J.W.; Lee, Y.J.; Park, B.H.; Park, S.Y. SIRT1, a histone deacetylase, regulates prion proteininduced neuronal cell death. Neurobiol. Aging 2012, 33, 1110-1120. [CrossRef] [PubMed]

146. Jeong, J.K.; Moon, M.H.; Lee, Y.J.; Seol, J.W.; Park, S.Y. Autophagy induced by the class III histone deacetylase Sirt1 prevents prion peptide neurotoxicity. Neurobiol. Aging 2013, 34, 146-156. [CrossRef] [PubMed]

147. Wang, J.; Zhang, J.; Shi, Q.; Zhang, B.Y.; Chen, C.; Chen, L.N.; Sun, J.; Wang, H. Scrapie infection in experimental rodents and SMBS15 cells decreased the brain endogenous levels and activities of Sirt1. J. Mol. Neurosci. 2015, 55, 1022-1030. [CrossRef] [PubMed]

148. Wang, J.; Zhang, B.-Y.; Zhang, J.; Xiao, K.; Chen, L.-N.; Wang, H.; Sun, J.; Shi1, Q.; Dong, X.-P. Treatment of SMB-S15 Cells with Resveratrol Efficiently Removes the $\mathrm{PrP}^{\mathrm{Sc}}$ Accumulation In Vitro and Prion Infectivity In Vivo. Mol. Neurobiol. 2016, 53, 5367-5376. [CrossRef] [PubMed]

149. Ismail, T.; Shafi, S.; Srinivas, J.; Sarkar, D.; Qurishi, Y.; Khazir, J.; Alam, M.S.; Kumar, H.M.S. Synthesis and tyrosinase inhibition activity of trans-stilbene derivatives. Bioorg. Chem. 2016, 64, 97-102. [CrossRef] [PubMed]

150. Birar, V.C.; Sheerin, A.N.; Milkovicova, J.; Faragher, R.G.A.; Ostler, E.L. A facile, stereoselective, one-pot synthesis of resveratrol derivatives. Chem. Cent. J. 2015, 9, 26-31. [CrossRef] [PubMed]

151. Sinha, A.K.; Kumar, V.; Sharma, A.; Sharma, A.; Kumar, R. An unusual, mild and convenient one-pot two-step access to $(E)$-stilbenes from hydroxy-substituted benzaldehydes and phenylacetic acids under microwave activation: A new facet of the classical Perkin reaction. Tetrahedron 2007, 63, 11070-11077. [CrossRef]

152. Ferré-Filmon, K.; Delaude, L.; Demonceau, A.; Noels, A.F. Stereoselective Synthesis O (E)-Hydroxystilbenoids by Ruthenium-Catalyzed Cross-Metathesis. Eur. J. Org. Chem. 2005, 3319-3325. [CrossRef]

153. Schmidt, B.; Elizarov, N.; Berger, R.; Hölter, F. Scope and limitations of the Heck-Matsuda-coupling of phenol diazonium salts and styrenes: A protecting group economic synthesis of phenolic stilbenes. Org. Biomol. Chem. 2013, 11, 3674-3691. [CrossRef] [PubMed]

154. Martínez, A.V.; García, J.I.; Mayoral, J.A. An expedient synthesis of resveratrol through a highly recoverable. Tetrahedron 2016, 1-4. (in press). 
155. El-Deeb, I.Y.; Tatsuya Funakoshi, T.; Shimomoto, Y.; Matsubara, R.; Hayashi, M. Dehydrogenative Formation of Resorcinol Derivatives Using Pd/C-Ethylene Catalytic System. J. Org. Chem. 2017, 82, 2630-2640. [CrossRef] [PubMed]

156. Caughey, B.; Raymond, L.D.; Raymond, G.J.; Maxson, L.; Silveir, J.; Baron, G.S. Inhibition of protease-resistant prion protein accumulation in vitro by curcumin. J. Virol. 2003, 77, 5499-5502. [CrossRef] [PubMed]

157. Hafner-Bratkovic, I.; Gaspersic, J.; Smid, L.M.; Bresjanac, M.; Jerala, R. Curcumin binds to the alpha-helical intermediate and to the amyloid form of prion protein-A new mechanism for the inhibition of $\mathrm{PrPSC}^{\mathrm{Sc}}$ accumulation. J. Neurochem. 2008, 104, 1553-1564. [CrossRef] [PubMed]

158. Yang, F.; Lim, G.P.; Begum, A.N.; Ubeda, O.J.; Simmons, M.R.; Ambegaokar, S.S.; Chen, P.P.; Kayed, R.; Glabe, C.G.; Frautschy, S.A. Curcumin inhibits formation of amyloid beta oligomers and fibrils, binds plaques, and reduces amyloid in vivo. J. Biol. Chem. 2005, 280, 5892-5901. [CrossRef] [PubMed]

159. Lin, C.-F.; Yu, K.-H.; Jheng, C.-P.; Chung, R.; Lee, C.-I. Curcumin Reduces Amyloid Fibrillation of Prion Protein and Decreases Reactive Oxidative Stress. Pathogens 2013, 2, 506-519. [CrossRef] [PubMed]

160. Pabon, H.J.J. A synthesis of curcumin and related compounds. Rec. Trav. Chim. 1964, 83, 379-386. [CrossRef]

161. Khan, N.; Afaq, F.; Saleem, M.; Ahmad, N.; Mukhtar, H. Targeting multiple signaling pathways by green tea polyphenol (-)-epigallocatechin-3-gallate. Cancer Res. 2006, 66, 2500-2505. [CrossRef] [PubMed]

162. Ramassamy, C. Emerging role of polyphenolic compounds in the treatment of neurodegenerative diseases: A review of their intracellular targets. Eur. J. Pharmacol. 2006, 545, 51-64. [CrossRef] [PubMed]

163. Chacko, S.M.; Thambi, P.T.; Kuttan, R.; Nishigaki, I. Beneficial effects of green tea: A literature review. Chin. Med. 2010, 5, 13. [CrossRef] [PubMed]

164. Ingolfsson, H.I.; Thakur, P.; Herold, K.F.; Hobart, E.A.; Ramsey, N.B.; Periole, X.; de Jong, D.H.; Zwama, M.; Yilmaz, D.; Hall, K.; et al. Phytochemicals Perturb Membranes and Promiscuously Alter Protein Function. ACS Chem. Biol. 2014, 9, 1788-1798. [CrossRef] [PubMed]

165. Tachibana, H.; Koga, K.; Fujimura, Y.; Yamada, K. A receptor for green tea polyphenol EGCG. Nat. Struct. Mol. Biol. 2004, 11, 380-381. [CrossRef] [PubMed]

166. Schneider, C.; Gordon, O.N.; Edwards, R.L.; Luis, P.B.J. Degradation of Curcumin: From Mechanism to Biological Implications. Agric. Food Chem. 2015, 63, 7606-7614. [CrossRef] [PubMed]

167. Baell, J.B. Feeling Nature's PAINS: Natural Products, Natural Product Drugs, and Pan Assay Interference Compounds (PAINS). J. Nat. Prod. 2016, 79, 616-628. [CrossRef] [PubMed]

168. Zhang, Q.; Tu, T.; D'Avignon, D.A.; Gross, M.L. Balance of Beneficial and Deleterious Health Effects of Quinones: A Case Study of the Chemical Properties of Genistein and Estrone Quinones. J. Am. Chem. Soc. 2009, 131, 1067-1076. [CrossRef] [PubMed]

169. Laurén, J.; Gimbel, D.A.; Nygaard, H.B.; Gilbert, J.W.; Strittmatter, S.M. Cellular prion protein mediates impairment of synaptic plasticity by amyloid-beta oligomers. Nature 2009, 457, 1128-1132. [CrossRef] [PubMed]

170. Dohler, F.; Sepulveda-Falla, D.; Krasemann, S.; Altmeppen, H.; Schlüter, H.; Hildebrand, D.; Zerr, I.; Matschke, J.; Glatzel, M. High molecular mass assemblies of amyloid- $\beta$ oligomers bind prion protein in patients with Alzheimer's disease. Brain 2014, 137, 873-886. [CrossRef] [PubMed]

171. Gimbel, D.A.; Nygaard, H.B.; Coffey, E.E.; Gunther, E.C.; Laurén, J.; Gimbel, Z.A.; Strittmatter, S.M. Memory impairment in transgenic Alzheimer mice requires cellular prion protein. J. Neurosci. 2010, 30, 6367-6374. [CrossRef] [PubMed]

(c) 2017 by the authors. Licensee MDPI, Basel, Switzerland. This article is an open access article distributed under the terms and conditions of the Creative Commons Attribution (CC BY) license (http:/ / creativecommons.org/licenses/by/4.0/). 